\title{
Plagiarism in high schools: A case study of how teachers address a perpetual dilemma
}

\author{
Geraldine J. Newlon \\ West Virginia University
}

Follow this and additional works at: https://researchrepository.wvu.edu/etd

\section{Recommended Citation}

Newlon, Geraldine J., "Plagiarism in high schools: A case study of how teachers address a perpetual dilemma" (2009). Graduate Theses, Dissertations, and Problem Reports. 3490.

https://researchrepository.wvu.edu/etd/3490

This Dissertation is protected by copyright and/or related rights. It has been brought to you by the The Research Repository @ WVU with permission from the rights-holder(s). You are free to use this Dissertation in any way that is permitted by the copyright and related rights legislation that applies to your use. For other uses you must obtain permission from the rights-holder(s) directly, unless additional rights are indicated by a Creative Commons license in the record and/ or on the work itself. This Dissertation has been accepted for inclusion in WVU Graduate Theses, Dissertations, and Problem Reports collection by an authorized administrator of The Research Repository @ WVU.

For more information, please contact researchrepository@mail.wvu.edu. 


\title{
PLAGIARISM IN HIGH SCHOOLS:
}

A CASE STUDY OF HOW TEACHERS ADDRESS A PERPETUAL DILEMMA

\author{
Geraldine J. Newlon
}

\begin{abstract}
Dissertation
submitted to the College of Human Resources and Education

at West Virginia University

in partial fulfillment of the requirements for the degree of
\end{abstract}

\author{
Doctor of Education \\ in \\ Technology Education
}

\author{
Neal Shambaugh, Ph.D., Chair \\ Jaci Webb-Dempsey, Ph.D. \\ Rebecca A. Schaupp, Ed.D. \\ Perry Phillips, Ph.D. \\ Daniel Hartley, Ed. D.
}

Department of Technology, Learning, and Culture

Morgantown, West Virginia 2009

Keywords: plagiarism, academic dishonesty, high school 


\author{
Abstract \\ PLAGIARISM IN HIGH SCHOOLS: \\ A CASE STUDY OF HOW TEACHERS ADDRESS A PERPETUAL DILEMMA
}

\author{
Geraldine J. Newlon
}

This was a multiple case study of all the 12th grade English teachers in one West Virginia county school system. Qualitative data collection methods involving teacher interviews and analysis of classroom handouts were utilized to reveal how they address plagiarism. Demographic statistics about the communities and schools was examined to enable comparisons between the schools and the participants. The research questions guiding this study were: (a) What are secondary English teachers' perspectives on plagiarism, and (b) What are secondary English teachers' practices on plagiarism. Data were collected and analyzed for any patterns, extremes, or relevancy to the related literature. Then significant quotes were copied and pasted from interview transcripts into tables containing plagiarism related topics. Document data were also coded and examined for a relationship to interview data. Data revealed that English teachers of students in advanced classes and students in schools with a higher socioeconomic status felt their students plagiarized less and for more honorable reasons than did teachers of students in regular education classes located in more rural, less well-off communities. The data revealed English teachers spent a great deal of time, most of one grading period, six or seven weeks, for instruction of the research project. Data indicated most English teachers enforced either an oral or written policy on plagiarism that usually includes a grade cut as the sole consequence. The opportunities for students to plagiarize and for teachers to detect plagiarism continued to evolve as their use of technology evolved. English teachers can help prevent plagiarism by insuring their instruction on research and writing is meaningful and comprehended by their students. All English teachers can help prevent plagiarism in any instance by having a communicated policy to deal with instances of plagiarism that involves discipline beyond simply the expected grade cut. 


\section{Contents}

Chapter 1: Introduction and Statement of the Problem 1

$\begin{array}{ll}\text { Purpose of the Study } & 4\end{array}$

$\begin{array}{ll}\text { Research Questions } & 4\end{array}$

Chapter 2: Review of the Related Literature $\quad 5$

Scope of Plagiarism $\quad 5$

$\begin{array}{lr}\text { Defenses for Plagiarism } & 8\end{array}$

$\begin{array}{ll}\text { Technology and Plagiarism } & 12\end{array}$

Detection of Plagiarism in Student Work 13

Electronic Plagiarism Detection Services 19

Administrative Implications of Dealing with Plagiarism 20

Effects of Plagiarism on Learning $\quad 23$

$\begin{array}{ll}\text { Antidotes for Plagiarism } & 24\end{array}$

Academic Dishonesty Policies $\quad 25$

Using Classroom Methods to Manage Plagiarism 26

$\begin{array}{ll}\text { Results of the Pilot Study } & 28\end{array}$

$\begin{array}{ll}\text { Continuing the Study } & 29\end{array}$

$\begin{array}{ll}\text { Chapter 3: } \text { Method } & 31\end{array}$

Research Design Rationale $\quad 31$

$\begin{array}{ll}\text { Case Study } & 33\end{array}$

$\begin{array}{ll}\text { Questions } & 35\end{array}$

Unit of Analysis

High School English Teachers $\quad 35$

Teacher Participant Profiles 37 
$\begin{array}{ll}\text { High Schools } & 39\end{array}$

Beaumont High School $\quad 39$

Horace Mann High School $\quad 41$

Laura B. Tyler High School $\quad 41$

$\begin{array}{ll}\text { Pine Valley High School } & 41\end{array}$

South River High School 44

Context of Teaching $\quad 42$

$\begin{array}{ll}\text { Researcher } & 44\end{array}$

$\begin{array}{ll}\text { Data Collection } & 46\end{array}$

Data Source, Collection and Analysis Procedure by Research Question 48

Research Question $1 \quad 49$

$\begin{array}{ll}\text { Research Question } 2 & 51\end{array}$

$\begin{array}{ll}\text { Assumptions and Limitations } & 58\end{array}$

$\begin{array}{ll}\text { Research Methodology Summary } & 60\end{array}$

Chapter 4: Findings $\quad 62$

$\begin{array}{ll}\text { Introduction } & 62\end{array}$

Case by Case Data Analysis $\quad 633$

Carrie Riggs

$\begin{array}{ll}\text { Marsha Callahan } & 67\end{array}$

$\begin{array}{ll}\text { Josh Richards } & 70\end{array}$

$\begin{array}{ll}\text { Jackie Marshall } & 72\end{array}$

$\begin{array}{ll}\text { Tracy Queen } & 75\end{array}$

$\begin{array}{ll}\text { Roxanne Carr } & 78\end{array}$

Brooke Hinkle $\quad 81$ 
$\begin{array}{ll}\text { April Thompson } & 82\end{array}$

Cross Case Data Analysis Organized by Research Question 84

Perspectives (RQ1)

Trends Based on Demographics. $\quad 85$

$\begin{array}{ll}\text { Prevention. } & 88\end{array}$

$\begin{array}{ll}\text { Unintentional versus intentional plagiarism. } & 93\end{array}$

Perception of involving administration. 95

$\begin{array}{ll}\text { Practices }(R Q 2) & 97\end{array}$

$\begin{array}{ll}\text { Detection. } & 97\end{array}$

Level of Technology Integration in Detection. 98

$\begin{array}{ll}\text { Prevention. } & 100\end{array}$

Managing academic dishonesty. 102

$\begin{array}{ll}\text { Plagiarism as part of a larger study of ethics. } & 104\end{array}$

$\begin{array}{ll}\text { Classroom instruction and materials. } & 105\end{array}$

$\begin{array}{ll}\text { Teacher expectations for senior research projects. } & 108\end{array}$

$\begin{array}{ll}\text { Consequences. } & 110\end{array}$

Chapter 5: Conclusions, Limitations, and Recommendations 113

Conclusions Organized by Research Questions 113

RQ1: Perspectives on Plagiarism 113

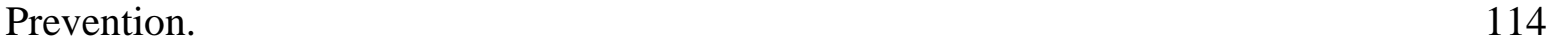

$\begin{array}{lr}\text { Detection. } & 118\end{array}$

Perspective on the phenomenon. 119

Major Research Conclusions on Teachers’ Perspectives on Plagiarism 122

RQ2: Practices on Plagiarism 122 
Prevention.

Detection.

Major Research Conclusions on Teachers’ Practices on Plagiarism

Recommendations to Secondary English Teachers

Prevention.

Detection.

Recommendations for Schools

Limitations of the Study

Further Research

References 


\section{Tables \& Figures}

Figure 1 Severity of Incidents of Plagiarism Displayed on a Continuum

Table 1 Acts of Plagiarism Categorized by Level of Intention

Table 2 Level of Technology Integration in Plagiarism Detection Methods

Table 3 Subjective and Objective Teacher Methods to Detect Plagiarism

Table 4 Study’s Inquiry, Participants, Methods, and Expected Results 
Appendices

Appendix A Cover Letter \& Participant Application Form

Appendix B

Interview Protocol and Script

146

Appendix C

Demographic Data Samples

148

Appendix D

Research Handout submitted by C. Riggs

163

Appendix E

Research Assignment Handout submitted by J. Richards

166

Appendix F

Research Assignment Handout submitted by J. Marshall

168

Appendix G

Research Assignment Handout submitted by T. Queen

170

Appendix $\mathrm{H}$

Plagiarism Policy submitted by R. Carr

172

Appendix I

Grading Rubric submitted by R. Carr

173

Appendix J

Plagiarism Policy submitted by B. Hinkle

174

Appendix K

Sample Originality Report printed from Turnitin.com

175

Appendix L

WV Dept. of Education CSOs for $12^{\text {th }}$ Grade English

176

Appendix M

Data to Support Conclusions on Teachers’ Perspectives

180

Appendix $\mathrm{N}$

Data to Support Conclusions on Teachers’ Practices 


\section{Chapter 1}

Introduction and Statement of the Problem

Rather fail by honor than succeed by fraud. Sophocles

Academic dishonesty is a perennial problem and a growing source of concern for teachers, school systems, and societies. In an ongoing effort to derail this problem, teachers develop policies, implement specific classroom management methods, utilize technological means, and invoke disciplinary actions. However, despite these efforts from teachers and school administrators alike, the academic phenomenon of cheating continues. The outgrowth of cheating, including plagiarism, is a real-life phenomenon causing stress to a national education system. A large, bureaucratic system already beleaguered with minimal funding, intense government pressure for better performance, and the constant looming risk that a disgruntled student will cause a massacre of school employees, as well as other people's children for which they are responsible.

Along with these crucial concerns is the initially less obvious, but potentially devastating effect of cheating and plagiarism. According to high school student responses in a confidential survey taken by ABC News in 2002, 74\% of students admitted to cheating on a test at least once that year (Cheating Crisis in America’s Schools, 2006). When students cheat or plagiarize, they do not establish an adequate knowledge base of their research topics. Plagiarism, committed in many different types of assignments ultimately decreases the quality of learning and makes it even harder for students to perform better on mandatory, standardized tests. A reference librarian, in a study by Isserman (2003), pointed out that “plagiarism isn’t a bad thing simply because it's an act of intellectual theft - although it is that. It's a bad thing because it takes the place of and prevents learning” (p. 14). 
Although plagiarism does inhibit learning, it has gained popularity among students and has become a significant element in most descriptions of academic dishonesty. Hartwick College, a private, undergraduate college located in the Catskill Mountains of New York State, recognizes the prevalence of plagiarism in their academic honesty policy by adding that "nearly every form of academic dishonesty is a species of plagiarism.” Fox (as cited in Saunders, 1993) claims that "the two most common types of student academic misconduct are cheating, usually through the illicit use of notes, and plagiarism, in which a student represents ideas or wording as his or her own without proper attribution to the original source” (p. 224). Common to most published definitions of plagiarism, Hartwick's definition, as well as others, includes “claiming others' ideas as one’s own”, and “failing to acknowledge their ideas.”

Purdue University’s Online Writing Lab has been a source of help with research and writing tasks for over 50,000,000 worldwide visitors every year for the last ten years. On their webpage dedicated to avoiding plagiarism, Purdue University states:

Since teachers and administrators may not distinguish between deliberate and accidental plagiarism, the heart of avoiding plagiarism is to make sure you give credit where it is due. This may be credit for something somebody said, wrote, emailed, drew, or implied (Avoiding Plagiarism, 2006).

Intentional plagiarism is a breach of ethics. Ethics has been an area of concentration for schools, colleges, and business for some years now in an effort to restore integrity to the classroom and the boardroom. The frequency of unethical acts discourages the confidence people have in the respectability of their society and further compels the need for its study. Whether a top federal government official is being indicted for illegally accepting campaign funds, or a 12-year old school boy is copying from his buddy's homework, the spiritual erosion caused by ethical breeches feels the same. Many authors write of the 
decreasing morality in our society. One disturbing question raised by Christine Tanner (2004) is whether dishonesty has "become so pervasive in our culture that cheating and plagiarism are becoming acceptable practice, necessities for survival in this fast-paced demanding society?” (p. 292). One answer to Ms. Tanner’s question may be in a 2004 study of cheating and high school students by Jason Stephens. The author found that although many students did accept the fact that what they were doing was wrong, they did it anyway. One high school student, who Stephens considered to be typical, explains:

Like people have morals, they don't always go by them. So I mean, even if you get that test and you're like, “Oh yeah, I cheated on this test,” it doesn’t lessen that grade. It says an A on the paper and you don’t go, “Oh, but I cheated.” You're just kind of like, “Hey, I got that A.” So it doesn't really matter necessarily if it has to do with your morals or anything, you just kind of do it. Further research by Roth and McCabe (as cited in Saddlemire, 2005) said that the students' decisions about their actions related to cheating were heavily reliant on the state of their value systems as they began school.

Plagiarism is a problem for most teachers that assign any type of project requiring writing. Thomas (2004) found the most common setting for committing plagiarism is in “preparation of written papers, assignments, and oral presentations” (p. 428). Writing is a skill that recently has become a subject of interest for comprehensive student evaluation. Standardized tests, such as the West Virginia Educational Standards Test (WESTEST), was developed by West Virginians to enable them to evaluate whether their students are meeting the Content Standards and Objectives (CSOs), which are course goals also developed by the WV State Department of Education (Appendix L). The WESTEST, given to fourth, seventh and tenth grade students, includes a writing component. This is one example of the apparent 
importance of articulated student proficiency in writing, along with the traditional subject areas of reading, math and science.

In a study of plagiarism done over five consecutive semesters, Martin (2005) concluded that "students who plagiarize less are more likely to develop the skills needed to complete their writing and research assignments” (p. 151). This finding supports the importance of teaching students what skills are required to complete a written research project successfully without copying. Although teaching students to write well on their own without plagiarizing can be challenging, good instruction in citing resources, summarizing, and directly quoting encourages students to go ahead and makes it more likely they will do it the right way.

\section{Purpose of the Study}

The purpose of this study is to determine how secondary English teachers perceive plagiarism and what they collectively do to control it in their classrooms. This study focuses on the issues that are centrally important to revealing secondary English teachers’ viewpoints and experiences with plagiarism, as well as what teachers do to prevent, detect, and manage this escalating problem in their classrooms.

\section{Research Questions}

The research questions for this study are:

1. What are secondary English teachers' perspectives on plagiarism?

2. What are secondary English teachers’ practices on plagiarism? 


\section{Chapter 2}

Review of the Related Literature

This first half of the literature review includes a comprehensive description of plagiarism in its current state, with specific examples to illustrate how extensively plagiarism has been employed in our society to fraudulently advance human endeavor. The review then describes ways that plagiarists explain their behavior, or why they did what they did. A description of technologies' effect on the growth of plagiarism is also included, as well as how teachers utilize technology in the detection of plagiarism. The review of related literature will conclude with a discussion of the implications of plagiarism for school administrators, the effects of plagiarism on student learning, and solutions for reducing the instances of plagiarism in the classroom.

\section{Scope of Plagiarism}

Plagiarism crosses socioeconomic and other possible perceived boundaries, and happens virtually in every high school. Donald L. McCabe is a professor at Rutgers University in New Jersey, and head of the Center for Academic Integrity, an association of over 200 schools with the common purpose of promoting and creating effective academic integrity programs. McCabe is a well-published, decades-long researcher of academic dishonesty in secondary and higher education. He claims that the frequency of acts of academic dishonesty, including plagiarism, does differ in private vs. public schools, and he reported differences have also been found when comparing incidents from various regions of the country (D. L. McCabe, personal communication, September 27, 2005).

However, even with differences found between incidents of plagiarism in private versus public schools and incidents in various regions of the United States, none are exempt, including higher education. It might be perceived that high school students would be more novice than college students in the proper undertaking of research, the art of citing references, and 
understanding of what plagiarism is. However, in a qualitative study of plagiarism in universities (Ashworth \& Bannister, 1997), higher education students also lacked a good understanding of why citing resources was important. The students did not give any clear reasons for not cheating other than to avoid disciplinary actions.

In discussing whether school characteristics influence incidents of plagiarism, McCabe said he was unaware of any "solid data" that supported differences in the frequency of plagiarism in high schools based on school size, rural ness, academic climate, or the composition, or makeup of the student body. However, if deemed desirable, data could be collected from a large sample that would confirm incidents of plagiarism in many, many different types of high schools, including those in the upper-middle class suburbs, those located in cordial, close-knit, working class neighborhoods, and those schools in areas where most of the students live in urban, low-income housing developments. Not only is there great variety in the characteristic of students that commit plagiarism, but there are more various contemporary types of plagiarism that cross traditional boundaries.

“Patchwork plagiarism” is a term coined by Hampshire (as cited in Hardin \& Bader, 1999) to represent what happens when a student copies and pastes blocks of text from different web pages into one paper. In recent years, and with the evolution of technology, incidents of plagiarism have become widespread and widely known. Easy access to unlimited databases of information containing the expressive fruits of human intellect is appealing and can tempt many to succumb.

Today, not even college presidents, media journalists, or noted book authors are immune. An interesting example of how plagiarism has permeated our creative human efforts involves a photojournalist for the Richmond Times-Dispatch who submitted a picture for an article about a local candy company. The picture bore a remarkable resemblance to a picture of candy recently 
used on the cover of an issue of Style Weekly that the photographer had seen while visiting the candy company. Although the photographer was told of the resulting similarity between the two pictures, he submitted it as his original work and as a result the photographer was fired for “visual plagiarism," according to an article written in response to the situation by the managing editor of the newspaper, Louise Seals (2005).

The media realizes the harmful effects of high profile plagiarism cases on the reputation of their industry. In the same Richmond Times-Dispatch article in response to what the photojournalist had done, the editor stressed the need to "talk more about ethics in general." The editor also said the newspaper would be "changing the way we introduce our interns to the newsroom. When they arrive, we will do more than hand them a copy of our "Guidelines for Professional Conduct.” The article promised the newspaper would start to emphasize honesty in the creation of intellectual property and the importance of integrity. The managing editor stressed in the article that from now on the newspaper wanted their staff to react to observed instances of plagiarism whether "visual or verbal” with an automatic response of "Wait a minute! You can’t do that! We don’t do that!” (Seals, 2005).

Even in traditional settings, like schools, where plagiarism is a concern, there is no way to accurately predict who will be the guilty ones. Three years ago in the high school where I teach, one of my former students, a well-liked, well-dressed, conscientious, and extremely busy student, who was also the president of the student council, purchased a term paper online to fulfill the requirements for an afternoon college-credit English class he was taking, and was promptly caught by the teacher because she was familiar with the website from where it was purchased. At the time this happened, I had already completed the pilot study for this dissertation, and had determined that my dissertation focus would be on how teachers manage 
plagiarism in the classroom. Consequently, given my obvious curiosity and preoccupation with this phenomenon, I found myself especially interested in the particulars of this case.

This plagiarism incident involving the student council president startled the administration and stimulated genuine concern among the faculty for the need and importance of insuring integrity in our students’ work. The news of what this popular student did spread quickly to the other students and as a result, it was during this time I developed my first academic dishonesty policy.

\section{Defenses for Plagiarism}

Plagiarism has evolved not just in scope, in the context of who is engaging in this behavior, but also has evolved in the scope and availability of defense mechanisms, including explanations given by those who are guilty of it. Without labeling it, Thomas (2004) explains in an article written to improve effective understanding of plagiarism that he believes students will, in the course of reading and writing on a research topic, include what they think are their own thoughts in a paper, when those ideas actually were someone else's they had come across in their study. He stresses that teachers should understand that students who do this do not believe their ideas are stolen. Thomas was explaining a defense to plagiarism that other researchers have already given a name to. Cryptomnesia or "unconscious plagiarism” is the "unconscious influence of memory that causes current thoughts to be (wrongly) experienced as novel or original inventions” (Marsh, 1993). This is not received by everyone as an acceptable defense according to a student in a qualitative study on plagiarism by Ashworth and Bannister (1997). The student felt that those who cheated were very cognizant of their actions and acted so out of possible rebellion or lack of interest in the course.

A student in a qualitative study of plagiarism (Ashworth and Bannister, 1997) recounts his experience with cryptomnesia although he did not identify that as the cause. 
When I'm taking notes for an essay in English I begin to take on other people's opinions on certain things and I end up with these big notes, some of which is mine, some of which is other people's and I begin to think, is this what I've said or what someone else has said? It comes that close, and I sometimes feel it's possible that I could have copied, just, like a sentence-an expression—from somebody else, describing what I agree with (p. 190).

A student might do the same thing and not be aware that they are plagiarizing from something they have heard while speaking with someone, while reading something, or while recounting an experience (Thomas, 2004).

Freedman (1998) found evidence of teachers accepting students' reasons for plagiarizing that they had “unconsciously memorized” (p. 37) lengthy segments of articles while doing research. I believe the work involved to memorize "lengthy segments of articles” would undoubtedly be more than the work involved in paraphrasing, quoting, and citing the research properly in the beginning. Newstead, Franklyn-Stokes, and Armstead (as cited in Saddlemire, 1996) suggest that “cheating is not a 'do' or 'don't' issue, but rather it exists on a continuum that allows students to interpret which behaviors are more severe than the others” (p. 12).

Accusing a student of plagiarism can be wrought with problems when the teacher is not sure exactly which acts the student has committed actually constitute intentional plagiarism. Figure 1 from Purdue University’s Online Writing Lab presents an example of a continuum on which instances of plagiarism fall between “possibly accidental plagiarism” and “deliberate plagiarism.” This figure may aid teachers in their diagnosis of instances of plagiarism, as well as provide a basis for analyzing data concerning the perceived deliberateness of various acts of plagiarism committed in high school English classes and revealed by the participants in this study. 


\section{Actions that might be seen as plagiarism}

Buying, stealing, or

borrowing a paper

Hiring someone to

write your paper
Using the source too

closely when

paraphrasing

Building on someone's ideas without citation

Copying from another source without citing (on purpose or by accident)

Figure 1. Severity of Incidents of Plagiarism Displayed on a Continuum. Note: From Online

Writing Lab (OWL) by Purdue University. Copyright 2006 by OWL at Purdue University and Purdue University. Reprinted with permission.

Table 1 describes three possible motives for plagiarism and labels specific student actions that constitute plagiarism as stemming from one of the three motives. Table 1 is based on Figure 1, which plots specific acts of plagiarism on a continuum according to the degree of how serious a specific act of plagiarism is.

Table 1

Acts of Plagiarism Categorized by Intent

Category of Intent for Plagiarism Description of Student Actions

Possibly Accidental Plagiarism When the student attempted to and had intention of doing credible research but was guilty of less serious infractions, for example citing the source, but paraphrasing that source too closely. 
Apathetic Plagiarism

Deliberate Plagiarism
Where the student attempted to complete the research project, but plagiarized because they just didn’t care enough about the assignment to put forth the effort needed, for example not citing the source but paraphrasing someone else’s idea as their own. Or even more deliberate methods including copying and pasting text verbatim from the source and not citing the source.

Where the student has not attempted to do the research at all, but has bought, stolen, or used another student’s paper, or asked or hired someone else to write their paper.

The benefit of having personal experience from two different situations, as someone who is in a position to commit plagiarism, as well as experience in someone's position who is responsible for detecting plagiarism would both help to yield a well-rounded, legitimate approach to classifying acts of plagiarism as either inadvertent or on purpose, and further when identifying the motives thereof. For example the experience a student has when finding it difficult to paraphrase an original source may be beneficial to forming an appreciation that all students may not plagiarize intentionally.

The reasons teachers feel their students plagiarize are discussed later along with the findings of this study. Though the teachers' perceptions of how intentional they perceive various acts of plagiarism to be may likely be different based on their attitudes and experiences. How deliberate each participant views different acts of plagiarism to be, will more clearly reveal the participants’ perspectives on plagiarism overall. 
Russell Baker describes another defense for plagiarism in his 1995 New York Times article (as cited in Pincus \& Schemlkin, 2003). In the article, Baker claims that inadvertent plagiarism could result due to the accidental storage to a computer and integration of the research findings of others, in with the text of a student's draft in the same file. If this were true and occurred frequently and on a large scale, students could simply say their plagiarized comments were the computer’s fault.

Another defense to plagiarism is offered by Freedman (1998, p.36), when he claims that “teachers and officials, not students, may be most responsible for the growth of plagiarism in schools...by not preparing for it, not recognizing it, or excusing it when they do uncover it.” Freedman maintains that other faculty members he has worked with overlooked obvious instances of plagiarism and defended the student by saying they were simply unskilled in quoting and using footnotes.

Teachers must be vigilant in combating plagiarism. Teachers should teach students to “identify and avoid plagiarism,” but instead, according to Wilhoit (1994), “We offer admonitions rather than instruction, threats rather than help” (p. 165). The defenses to plagiarism are many and have evolved over time both in level of sophistication and object of blame. Teachers have a responsibility to address these defenses with methods designed to improve instruction so students cannot use the claim that they are ignorant of how to do credible research as an excuse after being caught committing plagiarism. Procedures are also needed to enable teachers to answer questions they have regarding level of seriousness, as well as identifying incidents as accidental or intentional plagiarism.

\section{Technology and Plagiarism}

The evolution of plagiarism has led to new heights in academic honesty breaches and a new definition. Technology has played a major role in the growth of plagiarism and has 
catapulted it specifically by either enabling students to "cut and paste” their way to a grade, buy an existing paper using the Internet, or hire an expert to write a custom paper for them. These elements have changed the shape of plagiarism and added much to its definition. Anson (2003) reported that Kimbel Library at Coastal Carolina University had combined a list of over 250 “term paper mill” websites that sell completed papers on thousands of topics to students.

Campbell, Swift, and Denton (2000), concluded that the more recent increase in plagiarism is due to students’ increased use of computers, specifically, the Internet and its information sources, like the World Wide Web. A study by Martin (2005) researched the instances of plagiarism by college students over five semesters and found that students in the last three semesters of the study "plagiarized significantly less than did students in the first semester." Martin concluded that after the students realized the use of technology, specifically Turnitin.com, a web-based plagiarism detection service, had been implemented and was being used by their professor to detect plagiarism, the practice no longer seemed so appealing.

As a result of the growing interest in both committing and detecting plagiarism, the frequency of online occurrences of the word "plagiarism” has grown to astounding proportions. In a study by Baggaley and Spencer (2005), it was reported that in 1998 there were “37,419 online occurrences of plagiarism” when the term was searched using the 'Altavista' search engine. Then for comparison, the researchers at the time of the 2005 study, six years later, used the same search engine to identify 1,090,000 online occurrences of "plagiarism”. The same research states that in 2005 Google estimated the total of occurrences at 2,390,000.

\section{Detection of Plagiarism in Student Work}

Teachers must be assertive in their efforts to detect plagiarism in student writing assignments. When considering the importance of teachers' actions in detecting cheating in general, a sobering statistic illustrating the importance of teacher detection was found in a 1998 
survey from Who's Who Among American High School Students. In this study of 3,123 students, 95 percent of those who had cheated said, "they have never been caught” (McMurtry, 2001, p. 37).

The methods used to detect plagiarism have evolved and technology now plays a much more integral role. In the pilot study for this research (Newlon, 2003), the methods the high school teachers used to detect plagiarism were somewhat varied, but seemed to reflect the teacher's level of technological literacy and awareness of online resources. However, it is not to say computer technology is required to detect plagiarism in the classroom. About one-third of the high school teachers in my pilot study required students to turn in photocopies or printed web pages of all sources used in their research paper to enable easier detection. Although it requires more time and diligence, using manual detection methods by examining photocopied or printed out sources to verify that students performed the appropriate research writing behaviors could be comparable in success to an electronic plagiarism detection service.

Table 2 establishes three levels to describe the degree to which technology has been integrated in the plagiarism detection methods used by teachers. Document analysis of plagiarism detection software reports or search engine results submitted by the participants will also help to identify the level of technology the participants use in the detection of plagiarism in their classrooms. Little technology has been integrated when the initial and predominant detection methods used are manual in nature. To verify plagiarism the teacher compares the suspicious text in a student's paper with sources found on paper, like a student writing sample, or required photocopies or printouts of data sources used.

The next level in the table describes detection processes a teacher uses when technology has been integrated. When technology has been integrated, an online search engine, or metasearch engine of the teacher's choice is used to search databases of web pages for suspicious 
phrases or paragraphs. The teacher may also view familiar web pages known to be resources for the research topics that are assigned. A high level of technology integration has been reached when a teacher regularly uploads their students' documents to be compared with other papers in large databases, and all instances of text in the documents that have been taken from online sources are automatically documented in individual reports created for the teacher. To improve the detection of plagiarism in their classroom, the teacher may also add students' papers to the database that is regularly searched to improve the databases ability to detect plagiarism in local student work.

Table 2

Level of Technology Integration in Teacher Plagiarism Detection Methods

Categories of Technology Integration Description of Detection Methods

Minimal Level of Technology Integration

Technology has been Integrated

High Level of Technology Integration
Teacher manually compares suspicious text with printouts of original sources.

Online search engines are used to locate original sources for suspicious text.

The teacher systematically uses an online service to detect plagiarism.

Regardless of the method used, it is important for teachers to employ consistent detection procedures and consistent correction policies for students who do it. Freedman, (1998) in an article illustrating the significance of teacher action to diffuse the spread of plagiarism, found that students realize that some teachers do not detect plagiarism in student work because they do not care, and are inept in performing their duty regarding academic dishonesty in general. 
In addition to the instructional strategies they use, teachers also have influence over the political, social, ethical, and academic environment in their classrooms, and are held responsible for whatever goes on there. Consider the outcome of the Colorado high school teacher who was suspended for repeatedly making scornful comments about President George W. Bush (Colorado teacher on leave after alleged anti-Bush remarks, 2006). During a classroom discussion about the President's State of the Union address, the teacher claimed that some people "compared President Bush to Adolph Hitler.” It was during this discussion that a sophomore was taping the teacher's lecture and turned it into his father who then turned it into the principal, along with criticism for the teacher's actions. A district spokesperson said the reason the geography teacher was being suspended was because he controlled the exchange in his classroom by not leaving any openings for the students to disagree with him. Even though teachers are legally responsible for what they say in the classroom, the teacher's behavior was, in essence, excused. This example illustrates the freedom teachers have to express their opinions and directions and greatly influence the reactions and opinions of their students. Teachers unknowingly set limits for their tolerance for certain classroom behaviors, including plagiarism when they either act, or don’t act, on them. In a survey of 4000 U.S. and Canadian schools, McCabe (Cheating Crisis in America's Schools, 2006) reported that "half of all faculty members admitted ignoring cheating at least once.”

In a study of 309 first-year college students at Brigham Young University (as cited in Wilhoit, 1994), 50\% of the students in the study admitted to copying and pasting a majority of their papers from resources without citing the references. In addition, they reported doing so without any resulting penalty. Students surveyed were either not caught or simply not held accountable. Experts in a study by Thomas (2004) agreed that the "first line of defense against 
plagiarism” (p. 428) is to be cognizant of students' writing abilities so teachers will be able to identify suspicious student writing and be able to implement technological tools for its detection.

Detection of plagiarism can be difficult even for the most seasoned professional; though the interview data will likely reveal several different approaches utilizing varying degrees of technology used by teachers to detect plagiarism. However, a teacher's method of initially detecting plagiarism may have nothing to do with technology. According to the findings in the pilot study for this research (Newlon, 2003), what caused most of the teachers to initially suspect a student has cheated in any form in their classroom is the result of the teacher's instinct developed by experience in the same role. Usually a teacher instinctively knows what their students are capable of and may have already come to the conclusion a student has plagiarized without having confirmed it yet by possibly comparing the quality of suspicious text to student writing samples, or by entering suspicious text into an online search engine.

Table 3 describes several methods teachers use to detect plagiarism and classifies them as being more or less subjective or objective. This table also includes a description of various resources available to teachers when detecting plagiarism in their students' papers. A teacher's use of their own instinct to detect plagiarism in student work is by its very nature subjective, on the other hand, electronically submitting student work to an online plagiarism detection service to verify plagiarized text or to confirm that a student purchased a research paper online may be considered to be more objective. Table 3 includes information that can be used to help describe the methods teachers use to detect plagiarism in their students' work as either subjective or objective. As the table illustrates, the more technology is integrated into the process of plagiarism detection, the more objective the process becomes. 
Table 3

Subjective and Objective Teacher Methods to Detect Plagiarism

More Subjective

Less Subjective

Less Objective

More Objective
Mentally comparing a student's research with what the teacher perceives the student's writing ability to be.

Comparing the quality of suspicious text with student writing samples collected throughout the course.

Keying passages from the student's work the teacher finds suspicious into a search engine, such as Google, to get hyperlinks to web pages that may contain the plagiarized text.

Comparing contents of photocopies and printouts of data sources turned in by the students, with suspicious text in the student's research.

Submitting all student research papers electronically to a plagiarism detection service. Using a computer software program designed to identify instances of plagiarism. 


\section{Electronic Plagiarism Detection Services}

At the same time that technology has been the impetus behind the hastened evolution of “cut-and-paste” plagiarism, technology has also more recently been proven as a tool to control the instances of it. Plagiarism detection services have become valuable resources for teachers as they try to keep up with technology’s effect on plagiarism, while attempting to minimize plagiarism's effect on student learning. The detection services have a high degree of success, although the findings are unfortunate for high schools and colleges. John Barrie, founder of Turnitin.com, reported in a news article that about one-third of all the papers that are submitted are found to contain substantial amounts of plagiarism (Cheating Crisis in America's Schools, 2006).

Most services are proprietary and teachers, academic departments, and schools pay fees to subscribe to these services. Other available online services are MyDropBox.com and PlagiarismDetection.com. As of 2008 the Turnitin.com website, now in existence for 10 years, stated in its Features and Benefits section that their website had checked the originality of over 60 million student papers. In 2005 the subscription price per student was just 75 cents (Policing Academic Plagiarism Online, 2005). Subscription prices for the Turnitin.com service have increased; however, there are free detection services available, but they are harder to find, especially good ones.

Plagiarism exists not only in written prose, but in the creations of software programs as well. Moss and JPlag are computer programs used to detect student plagiarism in software programming code. In addition to using plagiarism detection tools to find instances of academic dishonesty in research, electronic detection services can also be used to teach a student who has committed plagiarism what they should have done to avoid it and produce credible research. This use of plagiarism detection services re-defines a tool traditionally used for detection and 
discipline purposes as a teaching or instructional tool to help students avoid doing it in the first place (Policing Academic Plagiarism, 2005).

Martin (2005) recommends the following guidelines for teachers using plagiarism detection services:

1. State in the class syllabus that students will be required to submit written materials both in paper and electronic form and that their papers will be screened by a plagiarism screening program.

2. Define plagiarism in class and use examples to show what constitutes acceptable and unacceptable attribution of sources.

3. Explain grading procedures regarding plagiarism in class.

Martin concluded that "students who have a stronger belief that plagiarism will be detected will be less likely to plagiarize” (p. 152).

\section{Administrative Implications of Dealing with Plagiarism}

Teachers and principals, as well as certain county school administrators are all responsible parties in a school system for discouraging plagiarism through good teaching and reteaching efforts and creation and consistent enforcement of an effective and communicated policy. According to research by Baggaley \& Spencer (2005), an “institutional approach to detecting and preventing plagiarism is vital in order to protect the interests of both the institution and the student.” (p. 61).

The "climate or culture of academic integrity on the school campus may be the most important determinant of the level of student cheating on that campus” (McCabe \& Trevino, 1996). Researchers found a specific effort to create an academic atmosphere of integrity by engaging students in student leadership training and rigorous training in the importance of 
academic integrity statistically reduced high rates of cheating in both small and large schools (McCabe \& Pavela, 2000).

Administrators of schools, both in secondary and higher education, have a special challenge ahead of them as they work with available resources to develop policies and procedures to support teachers' efforts to curb plagiarism and restore academic integrity to the classroom. In recent years, teachers of research and writing have occasionally found themselves in an unfamiliar situation when dealing with various instances of academic dishonesty due to the advancements in educational technology. Not only teachers, but administrators are also realizing a contemporary set of problems caused by this evolving academic phenomenon.

Students have more recently begun to dispute their school's right to upload their work to online plagiarism detection services in order to detect plagiarism, citing copyright protection of the student's work. Because when student papers are submitted, the papers are added to the service's searchable database of papers to be used in comparisons of future papers submitted (Baggaley \& Spencer, 2005).

A committee of teachers at McGill University in Montreal, (Eleff, 2007) when rendering a judgment on 19-year-old Jesse Rosenfeld's objections to having his paper submitted to Turnitin.com, agreed with his concerns and supported his decision. Events like this can make teachers more reluctant to actively detect and report instances of plagiarism to their administration because they are wary of being legally pursued by students. In a mixed methods study of 11 writing teachers at South-Coast University and their perceptions on plagiarism, most teachers were in favor of using electronic plagiarism detection services; however, two teachers felt that sending student papers to the detection websites violated a student's rights to copyright protection of their work (Sutherland-Smith, 2005). 
In March, 2008, a judge in Oakland, California rendered his decision in a case filed by four high school students who claimed the implied copyright to their own work was violated when their papers were used by the Turnitin.com web plagiarism detection service. The judge stated, "The use of archived student works to assess originality of newly-submitted papers constitutes a fair use under U.S. copyright law and is therefore not copyright infringement.” In addition, he states that such use "provides a substantial public benefit through the network of institutions using the Turnitin service“(Judge Dismisses Copyright Infringement, 2008).

In addition to copyright concerns, there are other difficulties that can be involved in accusing a student of plagiarism, especially if the act may result in failure of an entire grading period. Furthermore, English is a required course for high school graduation, so if a student's graduation is in question because of plagiarism, this can be intimidating to teachers and cause them to avoid confronting the problem by not bringing the act to light.

In a study by Sutherland-Smith (2005) nine of the 11 teachers interviewed felt that the "time, effort, and the sleepless nights utilized in deciding to take a case of student plagiarism through the correct channels is not worth the effort." When seeking advice from a "senior academic,” one teacher in the same study was told that she would regret any attempts to discipline an act of plagiarism because the "hassle involved" was not worth the effort. In a study by Biernacki, (2004), teachers claimed they had minimal knowledge of their school's academic dishonesty policy, and they felt the procedures used by the institution to handle cases of plagiarism were lengthy and complex. The teachers reported they did not want to involve the school's administration in the discipline process.

Overall, teachers’ impressions of administrative support for acts of academic dishonesty do vary; however teachers can feel isolated from administration when they regularly contain the disciplinary actions for a student who has plagiarized to their own classroom. Teachers may feel 
administrators prefer them to handle instances of plagiarism when they do not actively involve themselves possibly due to the sensitive nature of plagiarism and the difficulties that can arise when a teacher and a school's administration accuses a student of it. Then there are other teachers who are frustrated because even though their administration will address the problem, the process is beleaguering and can actually discourage a teacher from even presenting it. Conversely, in schools where teachers feel supported by their administration, academic dishonesty is handled assertively by the school's administration and teachers feel their supervisors support them in their efforts to manage plagiarism in their classroom despite liability risks.

\section{Effects of Plagiarism on Learning}

Researchers of this academic dilemma have long sought to understand this complex problem including how it is being managed in classrooms and schools in order to minimize its effect on the heart of all academic endeavors, student learning. Donald McCabe, long-time researcher of academic dishonesty claims, "We're seeing a generation in which more and more students are most concerned about doing whatever it takes to get ahead” (as cited in Hoover, 2002, p. 36).

Most people who have ever committed plagiarism on any level probably reluctantly realize afterward that they do not know as much about their study topic as they would have if they had done the necessary research. A reference librarian at Hamilton College asserts (as cited in Isserman, 2003) that “plagiarism isn’t a bad thing simply because it’s an act of intellectual theft—although it is that. It's a bad thing because it takes the place of and prevents learning” (p. 14).

Teachers, of all those involved in the educational process, realize the effects of plagiarism on learning. They evaluate students directly and see the deficiencies and in most 
cases, have theories about the reason(s) for the deficiencies. According to Freedman, (1998), it is imperative that teachers make the definition of plagiarism very clear to their students while not ignoring, consenting to, or denying doing anything that would stop plagiarism in their

classrooms. Freedman claims that to do this would be to "mock education itself".

\section{Antidotes for Plagiarism}

It was recommended in the pilot study for this research that teachers can go a long way in improving the chances their students won't plagiarize by first heightening student awareness of plagiarism, then following through with good instruction (Newlon, 2003). It was further suggested to increase awareness of plagiarism in the research and writing classroom an academic dishonesty policy should be communicated. The same study suggested for the policy to be effective it should include specific consequences for plagiarism that would involve the student's personal or social time, instead of their grade.

In my experience, high school students dread punitive actions that involve their own time out of the classroom. Out-of-class disciplinary actions for plagiarism could include days of outof-school suspension, although this action may actually be desired, in-school suspension where the student is removed from the rest of the student body, or in less serious cases several days of lunch detention or after school detention.

It is not easy at times to decide on an appropriate disciplinary action for instances of plagiarism. A zero-tolerance policy, although harsh-sounding, is not effective (Thomas, 2004) because the severity of instances of plagiarism exists on a continuum (see Figure 1). A blanket disciplinary action for all instances would probably lead to a conflicting system handing out excessively harsh sanctions to those guilty of minor instances, and much more severe ones.

However, repeated incidents of plagiarism should be communicated to students’ parents and coaches. Furthermore, if the plagiarist gains much exposure while being disciplined out of 
class, depending on their standing in the school, the student's reputation, among the faculty and students, could receive irreparable harm. This is what happened to the high school student council president mentioned earlier in this writing.

Another legal, established method to deter students from cheating used by the University of Maryland, as well as others colleges and universities, is the "XF" grade. If a student is caught cheating in any form, they receive an "XF" notation on their transcript for the course with an explanation that clarifies the student failed the course due to academic dishonesty. It is suggested that students with only a first offense be allowed to take several hours of instruction on academic integrity and have the "XF" notation removed from their transcript (McCabe \& Pavela, 2000).

Researchers of academic dishonesty stress that to beat plagiarism teachers need to get students to understand why academic integrity is important. Otherwise, in most situations students can “beat the system” (McCabe in Cheating Crisis in America’s Schools, 2006). McCabe as cited in Hoover (2002, p. 41), reiterates the importance of academic integrity in his warning to schools that even if they have an academic dishonesty policy that performs, that doesn’t mean students are “internalizing honor”. Internalizing honor and building societal values to combat plagiarism may require using corrective actions early on in a child's primary education, according to a study by Thomas (2004).

\section{Academic Dishonesty Policies}

Students realize that not all schools strictly enforce an academic dishonesty policy. In a qualitative study on students' perceptions of cheating and plagiarism by Ashworth and Bannister (1997), one student claimed, "It's not laid down exactly what does count as cheating ... So in the absence of any sort of clear guidelines you've got to put your own interpretation on what you think is right." Another student in the same study (p. 195) concurred, “The vagueness of the 
university regulations forces students to draw their own lines on this issue” (p. 194). Brigham Young University made efforts to educate students about their overall attitude toward plagiarism when they hung posters around campus showing silhouettes of two cowboys in front of a setting sun branding cattle with the words, “If it ain’t your work, don’t put your brand on it!” (Thomas, 2004, p. 423).

In a study of academic dishonesty involving more than 6,000 students, (Davis, Grover, Becker \& McGregor, 1992) it was concluded that if school administrators haven’t developed school-wide policies that would generate open dialogue regarding ethics in academia and are hesitant to address the problem of academic dishonesty, then it would be wrong to fault faculty for "following suit” (p. 20). The same research asserts that when faculty confront students about instances of academic dishonesty potentially problematic situations can arise entangling the faculty member in prolonged legal actions.

\section{Using Classroom Methods to Manage Plagiarism}

Based on my experiences and from the literature, the importance of the teacher's role in managing plagiarism is paramount. The methods used to reduce plagiarism presented in related literature support the vital role of teachers in preventing it, and include strategies such as creating diverse research topics, being aware of online resources available for research topics, collecting early samples of students writing, and requiring outlines and rough drafts for research projects (McMurtry, 2001). Researchers have identified several techniques used by classroom teachers that have shown to reduce the incidents of plagiarism.

To discourage plagiarism Renard (1999/2000) suggests requiring outlines and rough drafts to be turned in during the course of a project so the teacher can become familiar with the work in progress. Renard further recommends collecting writing samples from students at the beginning of the semester or course and contrasting the students' later writing assignments with 
the samples taken earlier in the course to see if writing ability and style are a match. These methods directly involve the teacher and support the importance of the teacher's role in managing plagiarism in the classroom. The same research warns teachers about making writing topics too general and fact-filled, as these are easy targets for plagiarism. Renard (1999/2000) further suggests teachers might give a writing topic that the students will have some personal experience with. He believes that giving students a topic they can make a personal connection with will make them more likely to engage in higher-order thinking.

Wilhoit (1994) found that fewer students are beginning college with a complete comprehension of the connection "between plagiarism and the rules about quoting, paraphrasing, and documenting material” (p. 163). In his research, Wilhoit theorized that students might be committing plagiarism because they are either instructed incorrectly or are simply ignorant of how to do credible research.

This study will examine the instruction in research writing and preparation given to students including the following research writing behaviors: (a) citing sources correctly, (b) paraphrasing, and (c) directly quoting sources. This study may reveal that teachers do prepare their students for writing about research by giving them instruction associated to these specific research writing behaviors. For students to be proficient in citing sources correctly they must be aware of the different formats used on a bibliography page for citing research from various sources, i.e. WWW pages, books, journals, statistical reports, personal communications, etc, as well as know how to use parenthetical citations.

Paraphrasing is a necessary skill and involves summarizing the text from the source and putting the author's ideas into your own words while giving credit to the original owner of the information. Sometimes when writing about what you have found on a topic in the related literature, it has more impact for the reader if the text is not paraphrased and the original text is 
included. When this is desirable, it is necessary to copy the text verbatim from the source into the research document while using quote marks and giving credit to the original owner of the information in the bibliography.

\section{Results of the Pilot Study}

A pilot study was performed in 2003 with a sample of five teachers working in the same county under study in the present writing. Qualitative methods were used to collect data from all the teachers at one high school that assigned research projects. Three out of the five teachers were English teachers. The purpose of this pilot study was to get "an overall understanding of how well teachers at [one high school] prepare students to do research in order to help prevent plagiarism, and how actively they engage in looking for and disciplining acts of plagiarism in their classrooms” (Newlon, 2003, p. 8). The teachers in the pilot study were interviewed individually for approximately one hour. Purposeful, network sampling was used to gain access to the sample in the study. Any documents, such as teacher-made handouts or policies, were also collected to triangulate the findings from analysis of the interview data. The school's population was approximately 700 .

The study revealed that most of the English teachers assigned their students written research projects; however, teachers in other disciplines were more creative in how the students presented their research and utilized student interviews, panel discussions, and PowerPoint presentations. The participants who taught English had the most to contribute to the study of plagiarism.

The pilot study also sought to reveal what classroom policies existed for laying out procedures to be followed in the event a student commits plagiarism. All of the teachers in the pilot study for this inquiry encountered plagiarism in their classroom, yet none of them used a communicated policy for controlling academic dishonesty or plagiarism. The pilot study 
concluded that teachers should quickly and clearly communicate a policy for dealing with incidents of all academic dishonesty.

Some participants in the pilot study for this research (Newlon, 2003) recommended teachers collect printouts of all web pages and photocopies of print material referenced in a student's paper to verify the student's sources. One English teacher in the pilot study required her students to complete an "E-Sheet” listing the URLs and describing the website used. It was concluded in the pilot study that if teachers had immediate access to all the sources, print-based and otherwise, used in student research projects this would increase the students' chance of getting caught and ultimately reduce the instances of plagiarism. Going into the pilot study, I thought I would find that overall the teachers' efforts would be somewhat lenient in managing plagiarism in the classroom. But largely, I found the teachers' methods were more creative, assertive, and diverse than I had originally believed they would be.

\section{Continuing the Study}

Despite all the effort being put into trying to control plagiarism, the popular media and available literature paint a bleak picture of decreasing morals amid an increase in forms of academic dishonesty overall. Perpetuated by advances in technology, there now exists a plethora of techno gadgets students can use to text message the test answers to a friend, display digital cheat sheets, search the web for an answer to a quiz, or save any picture or information they deem worth passing on to someone else. Plagiarism as a form of academic dishonesty has also ridden the wave of evolutionary change brought about by technology. Copying and pasting from the Internet is so common, the term 'patchwork plagiarism' was coined by Hampshire (as cited in Hardin \& Bader, 1999) to distinguish it.

In schools plagiarism is not only a concern because students are cheating and not doing the work assigned to them, it is a concern primarily because of how it affects student learning. 
Researchers have written much about the importance of a teacher's and a school's role in combating plagiarism in academia. Freedman (1998) urges teachers to reduce the chance their student will plagiarize by using every available resource to deliver meaningful instruction and to never deny doing anything that would keep their students from plagiarizing. To help prevent plagiarism, Martin (2005) suggests teachers have policies for plagiarism with consequences that are communicated to their students so they will be aware of what will happen if they plagiarize, thereby making it seem a more unappealing option. In the pilot study, all of the teachers assigned research projects but none of them used a plagiarism policy. However, research by McCabe \& Trevino (1996) indicates whether a student cheats is not dependent on a policy, but largely on the state of their value systems before a student even enters the classroom. Thomas (2004) concluded a moral character formed during the primary years is necessary to inhibit a student from plagiarizing later on.

Now I want to draw on what is known in the related literature about plagiarism and how to avoid it in the classroom, and expand on what the pilot study revealed about the importance of the teacher in controlling plagiarism. The current study will research closely the perspectives and practices of the teachers who have the most exposure to plagiarism in any public school; high school senior English teachers. Based on the results of the pilot and writing goals for English 12 students in West Virginia (see Appendix L), I decided to include as my participants all of the English 12 teachers in the same county where the pilot was performed. 


\section{Chapter 3}

Method

\section{Research Design Rationale}

The design of this study was a multiple case study consisting of all of the 12th grade English teachers, including regular and advanced placement (AP) English teachers, in one West Virginia county school system. The study utilized qualitative inquiry methods including participant interviews and document analysis. Demographic information was also used to support conclusions made in this study. Purposeful sampling was used to select one county school system in order to gain a deeper understanding of how high school English teachers in a single county school system address plagiarism in their classrooms.

Due to the more complex characteristics innate in any form of academic dishonesty, the best methods to study the academic phenomenon of plagiarism are qualitative. The dynamics of getting a close look at how educators in a county school system perceive plagiarism and of describing the ways that they address this problem, is too multifaceted to be adequately expressed utilizing quantitative means. Cronbach (1975) contended that statistical research cannot account for the numerous effects of interactions that arise in social settings.

As I reflect on my experience as a high school teacher, I deem public schools as social settings with peer groups and sub peer groups in close proximity producing an oasis of diverse relationships. The fruit of these relationships and how they affect the actions of all the participants in this study, when dealing with plagiarism would best be researched using observational methods of qualitative inquiry. Hoepfl (1997) acknowledges that "qualitative inquiry accepts the complex and dynamic quality of the social world” (p. 2). 
Even using qualitative methods a researcher cannot ignore the tertiary effects of social transactions and relationships on data collected from research participants about a societal problem. Studying plagiarism requires that we consider the effects of the values and opinions of others in the plagiarist's circle, such as colleagues or fellow students, regarding plagiarism and the effects of these peer perceptions on the frequency and acceptance of committed acts.

Merriam (1990) contends that "all research should take account...the relevant forces outside the unit being studied” (p. 2). In a qualitative study by Ashworth and Bannister (1997), the authors discovered feelings of "peer loyalty" when students were reluctant to turn other students in for cheating because the students felt overall that everyone has their own reasons for doing it. The same authors found that a "fellow feeling” existed among the students when an interviewee admitted he had committed a serious offense by actually stealing an assignment from another student, but made sure to include that when he did take the assignment, it was from someone he did not know. In another study concerning peer loyalty, a student participant admitted to stealing an assignment from an anonymous student and also said, “Yeah, I wouldn’t want to cheat using a friend's work without their consent, I think I might feel bad about doing that” (p. 195). The same researchers also concluded that students perceive the highest assault that could occur between them is one that causes problems for or hurts another student, including the problems that occur when students cheat. Ashworth and Bannister (1997) described further confirmation of “peer loyalty” when cheating among students by finding that cheating on exams was perceived by some students as “betrayal of the others present” (p. 197).

Peer observations and opinions also matter among teachers as well as students. In a qualitative study of one university faculty’s perceptions of undergraduate academic dishonesty, Saddlemire (2005) found that "faculty socialization plays a large role in the faculty understanding of, and response to, issues related to academic dishonesty” (p. iii). 


\section{Case Study}

According to Yin (2003), “case studies are the preferred strategy when "how” or "why” questions are being posed, when the investigator has little control over events, and when the focus is on a contemporary phenomenon within some real-life context” (p. 1). The focus of the research in this study was to find out how $12^{\text {th }}$ grade English teachers in one county school system address plagiarism. The results of studying how teachers in one county school system address the intricacies of plagiarism can be insightful, as well as extremely helpful for every educator and administrator in that school district and others that may be affected by plagiarism in the classroom or by disciplining students who plagiarize.

I selected to perform a case study using qualitative research methods that were designed to allow for much more depth into the context of plagiarism than the narrow reporting of a statistical result. Qualitative methods allowed for the descriptions of real situations occurring in one county’s high schools involving this popular breach of academic morals. When studying shared social behaviors, like cheating and plagiarism, the discussion thrives by way of insight when revealing the individual perceptions of the different participants. Merriam (1990) says research that includes the beliefs, insights and viewpoints of study participants makes the best contribution to the improvement of the educational process. The purported aim of all educational research is to improve the educational process, with an expected end result of improved student learning. Qualitative research methods offered the chance to learn about the teachers' background and experiences in managing plagiarism in the writing classroom.

Education is a social system, like government, health care, and religion. Although none function perfectly, Yin (2003) asserts that case study research has been an effective, regular research strategy in social science paradigms, such as those mentioned, as well as psychology, social work, political science, and even economics. Yin (2003) demonstrates using the case 
study method, for example, to study the successful economy of a single city as a common and preferred strategy. To investigate social events or any other complex phenomenon, like plagiarism, qualitative case study methods, according to Merriam (1990) are appropriate because the decision to use this type of research "stems from the fact that this design is chosen precisely because researchers are interested in insight, discovery, and interpretation rather than hypothesis testing” (p. 10). Merriam (2003) further supports that “case study research, and in particular qualitative case study, is an ideal design for understanding and interpreting observations of educational phenomenon” (p. 37). Plagiarism is an educational phenomenon.

Qualitative methods of data collection, like observations, interviews, and document analysis, provide the opportunity for research participants to elaborate on their opinions by relating personal experiences to convey the context of their answers to the questions before them and ultimately putting the researcher in their mindset. Qualitative methods helped to prevent confining a participant’s response to “circling a number from 1 - 5”, based on their perception of a single event or item.

By limiting the scope of this study to the teachers in a single county school system, one might question the soundness of any generalization made from the results. Yet in quantitative studies, generalizations are made regularly as results are reported. Yin (2003) ascertains that scientific generalizations are not made from one experiment either, but on "multiple sets of experiments that have replicated the same phenomenon under different conditions” (p. 10). Yin claims that the goal for researchers using case studies is to generalize theories using what they have discovered in their own study, instead of citing statistical frequencies. 


\section{Questions}

The research questions guiding this study are:

1. What are secondary English teachers’ perspectives on plagiarism?

2. What are secondary English teachers' practices on plagiarism?

The primary research focus of this study was how all of the $12^{\text {th }}$ grade English teachers in one county school system perceive and address the problem of plagiarism in their classrooms. The data used to answer the research questions guiding this study consisted of responses to specific questions asked of English teachers during an interview, documents were also submitted including classroom handouts, and other documents, as well as any classroom, department, school, or county mandated policies collected during the interviews regarding academic dishonesty or plagiarism. Demographic statistics from each of the communities where the five high schools are located was also collected and analyzed to report trends found in the socioeconomic and academic achievement level of student populations.

\section{Unit of Analysis}

Yin (2003) maintains that the researcher's definition of the chosen unit of analysis in a case study might be "revisited," along with other aspects of research design as a "result of discoveries arising during data collection” (p. 24). A unit of analysis in case study research can be a single individual, a business organization, a program, an event, or another specific entity. The unit of analysis for this case study was $12^{\text {th }}$ grade high school English teachers in a single county school system.

\section{High School English Teachers}

The participants for this case study were the $12^{\text {th }}$ grade English teachers, including teachers of AP $12^{\text {th }}$ grade English classes, in one county school system in central West Virginia. The recommendations for further research in a study about plagiarism by Ryman (2003) 
suggested that future researchers of teachers and plagiarism-related issues only study teachers who are most likely to be faced with plagiarism in their classrooms. It was also found in the pilot study (Newlon, 2003) that out of all the teachers in one high school who assigned research projects, senior English teachers were most involved with and had the most exposure to written research reports requiring reference citations, and plagiarism. In the pilot study most of the high school science and social studies teachers who assigned research projects had their students use a variety of alternative style of presentations to display their knowledge about their researched topic including panel discussions, computerized presentations, and interviews. Therefore, purposeful sampling was used in this case study to make use of the descriptive efforts of English teachers who have the most first-hand experience with plagiarism, the topic of this research study. This case study revealed the stories of eight senior English teachers, and the descriptions of the classroom documents they use, in order to describe how teachers address, and try to manage plagiarism in their classrooms. A consideration when defining the participants for this case study was the degree of accessibility to the participants.

The events and results one experiences when managing instances of academic dishonesty could not be adequately expressed with a survey. Conversation with teachers who are exposed to the majority of incidents of plagiarism in a school, by means of an interview, is much better at capturing a more comprehensive understanding of how this ethical dilemma is managed in today’s classrooms.

The study involved eight teachers of senior English in the county under study during the 2007-2008 school year. Three of the teacher participants in this study had over 20 years of teaching experience and three had less than five years experience. Overall, the participants easily expressed themselves and nearly all have leisure pursuits related to reading, writing, 
literature, performing, and the creative arts. The names of the schools were assigned pseudonyms.

At Beaumont High School, Laura B. Tyler High School, and Horace Mann High School, during the 2007-2008 school year there were two teachers that taught senior English, and at Pine Valley High School and South River High School there was one teacher that taught senior English. The most rural of all the high schools in the county, Pine Valley and South River High Schools, do not offer Advanced Placement (AP) English. A total of eight senior English teachers in the county, including two that were teachers of AP English at Beaumont High School and Horace Mann High Schools, participated in this study. A letter asking for the teachers’ participation (see Appendix A) briefly explained the relevance and the data collection procedures used in the study.

\section{Teacher Participant Profiles}

April Thompson taught at Beaumont High School and lived in the same community. Her 14 years of teaching experience were spread out among all four grades in the same school. She had an M.A. in English, two daughters, and she loved to boat along with other fun summertime activities. As was found common among most of the participants, April’s interests included reading and writing.

Tracy Queen taught at the same high school, but had only been teaching for two years. She and her husband were "huge WVU Mountaineer fans.” She was born in a small town with a rich civil war history about one-half hour away from where she taught. Her experience in the classroom had been with upper classmen. She had a B. A. in English Education and an M. A. in Reading. Tracy, not surprisingly also liked to read.

The teachers from Laura B. Tyler High School had even more contrasting amounts of teaching experience. Roxanne Carr, head of the English department, had almost 30 years 
experience teaching English. She was the most experienced teacher participant in this study. Roxanne had interests related to artistic performance. Her interest in theatre had led her to begin directing her school's plays; she had been doing it for the last several years. She also liked appearing in radio broadcasts when asked and was reportedly a favorite among the teachers in her school. Roxanne really stimulated my interest when she revealed she likes to collect autographs. After she told me this it made me wonder if she might have an autograph of a famous person I liked.

In contrast with Roxanne, Brooke Hinkle, who also taught English at Laura B. Tyler High School, joined the three teachers having the least amount of teaching experience in this study. In spite of her lack of extensive teaching experience, Brooke was very active with the student body in her school. As Pep Club advisor she had been very effective in motivating the student body and growing student spirit. She liked to work with pottery.

Carrie Riggs was a veteran-English teacher with 20 years total experience, 13 years at Horace Mann High School, which served the biggest population of urban students in the county. Carrie was degreed in English and also had an M. A. in Journalism Education. She taught advanced placement (AP) English to seniors and was from Wetzel County, a county bordering the base of the West Virginia northern panhandle. Carrie's interests are in the performing arts, music and singing, as well as reading, of course.

One of the more stimulating conversations I had was with Jackie Marshall, an English teacher with 22 years teaching experience. Jackie was born in Iowa, lived in Wisconsin, and was now living with her husband, who was a medical doctor in a small city in the county whose welcome signs read “Community of Choice.” This is the same community where Beaumont High School, the school having parents with the highest median household income is located. Jackie also likes reading and swimming and was a Pep Club advisor for 20 years. 
Marsha Callahan was the teacher in the study with the fewest years of experience and was the only senior English teacher at Pine Valley High School. Marsha likes the performing and communication arts as she had a B. A. in Secondary Education specializing in English, Speech and Theatre. She tutors students after school and likes to work out as well. During her short career she had already taught students from every grade level.

The only male participant, Josh Richards, taught senior English in the most remote high school from the others and was located in the southern part of the county teaching at South River High School. He was a coach with a B. S. in Education majoring in Comprehensive Communication. Josh had taught students at many grade levels, including teaching kindergarten students how to read. Josh was from Ohio and has similar interests to the other English teachers in this study. He is interested in music and plays guitar, and gives music lessons. Josh also writes music with his wife with whom he shares two children, Mason in the $4^{\text {th }}$ grade and Melissa in the $6^{\text {th }}$.

\section{High Schools}

The high schools in this study were located in central West Virginia and were managed by a county board of education with a county school superintendent. The high schools located in the county offered a variety of educational settings from which to study plagiarism, including a local variety of socioeconomic and racial climates. This county had five high schools that ranged in population from approximately 350 - 900 students and were located in different settings in the county.

\section{Beaumont High School}

Beaumont High School was the oldest high school in the county, and was located in Beaumont, a small, affluent city. The median income of the small city is $\$ 49,310$. This is proportionately disparate and approximately $\$ 22,000$ more than the median income of the largest 
city in the West Virginia county (Appendix C). The correlation between higher income and higher education has generally been known to be a positive one so it is no surprise that in this small city $37 \%$ of the residents age 25 and older had a bachelor's or advanced college degree (Appendix C).

The socioeconomic status for the community where Beaumont High School is located was readily known to everyone in the county to be significantly higher than the socioeconomic status of other communities in the county that are even as little as five miles or less away from Beaumont High School. According to figures that include the 2006 Career Pathways Information for $11^{\text {th }}$ and 12 grade students in the county being studied (Appendix C), 80\% of the students that attend Beaumont were enrolled in the Professional Pathway, meaning these students planned to earn a college degree and gain a career in a professional field. Compare this to between $48 \%$ and $62 \%$ of students being enrolled in the Professional Pathway in the remaining four high schools in this county.

This disparity was further reflected when studying the percentage of the students from each school who received free and/or reduced lunch. In the 2005-2006 school year only 15\% of the students at Beaumont High School were eligible for lunch assistance in a county where the percentage of students receiving lunch assistance in all the other high schools ranged from $42 \%$ to $52 \%$ (Appendix C).

The racial diversity index for each school in this study was represented as a percentage of white students out of the total population. The white students at Beaumont High School made up 97\% of the total student body. This high school also had the highest student population of all the high schools included in the study, almost 450 more students than the high school with the least students (Appendix C). 


\section{Horace Mann High School}

Horace Mann High School was the newest school in the county and served the students living in the urban or downtown area of the largest city in the county. West Virginia traditionally is less racially diverse and has a much higher population of white residents than the United States average. According to West Virginia state data from the U. S. Census (2000), 75\% of the United State's population is white, and 95\% of the people living in West Virginia are white. Of all the high schools, Horace Mann High School, serving the inner-city students, possessed the highest percentage of racial diversity with only $93 \%$ of the students being white compared to $99 \%$ in the least racially diverse school. Horace Mann High School was typical of most of the other schools in the county with regard to socioeconomic status. A little more than four out of ten students at this school received either free or reduced lunch (Appendix C).

\section{Laura B. Tyler High School}

Laura B. Tyler High School was a school attended by students who lived in two, middle, working class residential sections of the largest city in the county and those students who lived in the town's low-income housing development. The school also served students from several nearby, small, rural, unincorporated towns. Laura B. Tyler High School had the highest percentage of students receiving free or reduced lunch in the county (Appendix C). Beaumont High School had the lowest percentage of students receiving free or reduced lunch, only 15\% of the total student population, and is located only five miles from Laura B. Tyler High School, where $52 \%$ of the students qualified. The racial diversity of students at Laura B. Tyler High School was comparable to most of the other schools in the county (Appendix C). Pine Valley High School

Pine Valley High School was located in a rural section of the county. This school had the second highest student population and was serving students from a nearby small, town and 
outlying rural areas. This school's students were comparable to most of the other high schools' students in socioeconomic status as measured by the percentage of students who received free or reduced lunch, approximately 48\%. Pine Valley High School was also the least racially diverse of all the high schools in this study with $99 \%$ of the students being white.

\section{South River High School}

South River High School was located in a geographically remote and rural section of the county approximately 20 minutes south of the other four high schools and possessed the smallest student population of any high school in the county, approximately 400 . The racial diversity of South River High School was comparable to most of the other schools in the county with two percent less white students than Pine Valley High School, the least racially diverse high school in the county. South River High School was the most rurally located school and had the least number of students that plan to go to college and enter a professional career, $47 \%$, compared to the students at Beaumont High School, located in an upper-scale area of the county, where $80 \%$ of the student population plans to go to a 4-year college or university (Appendix C).

\section{Context of Teaching}

English teachers of high school seniors were chosen to participate in this study primarily because they have the most exposure to plagiarism related issues due to the required state curriculum goals regarding research. According to the West Virginia State Department of Education's standards, students in senior English classes in the county under study should be competent in "gathering and using information for research purposes" (West Virginia Department of Education: http://wvde.state.wv.us/ policies/p2520.1_ne.doc). State standards also required that students be able to "generate topics and plan approaches to research writing (e.g., graphic organizers; outlines) using pre-writing strategies,” in order to “produce a 
summative project (e.g., research paper; computerized presentation; web page) using an accepted format (e.g., MLA, APA).”

Regardless of the format used for expression of a research project, whether it is a computerized slide presentation, a web page, or a written paper, according to the West Virginia State goals for senior English, the student is generally required to cite sources for the information contained in the project that was not created or thought of first by the student. This should include textual, graphic, audio and video information.

There is also a specific goal that $12^{\text {th }}$ grade English students would address the integration of "the concept of intellectual property and plagiarism in all media (e.g., media copyright laws; private/public domain).” These research-related standards, along with the requirement for students to incorporate knowledge of copyright related issues such as plagiarism into their writing, made senior English teachers an ideal group to study in order to not only examine how teachers address plagiarism in their classrooms, but also to gain an understanding of how teachers embody and communicate principals of good research to graduating high school students. English teachers instruct students about how to write and also have the major responsibility of teaching students how to perform credible research by paraphrasing and directly quoting authors’ work, as well as properly citing sources. Selecting English teachers as teacher participants is to interview teachers from the most “information rich” discipline.

This study did not include teachers who teach special education English classes to mentally impaired and self-contained learning disabled students. According to a 30-year veteran special education teacher and department head teaching at a high school in the county under study, special education teachers usually do not require their students to complete a research paper of the caliber that would involve plagiarism. However, smaller reports on magazine articles are often assigned (Personal Communication, 2005). 


\section{Researcher}

At the time of this study this researcher was a business education and computer teacher in the county being studied. I had experience dealing with academic dishonesty and had witnessed the evolution of committed acts of plagiarism. In the past few years I noticed how technology had increased the incidents of academic dishonesty on assignments in my classroom and decreased some students’ test scores and overall quality of learning as a result.

At the high school where I had been teaching for the past eight years, at anytime during the semester, I would have an average of 5-6 students in each section of the computer classes I taught cheat during the semester using different methods including deleting their classmate’s name from the document on the screen, key their own name, then print out another copy and turn it in as their own work. The scope of the types of assignments in which my students cheated was expansive and ranged from verbatim copying of the answers to the chapter review questions in the textbook, to hands-on activities, for example where students performed a letter and mailing label mail merge or created a pie chart from data in a spreadsheet, or filled in a blank worksheet that I used to gauge student understanding. All kinds of classroom learning activities are increasingly being plagiarized or cheated, and as a result these activities could be perceived by the teacher as ineffective in helping students to learn the material well and ultimately pass an assessment.

The types of errors that I detected that led me to find cheating in my classroom included student work with identical text including the same unique typing, slang, or grammar errors, identical formatting errors, or two assignments with the same matching inaccurate and incomplete sentences that furthermore fail to answer the question that was asked. However, I realized there have been some instances when one student was totally unaware their work had been used. Several students in the past had admitted to me they cheated when they saw another 
student's document on their screen while that student was away from their desk printing, stapling and turning in their assignment and the cheating student issued the print command on their neighbor's computer and then took the printed document and wrote their name on it and turned it in as their work without the original owner knowing anything about it.

In my experience some students had attempted to hide the likeness of their work to another student's by at times changing the font, point size, alignment, margins, or color of the text. Some students, usually those having been caught twice, had even went to the trouble of changing a few of the words, but individual human expression in the written word is so unique that I was still able to find many instances to substantiate cheating had occurred. In my judgment as a classroom teacher, the students who are involved and knowledgeable about a cheating situation are all guilty.

I also found it distressing for example when a student cut and pasted text from a news web site to satisfy the requirements for a small homework assignment that done correctly should have taken between 15-20 minutes. The students had been assigned to summarize in their own words a non-fictional news story about a current event for a newsletter they were creating in a desktop publishing program.

I feel allowing any instances of academic dishonesty in the classroom instills in students a belief that they can get what they want by being dishonest. Teachers must become sensitive to student attempts at plagiarism and general academic dishonesty in their particular classroom setting. Each classroom setting offers its own unique environment for instances of academic dishonesty to further multiply as students’ efforts evolve to circumvent and manipulate the situation in the classroom. For example, in a computer class where technology is frequently used, some student assignments may be periodically graded right from the display on the monitor to help save paper and other computer lab resources. At other times I have graded a student's 
document from the screen because there was something I wanted to evaluate that couldn't be observed in a printed form, for example integration of multimedia and animation effects. In my experience, students that want to cheat and suspect that I may want to grade their document from the monitor display, prepare for this possibility by copying another student's completed document to their network folder and then open it up for me on their monitor to grade.

The problem of one student presenting another student's file on screen as their own can be remedied by checking the document properties, either through the application or system software, to reveal who the original author of the file was. Because of my own experiences with trying to manage academic dishonesty in my classroom over the years, I wholeheartedly agree with the viewpoint that experience is still the greatest teacher.

The English teachers under examination in this research study provided an opportunity to access participants who were willing to assist a local colleague in learning how teachers in their county manage plagiarism. Merriam (1990) depicts the results of a case study as a "rich, thick description of the phenomenon under study” (p. 11). I want to open up the world of plagiarism in high schools to the reader through a "rich, thick" description of the learning settings, the reactions, experiences, and opinions of the teachers in this study directly responsible for teaching about and detecting plagiarism in a classroom.

\section{Data Collection}

Data were collected during the 2007-2008 school year from the $12^{\text {th }}$ grade English teachers in one county school system. Qualitative methods, including participant interviews and document analysis, were used to study the English teachers in this county school system located in central West Virginia. Using qualitative data, a more comprehensive view of how teachers manage plagiarism in their classroom emerged. Participants were interviewed to capture the real 
essence of what they wanted to share about their background and experiences in managing and treating the problem of plagiarism.

I believe the best qualitative research method to reveal what teachers actually do when they discover any type of academic dishonesty, including plagiarism, would be natural observation of the teacher in the classroom setting. Though, due to the sporadic and secretive nature of plagiarism, it is not something that can be readily observed in a classroom. If it were, it would be much more controllable and would not present itself as such a widespread problem. Any themes that emerged as the data were analyzed were contrasted and compared where possible with results in the related literature

The interviews were planned to take place in the teachers' own classrooms to ensure ease of access to documents or artifacts that would help answer the guiding research questions in this study. Also, speaking to a participant in a familiar location where they are accustomed to being in a position of authority helps to put them at ease with the interview and audio recording process.

To maintain consistency during data collection, the teachers were asked the same interview questions in the same order. The phrasing and order of the questions (see Appendix B) was planned so the participants would not be under the impression their efforts regarding plagiarism were being evaluated or critiqued. If this were to have happened, they may have been hesitant to respond to certain items, as instances of plagiarism may be considered by some to be a negative reflection on the teacher's ability to teach students how to properly write about research and cite different kinds of sources, as well as paraphrase and summarize text. Therefore, the wording and sequencing of the questions was done carefully so the participants would not feel they were being judged. 
The questions were designed so that data would be collected to answer the research questions for this study. Interviews were intended to last 45 minutes, but it was understood they may run longer due to lengthy interview responses. The interview data were tape-recorded then transcribed. Several of the participants were interviewed during the school day in the afternoon and others were interviewed immediately after the school day. However, it was realized that participation would most likely be improved if data collection occurred during the teacher’s working day. Participants had the opportunity to request their interviews be made less intrusive by dividing them into two sessions, although all participants decided to finish the interview in one conversation.

Specific steps were taken to ensure anonymity to the county school system, the high schools and the English teachers who participated in this study. The high schools and each teacher participant were assigned a fictitious name. Any reference to a specific school in the interview transcripts was replaced with the school's alias name used for this research. In reporting the data from the interviews, brackets [ ] were used around the [replaced] text.

\section{Data Source, Collection and Analysis Procedure by Research Question}

This study employed two different observational research methods to collect data, as well as government demographic data from the communities and schools in order to support triangulation. Data were gathered using participant interviews and the collection of classroom documents. The data collected from the teachers were analyzed and the results from both data sources and the demographic data were used to answer the same two research questions, as well as find trends among the data while considering the socioeconomic characteristics of the schools and the communities where the schools are located. To help ensure triangulation I began to analyze the data by reading each interview transcription and submitted classroom document in its entirety. This process allowed the "research findings to emerge from the frequent, dominant, and 
significant themes inherent in the raw data” (Thomas, 2003, p. 2). The notes were “cooked” as I read and re-read the data and recorded any themes, patterns or other perceived relevancy of the data in the margins of the eight transcribed interviews and the collected classroom documents. Then I employed an efficient, familiar method that however lacked a specific label, but was revealed in the same article by Thomas (2003) that involved the use of the table feature in a popular word processing program to organize meaningful categories and sub-categories based on the research questions in this study. Using this method I then coded relevant data by copying and pasting, and organizing it into the appropriate category in the table structure.

Then after coding the transcript and classroom document data, I analyzed all of the data collected to identify if any relationship was found between the contents of the classroom documents and what statements the teachers made during the interviews that revealed how they view plagiarism and what they do in their classrooms to curtail it. Any themes that emerged as the data were analyzed were contrasted and compared where possible with the results in the related literature

\section{Research Question 1}

“What are secondary English teachers’ perspectives on plagiarism?” During data collection, participants were asked several questions that helped to reveal how they viewed plagiarism. The teacher participants were asked if they felt acts of plagiarism were common in their school (see Appendix B, Question 6). The teachers’ perceptions about the frequency of acts of plagiarism in their school may have an affect on how assertive their efforts are in managing it. I anticipated that some, if not most of the senior English teachers in this county would say plagiarism is a common occurrence at their school. Plagiarism is widespread and according to an experienced academic dishonesty researcher, D. L. McCabe, there is no "solid data" to support a variation in the frequency of acts of plagiarism in high schools that are different in size, student 
characteristics, how rural the school is, or the school's academic environment (Donald McCabe, Personal Communication, 2005).

Although according to McCabe there were not any obvious characteristics of schools whose students plagiarize more than others, I felt there may be more obvious characteristics of teachers whose students plagiarize less than others. Researchers have determined that teachers are able to change student behavior that can raise or lower instances of cheating in the classroom (Biernacki, 2004). Teachers that are effective in managing cheating are more willing to modify what they do in their classroom again and again in an effort to control the problem.

Teachers were asked how they make decisions about consequences for plagiarism in their classes (see Appendix B, Question 3). In answering the question they also revealed how serious they considered different instances of plagiarism to be. The participants described different acts of plagiarism that appeared on Table 1 which included three possible motives for plagiarism and labels specific student actions that constitute plagiarism as stemming from one of the three motives.

This study asked the participants to reveal what they say to their students about plagiarism, including how often plagiarism was mentioned in their classroom (see Appendix B, Question 8). The data collected were relevant to answering both of this study's research questions. Data collected regarding the matter and frequency with which a teacher addresses plagiarism in their classroom were helpful not only in revealing the participant's perception of the seriousness of the problem, but also in describing what senior English teachers’ practices were in the classroom concerning plagiarism.

The teachers' perceptions of plagiarism may have been affected by what they see as the students' primary motive for plagiarizing and whether they feel the students' motive justifies the act itself. To more clearly determine what teachers think students primary motives are for 
plagiarizing, the participants were asked why they think students plagiarize (see Appendix B, Question 7). In the pilot study (Newlon, 2003) the majority of the teachers felt that students commit plagiarism because they are "lazy and representing the ideas and opinions of others as their own is easier to do than learning to paraphrase, quote, and cite resources” (p. 2). Any trends discovered in the data describing why the teachers at different schools feel their students plagiarize were compared with the socioeconomic data for each community and school.

During data collection, the participants described experiences they have had over their career with plagiarism in their English classroom (see Appendix B, Question 2). Inside the descriptions of their experiences was introspection, belief, opinion, and judgment concerning plagiarism that helped to shape the image of how senior English teachers perceive this type of academic dishonesty and their role in controlling it.

Research Question 2

“What are secondary English teachers’ practices on plagiarism?” The data to reveal the various practices English teachers employ in the classroom to manage plagiarism came from teacher interviews and an analysis of the documents they use in their classroom when teaching their students about research and writing, and plagiarism. The documents collected included handouts used in the instruction of specific research and writing behaviors: paraphrasing, citing sources, and direct quotation, discussed in Chapter 2 that help students to avoid plagiarism by learning to do it the right way. Other documents collected were plagiarism policies used by the participants to discourage students from committing plagiarism by letting them know what the consequences are if they do. The contents of the classroom documents submitted by the participants were relevant in describing the teachers’ practices to address plagiarism in their classroom as well as supporting what the teachers reported their practices were in the interview regarding plagiarism. 
Participants were asked to describe their experiences with plagiarism, as well as any academic dishonesty policies that were enforced (see Appendix, B, Question 2). The data collected to answer this question helped to shape a more accurate image of how the participants define plagiarism, as well as how they react when they find plagiarism. Data collected included copies of classroom plagiarism policies submitted by the teachers, as well as interview data about enforced, and un-enforced classroom, school and county plagiarism policies. This document information when analyzed along with the interview data concerning plagiarism policies provided a good description of the use or non-use of a policy on plagiarism.

People tend to define what can be vague terms by using their own experiences and perceptions of events that are related to the term(s) being defined. Thus a classroom academic dishonesty or plagiarism policy created by the teacher may reflect for example as a definition of plagiarism, the types of plagiarism they have experienced in their own classroom. If no outside influence exists to expand the teacher's definition of plagiarism, any classroom policy used may likely be updated and changed only when the teacher encounters a new caveat of plagiarism they must deal with, making the policy inherently reactive instead of proactive.

To help further describe what teachers’ practices are on the topic of plagiarism the participants were asked what they did to teach their students how to properly prepare written research reports (see Appendix B, Question 5). The classroom documents submitted included instructional handouts with citation format for a variety of sources, information on paraphrasing, summarizing, and quoting published material, definitions of plagiarism, and research assignment handouts that include methods designed to reduce plagiarism, i.e. requiring works in progress and rough drafts. Research by McMurtry (2001) reinforces the use of works in progress in the writing process to helping teachers detect and reduce instances of plagiarism. 
The analysis and interpretation of the classroom handouts and other documents submitted by the teachers assisted with triangulating the interview data and provided further evidence of whether the students received instruction in being to able to perform research writing behaviors such as paraphrasing, directly quoting sources, and citing sources correctly.

Knowledge in properly preparing a research paper empowers students and helps them to overcome the urge to plagiarize. Therefore, by studying teachers' efforts in the classroom to teach their students how to do credible research, I was better able to describe overall how assertive the teachers were when attempting to reduce instances of plagiarism in their classrooms.

All the participants in this study were $12^{\text {th }}$ grade English teachers and all had the same state content standards and objectives for their classes. The participants having common course goals helped when analyzing the effectiveness of each participant's efforts. To study what practices teachers use to try to reduce instances of plagiarism they were asked to describe a research assignment they had given and the expectations they had for their students (see Appendix B, Question 4). Much of the available research on plagiarism in high schools includes the following summarized list of effective strategies teachers can use when assigning research projects to help prevent students from committing plagiarism: 1. Assign diverse research topics, 2. Become aware of available online resources for research topics, 3. Collect early samples of student writing, 4. Require early rough drafts or outlines of research papers to be turned in, 5 . Require the students to supply copies of original sources.

In my analysis of the research data, I examined what was there, or what I was seeing, and what wasn't there, or what I did not see. This analysis also applied to the pilot study (Newlon, 2003), where data were collected from five high school teachers in the county currently under study and from a variety of content areas. The data in the pilot study were analyzed and 
although all of the teachers required research projects to be done, none of them used a written or otherwise communicated academic dishonesty or plagiarism policy in their classroom. Also it was found in the pilot study that the only resulting repercussion to a student that plagiarized was a grade cut.

In the current study, the participants were all of the $12^{\text {th }}$ grade English teachers in five high schools in one county school system. The participants were asked if there was any kind of academic dishonesty or plagiarism policy in effect during the times when they discovered plagiarism in their classrooms (see Appendix B, Question 2). The interview and document data related to the use or non-use of any academic dishonesty or plagiarism policy were analyzed to identify emergent themes among the participants' responses. Knowing whether the teachers use a policy to in essence create a classroom directive about what plagiarism is and isn't in their classroom helped to reveal what practices the high school English teachers implemented to prevent plagiarism.

To research what the participants' efforts were to find plagiarism in their students’ work, the teachers were asked to describe their experiences when they found a student had plagiarized and how they detected it (see Appendix B, Question 2). The teachers were asked to include in their description of the incidents precisely what their students did that constituted plagiarism and what they did about it as a result. The specific acts of student plagiarism the teachers described in this study were included in the categories included in Table 1 that identify the range of intentional plagiarism from “possibly accidental” acts of plagiarism to "deliberate” acts of plagiarism.

To describe the teachers’ practices to manage plagiarism and other forms of academic dishonesty, the participants were asked to explain any changes they had made over the years in their classrooms or how they do things in an effort to reduce the instances of any academic 
dishonesty in their classrooms (see Appendix B, Question 9). For example, in the pilot study (Newlon, 2003) some of the teachers required their students to turn in photocopies or printouts of sources cited in their research projects. I anticipated the data describing teachers' efforts to reduce academic dishonesty in their classrooms to likely consist of a myriad of responses formed from each teacher's personal experiences and struggles with managing this academic phenomenon over the years in their English classroom. In Chapter 4 the results are discussed. When the teachers described their experiences with plagiarism in their classrooms, they were asked how they found it (see Appendix B, Question 2). The results also indicated the degree of technology integration in the plagiarism detection methods used by high school teachers outlined in Table 2.

The participants were asked how many years of teaching experience they had (see Appendix B, Question 1). Although teachers’ perceptions of academic dishonesty may be affected by the attitudes of their peers and their administrators, a study by Pincus \& Schmelkin (2003), found that the length of a teacher's career did not affect the teacher's perceptions of plagiarism. The levels of years of English teaching experience of the participants in this study were fairly evenly distributed. Approximately one-third had more than 20 years teaching experience, and one-third of the participants in this study had less than five years total teaching experience (see Table 5). The data were analyzed for patterns among responses from teachers with more and less teaching experience. I expected to find some similarity in the participants’ responses among those who had more teaching experience when describing how they addressed plagiarism in their classrooms.

During data analysis, I studied the data for any evidence of practices the teachers have on plagiarism, specifically the efforts the teachers put forth to re-teach, or remediate the skills the 
student who plagiarized will need in order to be able to revise and correct their own research paper thereby improving their ability to correctly write about research.

In the pilot study (Newlon, 2003) not all of the teachers were English teachers and it seemed the attention given by the teachers was on the punishment that was to be rendered rather than on trying to find out why it happened. In the pilot only one participant reported giving the student accused of plagiarism a chance to revise their research paper and do it the right way. In related research on plagiarism (Wilhoit, 1994), teachers were advised to teach students how to do credible research to avoid committing plagiarism, instead of concentrating on making sure students know what the consequences are if they do.

In analyzing the data for this study I read and re-read the interview transcripts and classroom documents. As I read the data, sub-topics of discussion associated to teachers’ perspectives and practices emerged. Then I copied and pasted relevant quotes from the interview data into categories in tables based on the sub-topics that had emerged. The relevant data in the documents collected were also coded for the same categories. The table categories were revised as I continued to study the data for relevancy to the research questions. During analysis I compared what each of the participants said about their perspectives concerning plagiarism. Accordingly, I also compared what each of the participants did in their classrooms when they addressed plagiarism. I looked for trends or themes in what the participants said and what they did. I also studied the data for what the participants said that was in contrast to their peers and obvious from the rest.

Also during data analysis I studied the interview transcripts and classroom documents submitted for things that were missing, as well as things I expected to find. For example, I expected the data to include evidence that a majority of the participants used some form of academic dishonesty policy in their classroom, or one created by the school or county to reduce 
instances of plagiarism (see Appendix B, Question 2). The results were compared to the demographic statistics for each of the different schools in this study to recognize trends in the data. In the pilot study for this research (Newlon, 2003), it was of note that even though most of the teachers in the study were not English teachers, none of the participants that assigned research projects in the entire school used a policy to try to control plagiarism in their classrooms.

When reacting to acts of plagiarism in a school, codes of ethics and other conduct policies are usually only as effective as the person or persons responsible for enforcing them. The participants were probed during their interviews about their perspectives and practices on the involvement of their school administration into reprimanding instances of plagiarism in their classrooms (see Appendix B, Question 2). The perceived pressure from a school or county administrator's actions in the face of plagiarism could influence what action the teacher takes when they encounter instances of plagiarism in their classrooms. In a study by Sutherland-Smith (2005), teachers did not inform their school's administration because of the bureaucratic nature of reporting plagiarism at their school. One participant in the same study, a veteran English teacher, told a fellow-faculty member her advice was not to report any instances of plagiarism to the school's administration because the trouble and time involved with reporting it was not worth the effort.

Participants were asked how they made decisions about consequences for plagiarism in their classroom (see Appendix B, Question 3). In describing how they made decisions about consequences for plagiarism, the participants revealed if they considered some forms of plagiarism to be more or less intentional, and how they accounted for the differences when disciplining their students. Teachers revealed their perceptions of the intention of different acts 
of plagiarism. Their responses were compared to Figure 1 which uses a continuum to identify various acts constituting plagiarism as being more or less intentional.

In a study by McMurtry (2001), 95 percent of the students in the over 3,000 sample population admitted they had cheated, but were never caught. With that many students getting away with it, this may indicate that teachers in all disciplines may at times excuse, or treat differently certain instances of academic dishonesty, including plagiarism. Data were collected that reveals some of the reasons teachers might excuse, or not treat as severely specific instances of plagiarism in their classroom (see Appendix B, Question 3). A teacher might excuse somewhat an instance of plagiarism when they feel what their student had done was a more innocent or accidental mistake, for example citing the source, but not paraphrasing well enough.

\section{Assumptions and Limitations}

According to academic dishonesty expert, Donald McCabe, there are no prominent contextual characteristics of schools that appear to affect incidents of academic dishonesty in a school (Donald McCabe, personal communication, September 27, 2005). Since there is nothing prominent about a school that makes its students more or less likely to commit plagiarism, and there are no characteristics of the high schools in this study that are considered to be exceptionally distinctive or particularly extraordinary, this study assumed the five high schools represented in this study were typical, or at least generally representative of other high schools in West Virginia.

Additionally, there has been much research on student cheating. However, most of the available studies on plagiarism have been limited to a single campus. Although this study included data collected from five high schools, an inherent limitation was that the unit of analysis was one county school system. Much could be learned about commonalities among instances of 
plagiarism and trends in cheating if studies were to encompass larger, more random student populations.

Also limiting the scope of participants in this study was that many college bound high school seniors in the county took advantage of dual credit college math and English classes that allowed them to leave their home high school, usually in the afternoon to take classes at a local community college where the college credit earned was also accepted by their high school as credit for the student's required high school English credit. So, another factor that limited the results of this study was that the college English teachers who taught these students were not included in this study. An example of an incident involving plagiarism with a student taking dual-credit English class was illustrated earlier in this writing when I recounted an experience at the school where I teach when a past student body president was caught when he submitted a research paper he bought online to his college teacher who was familiar with the document because it has been turned in to her before by previous students. Not including the college English teachers of these usually busy high school English students as participants in this study was a limitation of this study given their certain experience with perhaps even more deliberate forms of plagiarism.

An inherent constraint in this type of study given the data collection methods used, interviews and document analysis, was that although these collection methods were able to record the participants' answers to questions about their perceptions and practices concerning plagiarism in their classroom, and the methods facilitated the collection of classroom documents, the methods used in this study were limited in that they were only able to gather what the teachers reported to me in an interview and submitted to me on paper. Direct observation was not used; therefore, I was not able to verify what the teachers actually did in the classroom to prevent or detect plagiarism, or what they actually did when they found it. 
Additionally, another limitation inherent in the collection of documents was that the data required to answer the interview and research questions were not found in any certain or organized manner in the documents, if at all at times due to the random ways in which the documents were developed or chosen.

\section{Research Methodology Summary}

The research methodology of this qualitative study of how English teachers in one school district address plagiarism is summarized in a logical manner in Table 4. The table presents the research questions that guided this study and identifies the data sources and methods used to collect the data necessary to answer the research questions. The researcher's description of what the data looked like is also presented.

Table 4

Study’s Inquiry, Participants, Methods, and Expected Results

\begin{tabular}{|c|c|c|c|}
\hline $\begin{array}{l}\text { Research } \\
\text { question }\end{array}$ & Data source & $\begin{array}{l}\text { Collection } \\
\text { procedure }\end{array}$ & Results \\
\hline RQ1 & & & \\
\hline $\begin{array}{l}\text { What are secondary } \\
\text { English teachers' } \\
\text { perspectives on } \\
\text { plagiarism? }\end{array}$ & $\begin{array}{l}\text { Interview Questions 2, } \\
\text { 3, 6, 7, 8, and 10, and } \\
\text { classroom-related } \\
\text { documents. }\end{array}$ & $\begin{array}{l}\text { Teacher } \\
\text { Interviews, } \\
\text { Analysis of } \\
\text { Documents, } \\
\text { and Demo- } \\
\text { graphic Data }\end{array}$ & $\begin{array}{l}\text { An array of personal opinions and } \\
\text { perceptions based on experiences } \\
\text { managing plagiarism. Individual } \\
\text { teacher accounts describing their } \\
\text { current situation with plagiarism that } \\
\text { reveal varying philosophies, insight, } \\
\text { and expertise. }\end{array}$ \\
\hline
\end{tabular}


Plagiarism in High Schools 61

\begin{tabular}{llll}
\hline RQ2 & & & \\
What are secondary & Interview Questions 2, & Teacher & $\begin{array}{l}\text { Individual common and customized } \\
\text { english teachers' }\end{array}$ \\
practices on & $\begin{array}{l}\text { 3, 4, 5, 8, 9, and 10, } \\
\text { and classroom-related }\end{array}$ & $\begin{array}{l}\text { Interviews, } \\
\text { Analysis of }\end{array}$ & $\begin{array}{l}\text { instinctual, procedural, and } \\
\text { plagiarism? }\end{array}$ \\
& handouts. & $\begin{array}{l}\text { Documents, } \\
\text { and Demo- }\end{array}$ & $\begin{array}{l}\text { technological ways that attempt to } \\
\text { reduce the instances of plagiarism in }\end{array}$ \\
& graphic Data & English research papers, as well as \\
& & improve the detection of plagiarism.
\end{tabular}


Chapter 4

Findings

Introduction

So who wants to do research for their own assignment, when you can be 'IMing', listening to music, playing a game and cutting and pasting a paper all at the same time. April Thompson

The purpose of this study was to reveal how high school English teachers perceive plagiarism and what they do to address it in their classrooms. The guiding research questions in this study were: (1) What are secondary English teachers’ perspectives about plagiarism? and (2) What are secondary English teachers’ practices on plagiarism?

The participants included every full time English teacher teaching senior English in all of the five high schools in the same county located in northern West Virginia during the 2007-2008 school year. In this study, the eight participants' amount of teaching experience varied (see Table 5) with three teachers having 20 or more years English teaching experience, two teachers having 10 or more years experience, and three having 5 or less.

Socioeconomic demographics at the five schools varied greatly in some areas, and to some extent in others (see Appendix C), and were included for study in this research. The statistics about the communities and schools included in the data for this research included the median household income of the community in the school's attendance area, the number of students in each school that were planning to go on to a four-year college or university, the number of students receiving free or reduced lunch, the percentage of white students enrolled, and the attained level of education for adults 25 and over living in the attendance area.

I will initially report the findings of this research describing each teacher as a separate case. Each participant and setting in this study was unique and the discussion of each case will include samples of the relevant demographic information from the community and school, as 
well as samples of interview and document data collected from the participants. The data collected will be organized to answer the research questions in this study by helping the reader to form a description of the participants' viewpoints and practices when managing plagiarism in their classroom. Each case by case analysis will also include a description of the participant, the setting, and the general interview experience so the essence and context of how plagiarism is addressed in high schools will be well communicated.

After describing each case, I will present a cross case analysis of the relevant data collected that will report what was found, and was not found, as well as trends found across the data. Categories and sub-categories were used to organize the relevant data needed to answer this study’s research questions by describing the participants’ perceptions (RQ1) about topics like why teachers feel students plagiarize, and their views on involving administration, as well as their opinions on the relationship between plagiarism, morals and ethics, and perceptions they have of the effects of this multi-faceted phenomenon on learning in their classrooms.

The data will also describe the participants’ efforts and practices (RQ2) concerning the teaching of research and writing, and the detection, prevention, and consequences of plagiarism in the secondary English classroom. The relevance and relationship of the findings to the related literature about plagiarism will also be discussed.

\section{Case by Case Data Analysis}

Eight teacher participants were interviewed and asked ten open-ended questions. All but two of the interviews were held in the teachers' classrooms and each interview lasted between 35 and 90 minutes. During data collection, classroom documents used by the English teachers in their instruction of research and writing, and plagiarism were also collected from all but one teacher. This research attained triangulation by using multiple data sources through the use and comparison of demographic data for the schools and communities, transcripts from teacher 
interviews, and a collection of classroom documents used by the teachers to teach their students about research, writing, as well as how not to commit plagiarism, and what would happen if they did. I will describe each case and individual findings to provide a better understanding of the context of the teacher's role regarding plagiarism in today’s high school classrooms.

\section{Carrie Riggs}

Carrie Riggs was the first participant to be interviewed for this study. Carrie taught AP English, Mass Communications, and Journalism at Horace Mann High School. Horace Mann was built in 1995 to house some 1,200 students and had one of the biggest and most racially diverse student populations in the county. Although students going to Horace Mann lived inside the city limits, the school was situated outside the downtown area and located off a popular route in the county. On my way to speak to Carrie, as I was turning right, off of this route onto the road solely built for the school, I noticed the school was actually built in a very remote location at the end of a two-lane windy road that completely isolated it from the view of the main road and passersby.

She wanted to meet with me in a conference room located to the side of their tidy and large, but quiet school office, offering an obvious and stark contrast to my own school's small, cluttered, and often hectic headquarters. The conference room was warmly heated, and offered fewer interferences, but it did not offer me the opportunity to comprehend the environment in which Carrie taught her students, or her classroom's reflection of her personality.

Carrie was extremely articulate and had amassed 20 years of language arts teaching experience. Based on her personal descriptions, she appeared to be technologically savvy and familiar with the online resources her students had available to them. Although Carrie did not submit any documents that described the assignments she gave to her students, she did assign her 
students a research project and she stressed the need she felt to increase her students' interest by ensuring they engage in diverse research and writing experiences.

Carrie asserted, "I still think the fact that people are giving assignments like look this up in an encyclopedia and do a report on it is a culprit.” She realized that to simply assign students especially general research topics, i.e., an historic event or person, not only stifles the students’ ability to arrive at meaningful, insightful conclusions about a topic that is enlightening to them, but it also makes the ease of cut and paste plagiarism more appealing. Research on plagiarism supports creating diverse research topics that allow the student to build a personal connection with the topic (McMurtry, 2001) A study by Renard (1999/2000) also concluded that assigning creative research topics enables students to engage in higher-order thinking, and therefore reduces the likelihood of plagiarism.

Carrie was heavily involved in her school's media production and served as the advisor for her school's monthly newsletter, as well as literary publications that showcased student work, and the school's yearbook. She conveyed confidence when speaking about the abilities of her AP English students regarding plagiarism and technology when she described one student saying, "I have an AP student here who, I forget what the article was on, somebody that he had researched and there was nothing on Wikipedia about him, so [my student] presented the information to Wikipedia and they accepted it.”

She gave her students a broad background from which to learn about plagiarism by talking to them about it frequently and by giving them a spiral bound collection of approximately 30 handouts that began with a plagiarism/academic integrity pre-test. The collection was impressive and among many other topics included a definition of plagiarism and examples of intentional and un-intentional plagiarism. The first half of the pages in the collection she gave her students was strictly instructional in nature about how to report and cite research, including 
paraphrasing, quoting, and deciding if something is common knowledge or not. Carrie included in her handout the consequences of committing plagiarism in her class, as well as a glossary of terms and exercises to engage the students to learn. About two-thirds of the documents were downloaded from various university English lab websites.

Carrie's efforts to inform her students about plagiarism, and how she would deal with it were clear. Her description to me of the discussions she has with her students was assertive and related what she says to her students about plagiarism.

In my classroom, I really think I tell them that we can talk about and write about everything. It's just the manner in which we approach it. And where we get our information and how we document that. That we have to attribute everything we say to someone. You, you know somebody has to be responsible for that material. And if you wrote it, please put your name on it, if you got it somewhere else, we have to know who said that. Because it's not yours, although it’s free for you to use, but you can’t say you own it. Someone else owns it.

She was firm in her opinion of plagiarism. She taught AP English students and did not feel there were many instances of plagiarism in her classroom. Consequently, she also felt that outside of a grade cut, students who plagiarized should not be disciplined. She claimed These things I can handle myself, because for me it's not a matter of discipline, it's a matter of teaching what they did incorrectly and how we can do better next time. ... I think for me to have them suspended or tell their parents, that's just not an effective use of my time teaching.

Carrie taught advanced placement students, instead of regular education students, at the most urban school in the county. Her expectations for her students were high and from what she said her students meet them. 


\section{Marsha Callahan}

In contrast to Carrie Riggs, Marsha Callahan taught regular and special education students in the same classroom and felt many of her students plagiarized and did so without much concern for propriety. Also in contrast to Carrie Riggs' situation, Marsha taught at the least racially diverse high school in the county, Pine Valley High School where 99\% of the students are white (Appendix C), and the nearest incorporated town is 15 minutes away.

As I passed through several small communities driving to Marsha’s school, I was reminded how rurally the school is located. When I walked into her classroom, it appeared sufficiently organized for a small room, but almost cramped with 39 desks. The posters her students had made hung on the walls in the small room leaving little available wall space. Marsha acknowledged she liked the high school, the staff, and her students, where she has taught English at every grade level for two years. However, she felt that her students' behavior, how the majority of them act, was different than most students in other schools in the county.

When Marsha tells a student at Pine Valley High School who has plagiarized that she is going to call their parents, the reply is indifferent and the students tell her to go ahead and call their parents because, according to Marsha, the majority of her students feel their parents do not care. She believed this was a direct result of what she felt was a lack of parent involvement in the school's attendance area and she felt this was causing many of her students to be lazy and apathetic. So much so, that she claimed, "I could write a research paper for some kids and they wouldn’t even get up and bring it to my desk. It's that bad. They just do not care.” Marsha's perception was that her school was in a "different world over here," and that her students were that different from other students. After analyzing the data for each participant in this study, I realized Marsha's perception that her students are uniquely apathetic may be somewhat narrowed 
because Marsha had only been out of college for five years and had done all of her teaching, including her student teaching at the rural Pine Valley High School.

The only other substantive experience Marsha had in any high school was as a student at Beaumont High School, the high school in the county where less than one in six students qualified for free or reduced lunch, compared to where she was teaching at Pine Valley High School where over half of the students qualified for free or reduced lunch (Appendix C).

In comparing the two schools, it was also interesting that one of the participants in this study, April Thompson, who taught at Marsha’s alma mater and was her senior English teacher, revealed that she felt that a very contrasting and different problem existed at Beaumont inside many of the parent-student relationships at her school. According to April, during her experience teaching at Beaumont High School there had been a long-standing problem that a majority of the parents gave their children too much pressure stemming from the parents' desire for their children to make good grades for purposes of being awarded scholarships, getting into reputable universities, and a host of other reasons. According to April, the pressure for high grades at Beaumont, especially for seniors, influenced them to intentionally plagiarize, "I do see a lot of parental pressure here, and hearing oh if he doesn't do well this six weeks, is that going to keep him from med school 10 years from now, and I’m like No, I don’t think so.”

As a college-bound high school senior attending Beaumont five years earlier and prior to this research, Marsha Callahan may have felt the same pressure. This achievement attitude among the students at her alma mater provided a stark contrast for Marsha when she was faced with the unconcerned attitudes of the seniors in her own English classes at the Pine Valley High School, and may have caused her to feel as if her students were unlike any other students in the county, but when compared with the rest of the schools in the county they were actually more typical. 
However, given Marsha’s description of her efforts to teach her students about plagiarism, I found her to be competent and conscientious. She recognized the phenomenon of plagiarism to be a problem and described one way she taught her students how to avoid doing it. So we did something with the newspaper to practice how to paraphrase correctly. I gave that side of the class an article and this side of the class an article and they faced each other. And after they read it, [as a group effort] that side had to tell this side what they read, and this side had to tell that side and they had to judge if they knew enough information from what they were saying.

Her teaching materials included an example 15- page research paper complete with bibliography and margin annotations that identified and explained the thesis statement, in-text citations, indents, brackets, quotes, paraphrases, and summaries. Marsha also gave her students a rubric for their research paper so they would know what she expected. The other classroom documents Marsha used to teach her students about plagiarism included handouts on paraphrasing, quoting, and examples of what type of entries students must document in a research paper.

According to the document data, Marsha asked her students to read a 2006 news article from the New York Times about a novelist that claims cryptomnesia when similar comparisons are made between the plot and writing of her book and two books by another author that she had read four or five times each. Marsha's students examine the article to answer questions about the plagiarism committed and how it affected both the authors involved. Cryptomnesia as previously described in Chapter 2, occurs when someone plagiarizes someone else's words, thoughts, or ideas, but truly believes it to be their own because they have been exposed to it before maybe even several times and have now internalized it and sub consciously take it for their own. People who claim this defense for plagiarism as the reason they plagiarize usually see 
this as an unintentional form of plagiarism. Marsha wasn't the only teacher to mention cryptomnesia, as well as identify it as an unintentional form of plagiarism.

\section{Josh Richards}

Josh was the only male teaching senior English in the county under study during the 2007-2008 school year, therefore, the only male participant in this study. Josh taught at South River High School, the most distantly located of all the high schools, from the largest city in the county. The bell to excuse students at the end of the day rang as I was walking through the parking lot on my way into the school. I observed many students and faculty leaving the school and noticed that almost all of the students were dressed very casually; more than several had very visible holes in their jeans. As I observed the students' appearance, I remembered from the data that less than half of the students that attended South River High School were planning to continue their education past high school (Appendix C).

The school's office was small with a wooden counter and what struck me was a large round clock with the numbers in a mirror image hanging on the wall. The "three" on the clock was where the "nine" should have been and so on, and this created an instant brainteaser for me as well as I'm sure for everyone else who saw it. Meeting Josh was a nice surprise. Although he held a traditional role for a male in a high school serving as a basketball coach, he was cultured and kind. My first impression of his manner and appearance quickly reminded me Josh was not from the area.

His classroom was open and airy, but slightly disheveled. Despite the disorganization, I found Josh to be a different kind of individual personally and professionally. He was a thirtysomething coach who also gave music lessons and wrote music with his wife. Josh's diversity also extended into his teaching career. He had taught in a private Christian school and had other experience in public schools teaching elementary school children how to read. Josh was 
teaching his first senior English class during the semester the data were collected for this study. And as of the day we met, it was still early in the spring semester, and he had never assigned a formal, written research project to seniors. The two documents Josh submitted reflected this as one was a comprehensive assignment sheet for a career research project requiring varied sources and works in progress that he used in a past tenth grade English class he had taught. However, the other was labeled English 12 and was a student handout explaining an online periodicals unit consisting of several online research activities designed to improve the students' web searching skills, and teach them to paraphrase, to develop their skills of inquiry, and to develop a written stated opinion.

Although Josh had ten years teaching experience, most of it was teaching younger children. Therefore, his experience managing plagiarism in a high school classroom was very limited. I reason that to be the major factor in why his interview was the shortest one in this study, lasting only 35 minutes. At the end of our conversation, Josh made a comment that conveyed to me he may have been feeling some pressure before our interview due to the topic we would be discussing. Afterward, I was glad when he told me he felt our interview had been easy.

Even with Josh's lack of experience teaching senior English, he had a definite opinion of plagiarism and its effect on student learning when he told me what he had said to students in his sophomore English class about plagiarism.

I stressed that I'm more interested in what they know and what they can communicate and not so much on their technology skill of copying and pasting. So I want an accurate idea of what they know and think. Sometimes I will just use questions. We had a project; it was more of an oral presentation, but to find out if they really knew anything I just asked questions. So, [I will] just set the 
tone early that I want to know what they know and I will be asking questions.

And I'm familiar with your writing so I'm looking to see if you're writing in your style, just like you talk.

Many of the participants in this study mentioned using the writing process to teach students how to complete a research project. The writing process, as defined by the MIT Online Writing and Communication Center Website (The Writing Process, 2008), is a process that involves at least four distinct steps: prewriting, drafting, revising, and editing. Even though Josh did not use the words "writing process" in our conversation as most other participants had, he did give evidence that revision is part of the process he uses to teach research and writing when he said, "The [students] who were a little bit too close to the original, maybe they tried to change one word in the sentence and called that paraphrasing. I just wrote a note that I noticed and that they made an attempt, but it wasn’t enough and they had to fix it.”

The handout he had given to sophomores the previous school year that he submitted for this study also indicated he used the writing process in his classroom. The document indicated that Josh required his students to submit in successive order, source and note cards, then an outline, a thesis statement, and finally a rough draft. The document listed the required contents for the paper, which included among other things a body of 3-5 pages and a conclusion (Appendix E).

Jackie Marshall

Jackie was the most personally and socially diverse participant I observed during this study and my discussion with her yielded one of the longest interviews in this study lasting almost 90 minutes. Jackie was nearing or past retirement age and spoke in a non-threatening, but matter-of-factly tone. She described herself as largely liberal and spoke of raising her stepsons who were Quakers. Although she and her stepsons shared different religions, they both held the 
view that people are created equally, regardless of gender, race, or religion. Jackie even more interestingly, was candid when she spoke of her memberships in the American Civil Liberties Union and the Catholic Daughters, admitting the irony of the very opposite views of the liberal union and ultra conservative religious group to which she belonged.

She jokingly called herself "old" and spoke of using PMLA and Chicago citation in research papers when she was in college, as if mention of these would somehow date her. She was humble and at times humorous when referring to her age and how it affected what she did in her classroom.

I am an old lady who went to college in the 60s, and they're not going to shock me when they talk about LSD or something like that. Somebody picked up on Charlie Manson, but I told them you can’t tell me two days from now what your thesis is cause you don't know anything about Charlie Manson, and then she [the student] actually changed her thesis a bit.

Jackie wasn't from the area and had moved here to be with her husband, a prominent medical doctor in the community. Because Jackie lacked teaching experience in the county under study, she claimed she had only gotten the full-time position at Horace Mann, the most urban and racially diverse school in the county (Appendix C), because no other teacher had applied or had placed a transfer bid for the position when it became open.

Although Jackie was new to Horace Mann, she had 22 years teaching experience with $11^{\text {th }}$ and $12^{\text {th }}$ grade students. Due to her long career in teaching English and her experience in the field, she realized the importance of the research and writing process to a high school student's success when they are pursuing higher education, as she explains

I am not nearly as concerned with the Earth shattering nature of their work as I am that when they go to WVU, or West Virginia State, or Arizona that they know 
how to follow a process and take instruction. And [it's important] they know how their supposed to cite, and when they're supposed to cite, and they know what happens when they fudge on it.

Jackie utilizes her grading methods to insist her students learn how to write about research. Jackie informed me early on the phone me she would be the one participant to skew my data. She did just that when she revealed the aggressive move she makes as a senior English teacher to ensure her students learn research and writing. Jackie does something that not only no other participant in this study had done, but one I had never contemplated in all my extensive time thinking and studying about plagiarism. According to Jackie it was very effective to encouraging her 89 seniors to learn how to do a research paper the right way, whether they wanted to or not. She did not give them an F on a research project that wasn't turned in, or failed to meet her requirements for a passing grade, Jackie simply assigned a course grade of incomplete. Thereby making it impossible for the student to graduate from high school until their senior English research paper is turned in and receives at least a passing grade. She upheld her position and maintained that:

Until they give me acceptable work, they will get an incomplete grade, and believe me I'm Irish and stubborn, but I'm also generous if they try, if they try. But they don't need to know that. . . . If I'm going to go through the trouble of figuring out if they cheated, then they're gonna re-work it on my time.

The classroom documents Jackie submitted were very focused on the research assignment and included a layout for an outline, and a model and instruction sheet for the preparation of a works cited page, as well as a several page handout containing MLA citation examples for many types of sources. To explain the research assignment to her seniors, Jackie gives her students a handwritten handout (Appendix F). In the handout she requires her students 
to write a 3-5 page paper and turn in works in progress, and gives them a format to follow when doing their source and note cards.

Like Marsha Callahan and other participants in this study, Jackie Marshall also recognized the existence of cryptomnesia, a defense for plagiarism, as a possible event in the English classroom when she explained one thing she told her students about plagiarism, "I tell them some of these topics, if you read it so much, you will think in your mind you know about it.” I realized during my time with Jackie that her teaching experience had developed her insight and understanding of the phenomenon of plagiarism.

Jackie spoke quickly and gave me some of the fastest responses I received to any of the questions I asked when collecting the data for this study. Although she strayed from the topic at times during our conversation, she was rich with verbal expression and was able to succinctly summarize for me one of the ways she told her students what was required for a research paper. She told her students to "Say what you say, back it up, and come to a conclusion." As a result of her over 20 years of teaching research and writing to high school juniors and seniors, Jackie had resolved these things to be the most important tasks to master in research and writing, and she was able to communicate that to her seniors in one sentence.

\section{Tracy Queen}

My interview with Tracy intrigued me mostly because I would be interviewing a participant teaching in the extremely competitive and highly academically-achieving Beaumont High School. The high school and middle school in Beaumont has received awards for their students achieving the highest standardized test scores of all five high schools in the county. The principals at Beaumont High and Middle schools were again most recently awarded plaques in recognition of this honor at a county board of education meeting in 2008. The county’s superintendent of schools noted that Beaumont High School had received this award for the last 
seven years consecutively. That could quite possibly be when the award originated. It is highly unlikely Beaumont High School will give up that standing anytime soon, as $80 \%$ of the students that go there are planning to attend a 4-year college or university, compared to between a $48 \%$ and 62\% college going rate at the four other high schools in the county (Appendix C).

The early spring day I met with Tracy there was a constant rain. I appreciated the covered walkway that extended from the parking lot to the school, although it did seem a bit extravagant for a school in West Virginia. However, this high school was in Beaumont, a small, prosperous community in the eastern part of the county that strongly supported their local elementary, middle and high school, and the possibility is great that the funds for the covered walkways came from donors or fundraising activities held in the community.

Beaumont High School although lackluster in color with the walls, floors, and lockers painted tan, was home to a majority of the county's brightest and most athletically-talented students, and was a physical Mecca of school sports memorabilia filling to the rim 18 6-ft trophy cases that spanned the entire length of both sides of the cafeteria. Very large team pictures lined the walls above the trophy cases. In the hallway leading to Tracy's classroom, bulletins boards were sporadically located and posted statistics and results of the school's various sports teams, including track and field.

Tracy greeted me with a firm handshake and a professional manner. She was a younger teacher who had taught at Beaumont for two years out of her four-year teaching career. I observed Tracy as she moved confidently through her classroom gathering materials she wanted to submit for this study. I appreciated her organizational skills as she easily retrieved the handouts from different storage locations in her room.

During our conversation, Tracy appeared mostly relaxed as she sat at her desk; however she did cross her arms over her chest frequently throughout our conversation. It is possible that 
due to her limited teaching experience, she may have been at times slightly uneasy about the topic of our conversation. In any event, Tracy was articulate and appreciated plagiarism as a moral dilemma in her classroom. She tries to persuade her students to apply the basic concept of the Golden Rule when it comes to plagiarism by telling them that:

I relate it like you guys come up with your own ideas and how would you feel if someone out there says hey I thought of this and didn’t give you credit, you're doing the same things to these authors, you're not giving them credit.

During our conversation, she presented me with some handouts she uses in her classroom, one of them a teacher-made assignment handout for the research paper in her English 12 class. In this handout, one section was labeled plagiarism and stressed, “All information received from a source that is not considered common knowledge must be documented. ... Any plagiarism in your paper will result in failure of the assignment. If you have any questions about plagiarism, please see me.” (Appendix G) She does not define plagiarism more specifically, other than to include "paraphrasing does not mean just changing a few words.”

Several English teachers in regular classrooms in this study believed their students plagiarized frequently; however the AP English teachers did not feel this way. Carrie Riggs, an AP English teacher recounted, "I would say probably in each class, there’s usually one or two, and that's not a lot”. Although Tracy is not an AP English teacher, she was the only regular education English teacher that didn't feel it was common for her students to plagiarize

I think it happened sparingly; it doesn't seem to happen a lot. So either they are getting really good, or hopefully they are learning by time they have me it's not gonna fly. Which is great, I would rather be known that way.

What is interesting is that although outside of the AP English teachers, Tracy was the only regular education English teacher in this county to feel her students did not plagiarize 
frequently. Tracy teaches at Beaumont High School, a high school located in a community where 37\% of the residents age 25 and older have a bachelor's or advanced college degree (Appendix C). This raises the question of a possible relationship between level of education and frequency of incidents involving plagiarism. Beaumont High School is the only high school located in this community and the school benefits in numerous ways from the intellectual and socioeconomic characteristics of the community located in its attendance area.

It was during this interview I became more comfortable with the interview process, and began to use probes more effectively for the first time.

\section{Roxanne Carr}

My conversation with Roxanne was both engaging and entertaining. From earlier comments by her former students, she was a popular teacher at Laura B. Tyler High school, a school that sits atop rolling hills off of a major highway in West Virginia. In the county under study, Roxanne had been honored as the 2007 Teacher of the Year. She was also known as a local radio personality for regularly contributing an English quiz segment on a popular, local radio station and comments on events, etc. Roxanne had the most teaching experience of any participant in this study.

She was polite and pleasant during our conversation and admitted to keeping her students busy when they are in her class. One reason her students are busy may be that in her class they never do any of their work at home. In not assigning homework, Roxanne felt this reduced cheating in her class and better assured her that the answers she was getting on assessments and assignments in her classroom were a true evaluation of her individual students' abilities. It was important to Roxanne that her students learned the right way and mastered the competencies in her class, instead of them cheating and risking not learning how to write about research. 
Ninety minute blocks, I work them the entire time they are here, the seniors especially, until they leave. And I've even had over the years, a few parents say my child is not bringing a book home and doing homework. . . .Well, for starters when we are diagramming sentences for grammar, I can help them, instead of walking through the cafeteria and seeing someone take a friend's homework paper and just copy it.

Roxanne also implemented other strategies to reduce instances of academic dishonesty in her classroom. She creates a new exam for each of her classes every semester and when her students take a test, she requires them to use cover sheets to protect their answers.

Roxanne seemed conscientious in her efforts as a teacher both in her classroom and in her school. She produces and helps direct her school's plays and coordinates other school events. In addition to being reliable in her duties at her school, she also was conscientious about her preparation for our interview. In the beginning of our conversation, she quickly informed me that after she found out she would be participating in a study on plagiarism she did some research to update herself on the topic. Although I realized this may have affected some of her described perceptions about plagiarism, I was pleased she had taken such interest in the topic of my research.

The afternoon we met at Laura B. Tyler High School was quiet, a faculty senate day when students were not in school. The students that attended this school primarily came from two different neighborhoods of mostly working class people where large factories had been located years before. More students received free or reduced lunch at this school, 52\%, than at all five public high schools in the county (Appendix C). Despite this seeming barrier, Laura B. Tyler High School had more juniors and seniors enrolled in the professional pathway program of study than all the high schools, except Beaumont where $80 \%$ percent of the juniors and seniors 
who attended Beaumont High School were enrolled in a professional pathway (Appendix C). Furthermore, and not surprisingly, only 15\% of the student population at Beaumont received free or reduced lunch. Early during our meeting, Roxanne cascaded more than several articles about plagiarism on the desk in front of her. The documents became an arsenal of knowledge about plagiarism that she referred to throughout our conversation. Although the clear attention she had paid to researching plagiarism was stimulating to me and I liked hearing what she had found, I soon realized to best answer the questions in this study I needed to center our conversation more on her personal perspectives and practices on plagiarism and less on what she had read about plagiarism before our meeting.

Without realizing it, Roxanne gave me reason during our conversation to understand why she had been recently honored locally as an outstanding educator. She mentioned that she had held a Language Arts Fair at her school and had invited several judges from the local area that noted, among other things, the weaknesses in each of the students' projects. Roxanne used this feedback to implement instructional activities and specific strategies to improve the instruction her students received in the areas considered weak by the judges.

During my time with Roxanne, she appeared genuinely relaxed with her arm casually placed over the back of her chair and her legs crossed. Before our meeting she had gathered the documents she uses in her classroom related to the senior research project and plagiarism. Roxanne gives her students a written classroom policy that she titled, "PLAGIARISM WARNING!” (Appendix H) In this policy Roxanne warns her students that she will deducts points for plagiarism or late papers. She gives them a simple rubric listing each work in progress and the corresponding point values for each part as well as the total for the entire project (Appendix I). This way they are able to see how heavily each work in progress weighs in the final point value for the project. She also gives them two sample research papers, both with 
models for the works cited page. There are handouts dedicated to instruction for writing the rough draft and creating citations. She gives her students several detailed handouts, that include examples of formats for various citations; and some good general instructional information on how to do research is also communicated. Also, for guidance she gives them several pages that include the labeled parts of a note card and guidelines for creating them. In her handouts Roxanne stresses to her students the need to cite all of the sources they use.

\section{Brooke Hinkle}

Brooke, like Roxanne Carr also taught at Laura B. Tyler High School, a school attended by students from working-class families, as well as students who are raised in the town's lowincome housing development where local law enforcement positions a police cruiser most all the time. More students received free or reduced lunch at Laura B. Tyler High School, 52\%, than any other high school in the county (Appendix C). Although it would seem Laura B. Tyler High School would teach the most urban students in the county, Horace Mann High School was home to the students who live within the limits of the county’s largest city.

Brooke was a young teacher with less than five years teaching experience. She seemed to have higher expectations for her students learning. Hence, she was very conscientious about plagiarism, as well as pro-active in how she tried to prevent plagiarism in her classroom. Brooke did two obvious things when she taught her students about research and writing that improved the chance her students would not plagiarize. Brook was one of only two teachers in the study that used a supplementary text or workbook for teaching research writing. She used a 174-page workbook titled, “Writing a Research Paper: A Step-By-Step Approach”. Brooke describes how she uses the workbook in her instruction in an ultimate attempt to teach her students the right way to do research and limit the instances of plagiarism in her classroom 
There are things in here that kids struggle with the most ... [I will] use the information [in the workbook] to illustrate what I am telling them and to give them an opportunity to do practice exercises which do help. There's also a section on writing introductions, so we'll look at that, and there's a section on how to paraphrase and the difference between paraphrasing and direct quoting. She required her students to turn in photocopies or printouts of all the original sources they used in their research papers, she also had her students highlight the exact text they used. Two more participants, April Thompson and Tracy Queen, both teachers at Beaumont High School also required their students to submit photocopies of all their sources. Brooke described how she detects plagiarism using the photocopies of her students' sources

So, then I look at that work cited page, which I have to check, and then if it says in their research paper in an internal citation, Brown pg. 5, I look in their sources and I find it and I see if it's highlighted, then I know that's where they got their information. So they can't really, you know, they are accountable for it all. They can’t say, well, it’s a book I couldn’t find. They have to turn in a highlighted photocopy of the source for every single citation, so I can just go right to it and I will know if they gave me a bogus website or something else.

For her age and level of teaching experience, Brooke appeared to be an intuitive and keen educator. She was aware of the caveats that plagiarism produced in the classroom, especially the largest having already been identified earlier in this writing; the loss of student learning, April Thompson

April was the last participant to be interviewed for this study. Unfortunately, she was assigned to serve jury duty for two weeks at the end of the school year, so we met at her home in 
Beaumont shortly after the school summer break began. Even though I wasn't able to meet with April in her classroom, I considered her input to this case study valuable. April was one of only two senior AP English teachers in the county and had almost 15 years experience. Two other participants in this study, Tracy Queen who taught with April at Beaumont High School, and Brooke Hinkle, who had been a student of April's almost ten years earlier at Beaumont, both had already lauded April's teaching in my discussions with them, one described her as “a tremendous teacher”, naturally I looked forward to meeting her and seeing what she could add to my research of plagiarism in the English classroom.

April most certainly did not disappoint me and throughout our discussion gave me examples of how she accomplishes her goals with plagiarism in her classroom. She explains the importance of determining credibility of sources to her students using her experience of having once checked a student's web resources and found an interesting website that contained conspiracy theories. She felt the website was a valid source until she read further when the author accused Bill Gates of being the Anti-Christ. April repeats what she says to her students when teaching them why certain websites like this one would not be a credible source.

And I use this as an example because even if your website up here [at the top] sounds pretty feasible, keep reading it because when you get down here you have this crazy, radical, information that really negates what's up here and makes the website not credible.

April was the only participant in this study that did not submit any documents for analysis, presumably because April's interview was conducted at her home. Although April did not have access to her classroom documents, she did attempt to find her AP English syllabus on her home computer, but was unsuccessful. My discussion with April was the longest of this study. I found her perspectives on plagiarism and her strategies in the classroom to reflect 
foresight, insight, and at times hind sight. For example, April, like other English teachers, believed that being able to properly do a research paper was integral to their students' future success in college. However, April also appreciated and described another intrinsic value she sees of learning research and writing the right way in an effort to reduce plagiarism in high schools

I think it is much more important for me to teach them to learn how to learn than to learn about Romeo and Juliet. Not that that's not important, but they will learn how to learn, and part of that is if you're going to college and you're going into anything where you will have to read material on a subject and write, you've got to know what plagiarism is and how to avoid it.

In studying teachers’ perspectives about plagiarism, I also examined why high school English teachers think their students plagiarize. Some of the teachers particularly mentioned laziness as I had expected, and several others mentioned reasons in addition to laziness that will be discussed. However, April was the only teacher who specifically negated "laziness" as the reason her students plagiarize when she said, “I don’t even think that it’s laziness, as much as it’s they're forte to be on the computer looking for stuff and I think if it's right there, it's the whole mentality of if it feels good do it, and they’re like hey its right on the computer I can just. So I think a lot of it is just accessibility. It's amazing.”

\section{Cross Case Data Analysis Organized by Research Question}

According to Patton (2002), it is during the segment of a qualitative study when research data is being coded and sorted, that a structure is developed for organizing and communicating the data. A cross-case analysis is now presented for this study with samples and descriptions of the interview data, demographic data when relevant, and classroom document data collected from all the participants. The interview and document data has been coded and analyzed and the 
relevant data is now presented in categories and sub-categories that originated and were formed from the following research questions that guided this study:

1. What are secondary English teachers’ perspectives on plagiarism?

2. What are secondary English teachers’ practices on plagiarism?

Perspectives (RQ1)

Trends based on demographics. Each participant possessed his or her own unique life experience, personality, style of classroom management, and school population within to teach. They each also had definite perceptions about plagiarism that were molded by their experiences in the classroom and their exposure to published research and literature on plagiarism. The participants' years of English teaching experience were well distributed as shown in Table 5, with half the participants having ten or less years experience and the remaining half having over ten years experience.

Table 5

Individual Teachers' Years of Experience

\begin{tabular}{cccccccc}
\hline $\begin{array}{l}\text { Marsha } \\
\text { Callahan }\end{array}$ & $\begin{array}{l}\text { Brooke } \\
\text { Hinkle }\end{array}$ & $\begin{array}{l}\text { Tracy } \\
\text { Queen }\end{array}$ & $\begin{array}{l}\text { Josh } \\
\text { Richards }\end{array}$ & $\begin{array}{l}\text { April } \\
\text { Thompson }\end{array}$ & $\begin{array}{l}\text { Carrie } \\
\text { Riggs }\end{array}$ & $\begin{array}{l}\text { Jackie } \\
\text { Marshall }\end{array}$ & $\begin{array}{l}\text { Roxanne } \\
\text { Carr }\end{array}$ \\
\hline 2 & 4 & 4 & 10 & 14 & 20 & 22 & 26
\end{tabular}

Although the length of the participants' careers was fairly evenly distributed, some obvious trends developed when I studied the demographic data from the schools and from the communities in which they were located, and the interview responses from the participants that described their perspectives on plagiarism.

The regular education English teachers at the most rural and economically disadvantaged schools, South River High School and Pine Valley High Schools believed their students 
plagiarized more than did the AP teachers that taught in the more affluent Beaumont, and the more urban Horace Mann High Schools. April Thompson and Carrie Riggs; along with the only regular education senior English teacher at Beaumont High School, Tracy Queen, all expressed that they did not think it was a common occurrence for their students to plagiarize. It is also interesting to note, Beaumont's median household income is almost twice that of either the Pine Valley or South River High School attendance areas (Appendix C).

Tracy clarified her description of "not a huge occurrence” when she revealed, "It's happened maybe five times in the two years that I've been here. So, it's not a huge occurrence.” Carrie Riggs, the AP teacher at Horace Mann High School, also believed plagiarism was not common in her classroom when she declared, “I would say probably in each class, there’s usually one or two.”

The data in this study revealed that based on years of experience there were both differences, as well as similarities in the participants' perceptions about plagiarism in their classroom. Josh Richards was one of the younger teachers in the study and had the least amount of experience in teaching senior English among the participants. As of the date of our meeting early in the spring semester, he had not yet ever assigned a senior research project. However, his perception of why plagiarism was difficult to manage in the classroom encompassed a contemporary view that society simply did not consider plagiarism to be a serious problem. Josh felt that this being so, made plagiarism an even harder topic to broach and teach about in the English classroom. Similarly, Carrie Riggs, a veteran AP English teacher with over 15 years of experience assigning senior research projects, also described the lack of concern for the seriousness of plagiarism when she claimed her students just “don’t see any harm in it.”

The data indicated there was relatively no difference in the participants’ perceptions of why plagiarism is a serious problem. The participant in this study with the most senior English 
teaching experience, Roxanne Carr, also mentioned the existing lackadaisical attitude society has about morals and plagiarism and how it has had a negative result on effectively addressing plagiarism in the classroom. She described this when she recalls her response to three of her students turning in research papers that they had previously written for a science class assignment.

And do you know that hadn't occurred to me that anyone would do that. It never occurred to me that plagiarism could include pulling in another class's report. I just never thought of that before. I would never do that. But it's the difference in the generations. It's a difference in the quality. It's a difference in the time. . . And I think students think sometimes especially if we've been teaching a while that we are not technologically savvy. There are things they can slip by us, and they copy that homework or plagiarize that assignment, well that begins the process, I think. And they don’t see that as being that big of a thing. Results of this study revealed the AP English teachers, April Thompson and Carrie Riggs, had a less negative view of why their students plagiarized and attributed their students’ plagiarism to grade pressure and access to an abundance of technology. April Thompson admitted, “I do see a lot of parental pressure here, and hearing [parents ask] oh if he doesn’t do well this six weeks, is that going to keep him from med school 10 years from now, and I'm like No, I don't think so. And I do think a lot of it is technology, it's kind of a blessing and a curse, because students are so technology dependent.”

Other than the AP teachers, the only teacher who did not mention laziness as a reason they felt students plagiarize was Tracy Queen, the regular education English teacher at Beaumont High School, "I think one reason [is they] procrastinate, or they have too much going on 
extracurricular wise and they don't have time to properly sit down and really think out a paper, number one. Some of them have jobs so they work really late and don't have the time.”

This was in contrast to the other participants who were regular classroom teachers at the less affluent, more rural and smaller schools in the county who were more likely to say laziness or apathy was the primary reason they felt their students plagiarized. One teacher from Pine Valley eluded that:

The kids here do it because they are so lazy at this point, so when they need seven pages, they will go to the Internet and they're going to copy and paste to get seven pages. So, I think laziness is [a big factor] and some kids just don't care, a lot of kids just don’t care. . . . I could write a research paper for some of these kids and they wouldn't even get up and bring it to my desk. It's that bad.

Roxanne Carr taught at a school where over half of the students received free or reduced priced lunches and agreed, “I think some students are lazy, [although] I think that's kind of derogatory for me to say, but some kids say hey, I don’t want to do this.”

Prevention. The data indicated the participants in this study were conscientious in their efforts to prevent instances of plagiarism in their classrooms. However, several participants indicated they felt students did not think their teachers were going to look for plagiarism or find it. Jackie Marshall, a regular education teacher close to retirement, described her opinion of why she feels students plagiarize, "Because they are lazy and some of them think the teachers are so stupid that they won't catch it.” Another teacher acknowledged the possibility that plagiarism may be overlooked and admitted, "Students are able to get away with it more often than not. Um, you know it takes a lot of time to check their sources and I think they are willing to take the gamble that nobody is going to check.” 
The AP English teachers employed strategies customized to get the attention of their student populations when attempting to prevent their students from plagiarizing. It is common knowledge that AP students usually have higher than average grade point averages and are also commonly members of their school's honorary. Withstanding that these two things are unique to the students in an AP class, both of the AP teachers in this study reported they did include a warning to all of their students that in addition to the grade consequences, if they committed plagiarism they would be in jeopardy of losing their membership in the academically elite teenage group, the honor society. One AP teacher elaborated on the severity of the harm done to an accomplished student’s reputation when they are caught plagiarizing, "I had to go over everything he wrote after that with a fine tooth comb. So, and you can't repair that, you can put a broken plate back together, but you are still going to have the cracks.”

The coded data produced answers to the research questions in this study, as well as revealed the participants' perceptions of what plagiarism was, and was not. Jackie Marshall felt she had discouraged plagiarism to her senior English students over the years by encouraging them to do a good job and to keep a copy of their note and source cards and works in progress, as well as the final paper from her class. She suggested to her seniors that if they are interested in the topic they chose, they should use their paper as a basis and build on it for future research papers they may have to do in college. Although Jackie gave this as advice to her students, she admitted to me that she realized she may not be right in doing this.

However, she recounted a good experience she had with a student after having given her students this advice in class, and Jackie obviously held faith in her perception of this practice as honorable. She relayed a story to me about one of her students who had written about teenage suicide and was very interested in the topic. Jackie said the girl had followed her advice about adding to the same topic later, and had actually built on her senior research paper several times 
during her college career. According to Jackie, one of the girl's college professors asked her if he could make a copy of it and told the student it was the most interesting thing he had ever read about teenage suicide.

It is likely that a good number of students may not consider this to be plagiarism as well. However, college administrations usually do consider using research from one class to help fulfill requirements in another class plagiarism if it is done without the professor's consent. Binghamton University in New York states in their student academic honesty code (Binghamton University Student Academic Honesty Code, 2008), a definition of plagiarism that includes, "Multiple Submissions is submitting substantial portions of the same work for credit more than once.” Hostos Community College also includes a version of the same act on its website clarifying that plagiarism includes, "Submitting substantial portions of the same paper to more than one course without consulting with each instructor.”

In discussing the research and writing projects they assign in their classrooms, many of the teachers seemed as interested in the process as they were in the product. Many of the participants expressed their concern of good research and writing skills as important to their students' further success in college, as well as important deterrents for committing plagiarism now and in the future. Marsha Callahan had graduated from college only two years earlier at the time the data were collected for this study, and she expressed that she understood what would be expected of her students when she explained, "I basically gave them detailed notes on MLA citations because I know that in college this could be a really good thing for them.” Marsha also realizes the struggles some students will continue to have if they don’t apply themselves in high school when she added, “You know a lot students will go to college and say I wasn’t prepared, I didn’t get what I needed.” Jackie Marshall also realized the importance of preventing plagiarism and preparing students for college by teaching them how to properly do a research 
paper when she explained what she told her students, “I'm really interested when you graduate, wherever you go, that you can do the research. And you know how to start out with a topic and narrow it to a thesis. . . .I want the dumbest kid to know the process. I want the sharpest kid who’s going to MIT to know the process.”

Several of the participants mentioned the confusion created when their students do not understand the difference between text that is common knowledge and text that is not. Carrie Riggs indicated this confusion can increase the possibility of plagiarism occurring. She describes the difficulty of teaching her AP students why everything is not common knowledge. Because it's not yours, it’s free for you to use, but you can’t say you own it. Someone else owns it. And deciding if something is common knowledge, sometimes that can be questionable especially when you get upper level seniors who are very, very smart. They think everybody already knows this and it doesn't need to be cited. You know what I mean.

When given their choice of research topics, the data suggested students often will write about something they are familiar with, and the topics are usually based on the student's personal interest or life experience. When reading about a topic that is personally interesting to a student they may be more likely to internalize some of the information they are studying. In the context of common knowledge, this can cause a student to perceive that what they have learned is common knowledge, although it is not something commonly known to the general population and should be cited. Jackie Marshall commented on common knowledge, saying that:

Common knowledge ... . if you are giving me technical information about diabetes, and I have a girl who is a severe childhood diabetic with a pump, and she is talking [in her paper] about how diabetes is containable ... I was reading her rough draft and I said to her, ok, you have bulleted these things as the 
symptoms of something and I know that you know them, but you took it from a source, let me see your note card, and she did. I said that has to be cited.

The documents submitted by a few participants included information about common knowledge which can be casually defined for a student as information they knew before they began their paper. One handout used by Roxanne Carr included an explanation.

After every fact or idea that is not common knowledge, you must put a set of parentheses containing the author and page number of where you got the information. For example, the fact that the sun rises in the east is common knowledge and it's something most people know; however, the fact that John Quincy Adams was born in Braintree, Massachusetts, is not, and must be cited in your paper.

Just like learning anything else, learning the difference between common knowledge and a source that needs to be cited can be made easier by using meaningfully shown examples.

Tracy Queen, one of the senior English teachers at Beaumont High School said she actively tries to prevent plagiarism in her classroom by making use of her former students’ work. "I also show them copies of other previous research papers that have been turned in and works cited pages that have been turned in. I give them so they can see how to do an internal citation or a works cited page.” April Thompson also confirmed she uses student examples to aid in her instruction of research and writing when she elaborated that:

We actually use a lot of former student examples with their permission. . . I will use the papers to show my students the progression from first effort to final draft. I'll show them ones that are done really well in terms of paraphrasing and quote incorporation and all that. And then I will show ones that were struggling or borderline plagiarism, or they were unintentionally plagiarized. 
Unintentional versus intentional plagiarism. Evidence in the interview and document data indicated the majority of the teachers felt certain forms of plagiarism could be intentional and unintentional. A classroom handout submitted by one participant (Appendix D) included many examples of plagiarism and categorized them as intentional and unintentional. The information in the handout supported a statement made by the same participant that she acknowledged students may sometimes plagiarize inadvertently, "Now there have been years like in a research paper that they didn’t maybe understand that what they were doing was incorrect.” She acknowledged at times she assumed her students maybe should have learned more about what plagiarism was in earlier grades than they actually did, “Obviously they haven’t grasped that concept somewhere, so you have to go back and re-teach it. I can’t hold them responsible for something they haven’t been taught.”

Brooke Hinkle felt that research and writing was a difficult topic for students and required them to perform under more complex requirements. She describes her view of unintentional plagiarism.

I just don’t want them [to plagiarize], even if it’s unintentional, because they can unintentionally plagiarize. It's something you have to be very conscious of, citing sources .... There's a difference between not citing and mis-citing, or citing incorrectly. Because [if you mis-cite] you are still giving credit, you're not trying to claim it as your own, you just might not have cited it correctly, which is different than cutting and pasting off the Internet. You're trying to cite, you're just not, some of the kids just don't know how. It's hard. It's hard for me even as a teacher.

The data indicated that even though the majority agreed plagiarism could be unintentional, about one-third of the participants said they would give the same grade cut 
regardless of whether they felt the student's plagiarism was intentional or unintentional. One veteran English teacher acknowledged, “Yes, [my consequences are the same] for both intentional and unintentional plagiarism, simply because these kids, I don't know how to be consistent any other way.”

Another teacher allows for individual differences by responding, “The kids who need modifications, obviously I'm going to give them a little more leeway there, um because they might not pick up on it the way that my regular functioning kids could.” However, when it came to any grade cuts in research papers for her regular education students, this same teacher revealed she expected more from them, "I probably would maybe gauge it a little bit for them [if the plagiarism was unintentional] but not much, I mean if it’s plagiarized, it’s plagiarized.”

Cryptomnesia, as described in Chapter 2, occurs when students mistakenly believe the text they have included in a report originated from their own thoughts, when actually it is the intellectual residue of reading a lot of outside research on a subject and then without thinking they combine what they have read with what they themselves think. And because some of what they write is what they themselves do think, they believe all of what they are presenting as their own ideas really is their own. Cryptomnesia is often referred to as "unconscious plagiarism”. Jackie Marshall describes her encounter with this kind of plagiarism.

They [the students] will say they have read so much about it, and that these are their own words and I will tell them no, they're not; you don’t talk that way. . . . And, I may be being generous, but I think half of it is unconscious plagiarism, and then I think the other half is let's see if we can get one over on her.

In Figure 1, different acts of plagiarism were placed on a continuum labeled “deliberate” at the extreme left to "possibly accidental”, on the extreme right. The act of plagiarism listed in Figure 1 that most accurately describes cryptomnesia is "building on someone's ideas without 
citation.” This act of plagiarism is on the continuum closest to the end labeled, "possibly accidental.” Each of the acts included in the table was mentioned during the interviews by the participants as examples of what they believed constituted plagiarism. One participant clarified how they can tell the difference between unintentional and intentional plagiarism, "Now the kid that does 90 percent of it and you can see it has been copied and pasted, and the kid tells me it was accidental, then no. I don't believe that because they had to physically copy that onto their paper." Another teacher confirms the understanding that some plagiarism is unintentional when she states, “There's a difference between the kid’s paper who changed the adjectives in the paragraph in an attempt to paraphrase it, and the kid who copied a whole paragraph, that's different. ... I think the grey area for them is the accidental plagiarism, where they forgot to cite one line or something.”

Perception of involving administration. The data suggested the teachers had mixed opinions about involving administration in the discipline of plagiarism in their classrooms. Roxanne Carr was concerned about a possible lack of support from administrators.

I was speaking with a school administrator about a TV newscast, one of the major, I don’t know if it was Dateline, I didn’t see the show, but this teacher, I believe it was in Florida, had assigned a high school research paper with a contract against plagiarism that the student had to sign and the parent had to sign. Still there was a paper that was plagiarized and even though the parent had signed the agreement, because the child had taken a few words out of the original text and substituted his own maybe two for a paragraph even, the teacher lost the case. The administration did not back her. It sort of makes a teacher at the high school level discouraged and even fearful, you know. 
Although she expressed some anxiety about involving administration in incidents of plagiarism in her classroom, she indicated she believed there is a need for a school or countywide policy for dealing with plagiarism when she said "I think we need to establish a policy and include the board of education and ask how many schools have a policy in effect and then go from there."

Tracy Queen taught at Beaumont High School and enforced her school’s plagiarism policy in her classroom. She actively involved her school's administration by referring her students for further discipline and further supported her school's efforts when she said, "Yes, it's helpful. I think it's a teacher's choice, but I always do because that's a major component of English - to write using sources and giving credit where credit's due.” Beaumont High School's administration was the only administration in the county that actively involved itself in the discipline of acts of academic dishonesty. Consequently, both the senior English teachers there felt they were supported by their administration. The data collected from the rest of the participants indicated they did not refer a student who plagiarized to the school's administration for discipline, but instead contained any punitive actions to their own classroom. These teachers, except for those teaching at the upscale Beaumont, felt somewhat isolated from their school's administration for one reason or another. However, none of the participants reported feeling “frustrated by their administration.”

In her personal experience, April Thompson formed an early and negative impression of a school administration's involvement in managing plagiarism when she was accused of plagiarism while she was a student in college and had to report to the dean of the department. Her intrinsic familiarity with the phenomenon of plagiarism armed her in her discussion with the dean and she reminded him that a student can be innocently accused. This she did before explaining to him how a mistake on her part had caused the problem. April is now teaching at 
Beaumont High School with Tracy Queen and both teachers feel their school's policy is an effective one. She described the policy saying "It is academic dishonesty, so they get three days after school detention, if they're in National Honor Society that could be revoked.”

Practices (RQ2)

The second research question guiding this study sought to reveal how teachers address plagiarism in their classrooms by describing how they detect, prevent, and discipline acts of it in their classrooms.

Detection. Technology has provided at least easier and more objective methods to detect plagiarism, including web-based plagiarism detection services. These services work when you simply upload your students’ documents and promptly receive an online report (Appendix K) listing the percentage of the paper that is plagiarized, as well as the suspect text and links to web pages containing the verbatim text.

All of the participants in this study used essentially the same objective and subjective methods of detection. All of the English teachers utilized their experience and intuition, albeit a more subjective process, to initially detect plagiarism first by comparing their student's work to what they perceived the student's ability was based on their earlier performance, and writing samples gathered in class. Tracy Queen describes, "My kids do a lot of writing in class so by the time we do any kind of research paper, or persuasive paper, where they have to get sources to back up their points, I know their writing style, so if it’s something they worded how they normally wouldn’t word it, it’s usually a clue.”

Other participants also spoke of using their familiarity with their students’ writing abilities to be able to detect plagiarism in their students’ papers. April Thompson rationalized, “If you have a student who can’t form a complete sentence and then suddenly they turn in a 
paper that's been assigned as out of class work and they're using college level vocabulary and perfect sentence structure, you know something’s not matching up.”

In Table 3, various methods of plagiarism detection were categorized according to their degree of subjectivity or objectivity. The interview data revealing the plagiarism detection methods the teachers used, when applied to the categories described in Table 3, indicated most of the participants in this study initially used the more subjective plagiarism detection method of comparing their students' writing in the research paper with the student's ability as evidenced in writing samples the student had submitted earlier in class. Teachers only used these more subjective detection methods before moving to more objective means.

Level of technology integration in detection. When the teachers revealed how they detected plagiarism in their classroom, they also indicated their level of technology integration into the plagiarism detection process as well. After the teachers initially suspected plagiarism in their students' papers using the more subjective method of comparing their students' perceived abilities with the writing in their research paper, every participant, except for one, also mentioned searching for the verbatim text online using the Google search engine. Using a search engine is a more objective method of plagiarism detection, listed in Table 3 that involves locating web pages that contain the suspicious text verbatim.

Roxanne Carr, a veteran English teacher describes how plagiarism can be verified, “The most popular detection is to go to Google.com and type in a line, even a few words.” Carrie Riggs uses Google in her classroom, and was also aware of popular plagiarism detection software available, she explains, “There’s a couple programs you can use on the Web, you can use Turnitin.com, but our school doesn't supply that to us. Apparently, there is a fee and they don't do that, but if you simply put a phrase in quotation marks and Google it. All the hits will 
come up, so I was able to find the exact stories, so I printed them out and attached them to the student's version and um, obviously they failed the project.”

None of the high schools in this county school system made any plagiarism detection software available to their teachers, nor did they pay subscription fees to an online service, such as Turnitin.com. Results from research by Martin (2005) suggested the use of any electronic plagiarism detection dissuades future classes of students from plagiarizing once it is known that an easy, electronic, and sophisticated method is being used by the teacher. Tracy Queen and Carrie Riggs were the only participants to mention any electronic means of detecting plagiarism outside of the Google search engine. Tracy speaks of how she learned about Turnitin.com There's one [she tries to remember the name Turnitin.com] out there the teachers were talking about this past summer and it doesn’t matter what you teach, it goes with all disciplines and any paper they turn in via the Internet or email whatever, it is sent through that system and it will tell you how much of it is plagiarized and where it came from, the website and everything. . . I think it would be helpful. Maybe a grant could be written or something for our school.

When I analyzed the data in this study, I studied it to appreciate what was there and what was not there, and although most of the teachers in this study expressed an ability and understanding in using computer technology, not all did. One participant admitted so. Nearly 80 out of 100 students are much more proficient with cutting and pasting and manipulating word processing and computer skills than I am. They know how to get to Internet sources that I would never know. I don't want them to know that I don't know. You know, so I try to stay ahead. . . . . I can work with online public access libraries or Boolean searches, but for the life of me I couldn’t 
tell you how to put a screen saver on this thing [as she points to her computer].

So students have the technical expertise to bury me.

Prevention. Some of the teachers gave their students a printed plagiarism policy

(Appendices A and J) explaining the acts that constituted plagiarism, as well as the

consequences. Most of the participants reported to have what they considered to be an orally communicated policy on plagiarism in their classrooms. The data also revealed that most of the participants speak about and teach an awareness of plagiarism early in the course, and make their students aware of the policy that exists before they began their senior research projects. Some of them had a written policy, like Brooke Hinkle, a young teacher, who prepared her students well with a written policy that included a precise definition of plagiarism and several bulleted examples (Appendix J). A pointed warning about the resulting ethical breach that occurs when students plagiarize appears at the bottom of her classroom policy handout and summarizes her intent by including, "In other words, plagiarism is an act of fraud. It involves both stealing someone else’s work and lying about it afterward.” Brooke’s description of her plagiarism policy during her interview reiterated her position

I always come out swinging the first time when I introduce the research project, that's when I do my biggest plagiarism talk. I do give them a written policy on it. ... I am very clear to my kids, I mean if there’s no citation, then it’s plagiarized. I mean if you don't give credit, then that means you are claiming it as your own, and it's plagiarized. . . They are aware that they will fail if they plagiarize the paper.

Josh Richards was the only participant who had never assigned a written research project to seniors, and probably as a result, was also the only teacher that had not developed a policy on plagiarism. Josh explains, “Um, no, I probably don’t [have a policy]. What I probably will do is 
go back to the school's policy and review that. But I think if I continue teaching senior English [after this school year] I can see developing something. I can see that happening soon. But there's nothing that has been real formal.” Although lacking in documentation probably due to her recent move to West Virginia, Jackie Marshall describes her classroom policy on plagiarism, "Prior to announcing research papers to students, I tell them my policy is that if I ascertain that there’s plagiarism, they don't get an F, they get a zero.”

The schools in this study possessed varying population characteristics and were, in most cases found in diverse socioeconomic settings. Beaumont High School was the only school where teachers acknowledged that a school-wide plagiarism policy existed. Although the teachers there were not required to refer a student to the office, they were however encouraged by the administration to enforce the policy in their classrooms. The school disciplines a student guilty of plagiarism by assigning the student to several days of after school detention. Tracy Queen, a regular education senior English teacher at Beaumont explains how she feels about her school’s discipline policy for plagiarism, “I think it’s helpful. I think it’s a teacher’s choice, but I always do because that's a major component of English - to write using sources and giving credit where credit's due.”

Laura B. Tyler High School did not have an enforced school policy. At the departmental level, there had been a policy created by a former English department head, but it was currently not being enforced. Roxanne Carr, the current department head at the same school, acknowledged the need for a standard policy when she said, "We don't have that kind of policy [department or school] and I don't know if other high schools in [this] county do. But it's needed. Even if it were a county wide policy, it’s becoming such an issue.”

The county school system participating in this study had a printed policy on academic dishonesty and plagiarism in its 2007-2008 Policy and Administrative Regulations Guide that is 
distributed to each student. The policy states that "A student will not plagiarize, cheat, gain unauthorized access to, or tamper with educational materials. The response to violations under this section may include academic sanctions in addition to other discipline. This includes lying or cheating on tests or assignments or falsifying passes or excuses.” The policy does not include a definition for plagiarism. However, this is not necessarily a bad thing because if relied upon it opens up the opportunity for teachers and administrators in the county to consider and manage a variety of incidents of plagiarism when they occur and without limiting the context.

Managing academic dishonesty. The participants were asked about the classroom methods they have adopted over the years in their classrooms to deter any academic dishonesty in their classrooms. With this question, I had hoped to uncover specific, unique, and innovative methods that teachers use in battling all kinds of cheating, including plagiarism. Several of the teachers mentioned a small class size as a reason it was more difficult to control cheating on tests and other assignments. When asked about the classroom methods she used to combat this, one participant claimed that:

Well [what I do] to discourage cheating on tests comes to mind. Last year I was in a different room and there were 43 desks in my room. I had 43 kids. I had a time. ... One thing is that especially I would make three different copies of a test and just randomly give them out. . . .It's bad because I can’t walk up and down these rows because there are too many desks in this room.

Another participant in a different school, but experiencing the same situation stated, "I will change the first page on a test, or I will move around the sections of a test. I have a cramped class as you can see, so I don’t have much luck trying to move them apart, so I give more than one version of the same test.” 
Roxanne was fascinated with the phenomenon of plagiarism, perhaps due to the recent research she had read, and then when I asked her what she does in her classroom to limit cheating or plagiarism, she replied with something that surprised me for its outward simplicity.

Well, you can see what a small room this is and I have 33 seniors in a fourth block class ... every time I give them a test I also pass out a green cover sheet, and I tell them if they don’t use it [to cover their answers], I will deduct something. . . . I tell them if I see them or even suspect, I'm ripping your paper up. I never have to do that because I walk the aisles and I really, really try and I never sit down.

Most methods the participants reported using included passing out more than one version of a test, walking around extensively during a test, using a cover sheet, and a method used by some teachers that is more specifically aligned to reducing plagiarism—is the act of modifying how their students selected the topics of their research. The related literature on plagiarism recommends teachers not allow students to select their own topics. It also suggests teachers do not assign very general research topics due to the increased likelihood students will copy and paste information from the Internet, rather than having to come to their own conclusions, as they would have to with a more original, or complex research topic (Renard, 1999/2000). Carrie Riggs, understood this and acknowledged it in our interview when she said, "It's difficult to put research on a very general topic into your own words. It increases the likelihood for students to plagiarize, and if the topic is less general, it decreases the opportunity to plagiarize.”

About one-third of the participants allowed their students to select their own topic, and as the following interview data samples reveal, the teachers that did this realized they may have increased the likelihood their students committed plagiarism. One younger teacher admitted that: 
Instead of the traditional book report, now I have like a list of 20 projects that they can pick from that aren't necessarily a report that they could just find on the Internet. They have to do something that's a little more creative. So, that's probably the biggest thing I have done [to decrease cheating and plagiarism]. I modify the assignments and my approach.

Another participant, a veteran English teacher, said she had tried something new that school year, but didn’t quite have the success she had hoped.

You know I had a sheet this year, and I asked them to pick from the sheet, but several said they didn’t like the topics. I think I erred in allowing them look elsewhere because I found three papers that were recycled from other classes. Plagiarism as part of a larger study of ethics. There is a close relationship between plagiarism, morals, and ethics, as all involve the awareness of the difference between right and wrong. Several participants mentioned actively including ethics instruction in their curriculum. Carrie Riggs, an AP English teacher describes what she teaches her English and journalism students about ethics.

I always start with ethics every year. Every year I start it with a unit on ethics and we talk about what's appropriate and what's inappropriate. And what things we can cover and how we can cover them. The things we can talk about and how. So I have to start with that unit, so we can always go back there. When discussing the relationship between morals and plagiarism, Josh Richards felt that a teacher's own ethical behavior could affect the quality of communication about ethical topics, like plagiarism, between a teacher and their students. He acknowledged topics like a teacher breaking copyright, for example, duplicating a music CD or photocopying copyrighted material for use in the classroom, may affect what they will say and do in their own classroom concerning 
teaching topics related to ethics and copyright. Josh further considered this to create a direct conflict of ethics between the teacher's own actions and the responsibility they have to teach their students to do the right thing.

Classroom instruction and materials. The instructional time the teachers used in the senior English classes in this county to teach the written research project was extensive, and as well disparate when compared to the number of CSOs related to research and plagiarism (Appendix L). There were 34 total CSOs for senior English in this West Virginian county, of which six were related to the skills necessary to fulfill the requirements of a senior English research project. The results indicated most of the English teachers actively taught the research and writing behaviors of citing sources, paraphrasing, and directly quoting described in Chapter 2, to their students and utilized hands-on lessons available on the World Wide Web, as well as in-class group and writing activities.

Most teachers indicated their students used technology to locate a majority of their resources and key the research paper. However, less than half of the participants mentioned integrating technology into their instruction of the research writing behaviors. Jackie Marshall elaborated, "I get so tired of Power Points, I like my kids to actually pick up books and use paper and pencil, and I use the overhead and the chalkboards .... So I tell them I am their pencil and pen teacher.” However, in an effort to prevent plagiarism in her classroom and reduce the likelihood her students will plagiarize, Jackie, although admittedly weak in her technology skills, makes sure her students know how to use the MLA Online Citation Guide website that constructs their research citations after they key all the needed information into separate fields. Although the act of inserting information into textboxes on a webpage alone is not enough to ensure plagiarism does not occur, using this website would help students to properly format their 
citations. However, plagiarism could still occur if a student cannot discern what information they have included in their paper that needs to be cited.

Carrie Riggs utilizes technology in her instruction and instructs her students to take a pretest online titled "Plagiarism/Academic Integrity Quiz.” She uses the results of this quiz to gauge her instruction so to more effectively address and clear up any confusion her students may have about plagiarism. Carrie also garnered most of her 30-page handout from higher education websites.

Marsha Callahan describes how she utilized manual means to teach her students to paraphrase text, which can be a somewhat intimidating task to many students.

I gave them um, an article and it came out of Time magazine [participant presents magazine] and so we read it little by little. And I had them turn it over and write down on a sheet of paper just like they were telling me a story like they just wanted to tell me exactly what they read, write it down. And you know then I asked them if that was easy and they said yeah and I said that's it. That's all you have to do, just put it in your own words.

As mentioned earlier in this writing, the interview and document data indicated all of the participants in this study employed the writing process in their instruction of how to write about research, thereby helping to prevent students from plagiarizing in their classroom. Each of them mentioned using or planning to use the writing process during their interview. Carrie Riggs confirmed the importance of the writing process by stating, "If it's something that we're working on and they turn in a rough draft, a working copy, by all means I will say, oh, you need to go back and tell me where you got that. You know what I mean, give them a chance to, that's part of the writing process.” April Thompson explained how she prevents plagiarism by employing 
works in progress, "We go through at least three full drafts before they turn in their final draft. And so chances are I will have caught that issue before they turn their final draft in.”

Roxanne Carr supported the need for using the writing process in the instruction of research and writing when she said, “[Just giving them] a rubric really isn’t enough, but the very best method is to grade it step by step by step, and give it back to them and say you're going the wrong way.” The other senior English teacher at Laura B. Tyler High School, Brooke Hinkle, also found value in using works in progress and stressed that:

Because I do the research paper in so many steps so I can catch it early on so they don’t fail the entire paper, they just fail that mini grade on that work in progress. I try to catch it early so it doesn’t get to that final part, because my seniors that makes or breaks their graduations.

Evidence in the classroom documents collected also supported that the English teachers in the county under study taught their students using the writing process of pre-writing and rewriting, as well as requiring works in progress, such as source cards, outlines and rough drafts, to effectively teach their students how to write about research (see Appendices E, F, and G).

Most of the instructional materials used by the teachers were downloaded from the WWW. However, the assignment sheets the teachers submitted that described the research projects were created by them. About half the participants included models of research papers and/or works cited pages. Marsha Callahan included a model of a 15-page rough draft copied from what she described as a "little, tiny book called Writing Research Reports.”

Brooke Hinkle submitted for study a copy of a workbook titled, "Writing a Research Paper: Step-By-Step Approach,” which she used to teach her students how to cite, paraphrase, and directly quote from sources, as well as apply their knowledge doing exercises in the workbook. Although she acknowledged using only parts of the book in her instruction, the 
supplementary workbook was 153 pages long and included instruction covering from choosing a topic, all the way to preparing the final manuscript. The workbook also included information and exercises on writing a thesis statement and a title, as well as specifics on proofreading.

The classroom documents were collected from the teachers to support the findings in the interview data and to reveal what English teachers develop and distribute to their students about research and writing, and plagiarism. The quantity of teacher handouts the eight participants in this study used varied from one, used by Josh Richards who was teaching senior English, but had not yet assigned the senior research project, to a packet of 30 handouts that Carrie Riggs, an experienced AP teacher had compiled and distributed to her students bound in a spiral binder. Most of the teachers also submitted handouts that included the teacher's expectations of the research project.

Teacher expectations for senior research projects. Inside a one-page, teacher-made classroom policy on plagiarism (Appendix H), one participant included the following expectations for the research project verbatim in her handout "The reasons already stated for doing this paper were: (a) exposure to MLA Style and research methodology that prepare students for college and (b) expansion of new knowledge through research.” According to the data collected in this research study, the only citation style used by this county's high school senior English teachers was the one promoted by the Modern Language Association (MLA). Most of the teacher participants required their students to have between three to six different sources. The documents submitted by Tracy Queen (Appendix G) included a section labeled Sources that states, "Use at least five separate sources. Only one may be an encyclopedia. ... Please use a variety of sources. Do not rely too heavily on the Internet.” Roxanne Carr, a veteran English teacher realized her students liked to take advantage of the convenience of the Internet 
I tell them to have three different resources, and to try to read parts of a book, I tell them not to just go online and get everything online. Technology has made it so easy. Then they said how about three web resources and I said only in the event that you cannot find a book or magazine articles on the research level. They all wanted to strictly do it from the web.

Half of the participants reported they did not allow their students to use Wikipedia, a relatively new online database, resembling an encyclopedia that includes information about a very widespread assortment of topics that anyone can edit or add to. The Wikipedia website has editors that regularly review submitted revisions, deletions and additions before allowing them to become permanent text on the site. Some of the participants mentioned the value of the database for general information, but denounced the scholarly value of the information presented there. Jackie Marshall gave evidence of this both in her interview and in the classroom documents she submitted. In the handout she gives her students that explains the requirements of the research project (Appendix F), she requires them to use an encyclopedia as a source, but also next includes the text, "No Wikipedia.” This was reiterated during her interview.

I have a no Wikipedia policy. I tell them Wikipedia is fine for someone who doesn't have a clue and wants to get a very general overview. In fact some of you might want to go in and add something to Wikipedia, but it's not a legitimate source period.

About one-third of the participants in this study, and in the pilot study for this research, required their students to submit photocopies of the sources they used in their papers, sometimes with the exact ideas or text highlighted. Brooke Hinkle explained how she used this strategy to help her detect plagiarism in her students’ research papers. 
They are accountable for it all. They can’t say, well, it’s a book I couldn’t find.

They have to turn in a highlighted photocopy of the source for every single citation, so I can just go right to it and I know if they gave a fake website or whatever.

April Thompson, an experienced senior English teacher required her students to turn in photocopies of the sources they used any time they had included a great amount of cited information in their paper. She also used the photocopies of the source text to improve her instruction and feedback of the entire research and writing process.

They can turn in books or photocopies and I tell them that although that probably will not happen in college, I'm trying to make sure they are citing sources using proper protocol and I'm trying to teach them how to paraphrase ... I have a lot of students who don't understand the research process, and don't understand the paraphrasing until you show them, ok here’s the original. Then because I have the original passage in front of me, I can give them a good example right then and basically let them know they haven’t changed it enough so.

Consequences. All but one of the participants reported they gave their students a zero or an F on a plagiarized assignment. Some indicated this could fail the student for the entire grading period if the total of the points possible was not large. Carrie Riggs adds, "For me plagiarism academic dishonesty is an immediate $\mathrm{F}$ on that particular assignment, not for the six weeks, not for the year....So, [after catching two students] I think one of the two actually failed the grading period, but the other one had enough points to bring it up to a D.”

Brooke Hinkle explains what she does when a student has plagiarized in her classroom, “I put a zero on it and I write 'Plagiarized' and I give it back. Then they will get a zero for that grade, so, ultimately it could make or break them for graduating.” Brooke’s classroom 
plagiarism policy (Appendix J) supports that she does this and includes, “Any plagiarism will result in a failure of the assignment. If you have any questions concerning plagiarism, please ask me.”

Most of the participants possessed a rather astute philosophy concerning the grade-based discipline they administered in their classroom. However, most did not involve administration when reprimanding their students for committing plagiarism. A study by Sutherland-Smith (2005) found most high school teachers were hesitant to refer students to administration for further discipline due to the risks involved and the possible lack of support from the administration. Veteran English teacher Roxanne Carr was concerned about repercussion from cutting a student’s grade too much as discipline for plagiarizing. She explained, "But I don’t think you should cut it too much. . . The parents or the child could contest it on that basis alone”. Jackie Marshall gave her student a lower grade because she had plagiarized in several places in her paper. She described her experience with a school's administration, "It was a smaller school and it was one of those where everyone was equal, except a few families were more equal than others and that turns me off. .. . The administration balked a little bit when I told them I wasn’t changing her grade.”

Not all the participants believed the consequence of discipline through the school's administration was in order when a student plagiarized. Carrie Riggs, an AP teacher at Horace Mann High School claimed, “I think for me to have them suspended, or tell their parents, that's just not, it's not an effective use of my time teaching. . . The point is they need to learn what they did was wrong and how can they not do it again.” However, the consequences for AP and regular education English students who plagiarized at Beaumont High School routinely included a failing grade on the assignment in class, as well as two or three days of after school detention 
assigned by the administration of this high school located in the only affluent community in the entire county.

The teachers' consequences for plagiarism varied, as well as how the teachers reacted when they found any kind of academic dishonesty in their classroom. The interview and document data revealed specifically what the teachers did inside their classroom to a student's grade as just a part, or all of the discipline they received for committing plagiarism. One participant tidily explained what she did when she encountered plagiarism in her student's papers, “They receive zero for a grade and they can’t make it up.”

The data indicated the majority of the teachers’ consequences for plagiarism involved giving the student a failing grade. However when analyzing the data, the following punitive actions used by the senior English teachers were also revealed: (a) Student failed the entire assignment; (b) Student received a grade cut on that assignment only commensurate with the teacher's perceived seriousness of the infraction; (c) Student initially failed, but could receive a passing grade if they revised their paper correcting the mistakes; (d) Referral to the school's office for further discipline; and (e) A combination of more than one of these actions. 


\section{Chapter 5}

Conclusions, Limitations, and Recommendations

\section{Conclusions Organized by Research Questions}

Patton (2002) claims that during the interpretive phase of a study the following happens:

“1. Meanings are extracted from the data, 2. Comparisons are made, 3. Conclusions are drawn, 4. Significance is determined, and in some cases, 5. Theory is generated” (p. 353). Each of Patton's claims transpired on the path I took in coming to conclusions about the data that was collected in this study.

Two tables (Appendices $\mathrm{M}$ and $\mathrm{N}$ ) display samples of the significant data collected that supports the major conclusions made in this study regarding high school senior English teachers’ practices and perspectives related to plagiarism. The data used to make these conclusions was collected during participant interviews and from classroom handouts the teachers submitted. Where relevant in establishing relationships and making comparisons, data samples in the tables also include demographic statistics about the schools and the communities in which their students live (Appendix C).

\section{RQ1: Perspectives on Plagiarism}

The participants in this study were asked direct questions related to their viewpoints on plagiarism. Data to describe teachers' perspectives on plagiarism was also revealed inside their descriptions of their own experiences managing plagiarism in their classrooms. This is important to this research study, because a teacher's perspective on plagiarism may affect their practices, or what they do about it in the classroom. For example, the participants were asked if they believed it was possible for a student to accidentally plagiarize. Brooke Hinkle agreed it was and described how she believes this can happen when she said, “There’s a difference between not citing, and citing incorrectly. Because you are still giving credit, you're not trying to claim it as 
your own; you just might not have done it correctly which is different than cutting and pasting off the Internet.” Because Brooke believes students can unintentionally plagiarize, she explains how this affects her grading practices when she evaluates her students’ research papers, “Yes, I will take more points from someone who did not cite at all because they did not give credit to anyone for the idea. ... as long as they provided that source and I see that they did get it there, but they just did the citation wrong, then I won't take as many points.” Hence, there may be a cause and effect relationship between the two research questions guiding this study.

Researchers have written much about the importance of the teacher's role in combating plagiarism in the classroom. Wilhoit (1994) stresses to educators to prepare their students well to do research and writing and to hold them responsible when they do plagiarize, whether it was accidental or on purpose. Furthermore, everything a teacher does in the classroom to discourage plagiarism has an impact on whether a student will consciously decide, or not decide, to plagiarize. A study by Martin (2005) followed the instances of plagiarism in one professor’s college English class for five consecutive semesters. After the students realized their teacher was using a web-based service to detect plagiarism in their papers, plagiarism decreased significantly during the last three semesters.

Prevention. Data analyzed in the classroom handouts and interview transcripts in this study and displayed in the data display table (Appendix M) indicates English teachers recognize the importance of teaching students about morals and ethics in an effort to prevent instances of plagiarism. The need for morals and ethics teaching in schools is evident given the many news stories written about widespread cheating in schools. A study by Christine Tanner (2004) recognized this and questioned whether cheating and plagiarism had become so pervasive that they were viewed as necessary to survival and keeping up in an ever-moving, challenging society. 
When a student commits any form of intentional academic dishonesty such as cheating on a test, the student accepts the unethical nature of their act and understands if they are caught, there is a very good possibility they will be punished. Lately there has been mention of lack of a “morale compass” by many of those in government, just as incidents of academic dishonesty, as well as political and corporate corruption, and ever present greed continue to escalate. As a result ethical and moral applications in subject matter and critical thinking activities, including case studies requiring ethical decision making are more heavily than ever intertwined in current teaching materials for most disciplines, including English, all in a cumulative effort to reduce instances of academic dishonesty.

In the English classroom, through the reading of plays and exposure to time-honored literature, classic tales that describe the extraordinary strengths and weaknesses of human nature are solidly communicated and passed on to students. During this time adolescents' discovery of, and new insight into the paradigm of humanity, with all its vulnerabilities, effortlessly produces a genuine opportunity in the classroom for students to engage in the vibrant discussion of right versus wrong, creating a strong case for the virtue of giving credit where credit is due. April Thompson, an AP English teacher, describes her interaction with her students.

There is so much about morality and ethics that comes up in literature. . . So we talk a lot about ethical and moral issues the entire class. So the whole idea of taking someone else's work or taking credit or whatever, it comes up pretty frequently because we talk about what you would have done in this situation, would you have made the right choices. We do talk a lot about making the right choice, so I feel like when we talk about plagiarism, there is a bigger picture there. There is more at stake. 
Additionally, evidence in the document (Appendix E) and interview data, including a handout that was submitted by a participant that was created for his $10^{\text {th }}$ grade English class, because he had not yet taught a senior English class, indicated at least some students in lower grades in this West Virginia county school system were taught about plagiarism and completed various research-related exercises, and in this teacher's case even wrote a short research paper. This prior instruction in research and writing, and plagiarism equips students by the time they are seniors with pre-requisite knowledge about plagiarism which in itself provides a context for expanding the discussion of plagiarism and related topics, such as ethics and morality in an effort to reduce instances of plagiarism in the classroom.

Teachers view plagiarism as a single entity, as well as part of a larger discussion of morals and ethics in their classroom. The data suggests English teachers realize when their students are involved in moral discussions it creates a more positive likelihood they will think twice before plagiarizing or cheating in their classroom (Appendix M). Instruction in plagiarism and ethics should begin near the beginning of the course, as it is valuable in setting the tone for appropriate student behavior, and provides teachers and students with a reference point for discussion of these topics throughout the semester. The younger and older teachers alike in this study realized the benefits of early instruction in these areas not only in encouraging their students to realize they have a responsibility, but also to get them to realize why plagiarism is at its core such a significant concern.

Although teachers, schools, and textbook publishers are making an effort to include morals and ethics among their topics covered in an effort to help curb all forms of cheating, research by McCabe \& Trevino (1996) revealed that whether or not a student cheats is mostly dependent on the state of their value systems before the class begins. 
As far as preventing plagiarism, the data revealed no new or foolproof classroom strategies for intrinsically encouraging students not to plagiarize. However, trends in the data revealed many times teachers try to encourage their students not to plagiarize when they are speaking to them by comparing plagiarism to the act of stealing; something the students have probably heard was wrong from the time they were small children. Most English teachers try to communicate the reality of what plagiarism is to their students by relating it to the theft of items they believe their students would find a personal connection with therefore creating, even if temporarily, a sense of loss. For example, the theft of music or lyrics belonging to the student's favorite band, or even the theft of a sentimental personal item, or a great idea they themselves had come up with but whose ownership was now being claimed by someone else. Teachers use these examples hoping that if they can get their students to really identify, if even just for one second, with what it would feel like to have something they consider valuable stolen from them, that they would think twice before plagiarizing (Appendix M).

Also helpful to the continued prevention of plagiarism in the classroom is the persistent faith that teachers have that ethics related instruction will someway encourage their students to attach intrinsic value and personal meaning to the act of doing the right thing, including when performing activities involving researching and writing.

Good instruction in research and writing utilizing works in progress is touted in the related literature as effective in decreasing instances of plagiarism in the classroom (Wilhoit, 1994). Data related to the English teachers' perspectives on plagiarism indicated the participants in this study viewed their use of works in progress, such as outlines and rough drafts, as a preventative means to keep their students from plagiarizing whether intentionally or unintentionally. Overall, the English teachers in this study had a constructive and helpful outlook, and viewed early correction during the rough draft phase as a necessary opportunity for 
valuable re-teaching of plagiarism-related topics, instead of a chance to punish their students and cut their grade for even plagiarizing in the first place.

Detection. The data revealed that when English teachers detect plagiarism in their students' papers, they do perceive a difference in the seriousness of different instances of the plagiarism they find (Appendix M). Senior English teachers believe an act of plagiarism could be at best unintentional, or possibly accidental plagiarism, and at worst, intentional or deliberate plagiarism. Table 1 plots several acts constituting plagiarism on a continuum labeled from possibly accidental to deliberate. The results of this study indicated the English teachers' determinations of acts of plagiarism as either possibly accidental to deliberate very closely resembled the described results in Table 1.

English teachers acknowledge and are aware of the easy opportunities students have to deliberately acquire a research paper without writing one of their own. At the same time, many English teachers accept that students who do write their own papers may at times not cite, or properly quote or paraphrase because they are confused and simply do not understand the process of research, writing, and citation. Senior English teachers also realize the possibility that a student's confusion may be caused by limited instruction in earlier grades and in light of this, they are hesitant to hold this aggressively against them. From studying the data, it appears the teachers understand and appreciate the value of their students knowing how to write about research when they go to college, and in the face of confusion they will work harder to teach their students how to do it the right way.

An English teacher's experience teaches them that not all students plagiarize knowingly. Cryptomnesia was defined and described earlier in this study by Marsh (1993) as an unintentional act that occurs when a student has been exposed to research and accidentally combines ideas they have read in the research with their own ideas on the topic. This person 
believes all the ideas are theirs and reports them as their own without giving credit to any other source. April Thompson, an AP English teacher recalled an experience that typifies the defense of cryptomnesia, “So I said [to student], ‘What wasn’t plagiarism about it?', and he said, 'Well, I read that stuff and I had those ideas too, so even if somebody already said it, it's still my ideas too.’” Like most English teachers, April believes plagiarism can be intentional or unintentional (Appendix M), and in this case the teacher believed her student because she felt he "really didn't know what it was.” This student believed because he had read something and acquired the knowledge or ideas in his own mind, that they actually belonged to him and were his, and that it really didn’t matter where they came from because he knew it now. English teachers perceive this nonchalant and somewhat disrespectful attitude toward the rights of ownership of more elusive things, like intellectual property, as widespread. Another factor contributing to a lack of respect for the copyright is the availability and popularity of the World Wide Web, where most things are easily accessible, and with technical skill and the right program- anything is up for grabs. As expectations for personal responsibility and integrity wane across the board, cryptomnesia will only become a more common defense for students who plagiarize.

Perspective on the phenomenon. Academic integrity expert, D. L. McCabe, claims there are differences between the reported frequency of incidents of plagiarism between private and public schools, and in different regions of the United States (Donald McCabe, Personal Communication, September 27, 2005), but that no other school population characteristics have been proven to serve as indicators as to the frequency of incidents of plagiarism in a school. However, trends in the data for this study of a West Virginia school system indicated a relationship exists between the socioeconomic characteristics of a school and its community, and its teachers' perceptions of why students plagiarize and how often they plagiarize. Teachers at high schools in the county under study located in more rural communities that possessed lower 
household incomes and had fewer adults who are college educated (Appendix C), felt their students plagiarized predominantly because they were lazy (Appendix M). Teachers in these more rural schools also perceived the frequency of incidents of plagiarism in their classrooms as "real" to "extremely" common.

In contrast, the AP teacher and the regular education senior English teacher from Beaumont High School felt their students plagiarized due to pressure from outside work and school obligations (Appendix M). Beaumont was a prosperous and educated community where the median household income was double that of any neighboring community, almost half of the people living there had a bachelor's degree or higher, and $80 \%$ of Beaumont's students planned to go to a 4-year college or university (Appendix C). The data suggests English teachers from schools in more affluent communities believe plagiarism isn't common in their school and that it is not a big problem (Appendix M). The only other teacher that felt plagiarism wasn't common in their school was an AP English teacher at Horace Mann High School, an urban school. When assessing the accuracy of the teachers' estimation of how frequently their students plagiarize, it is useful to take into account a study by Hard \& Moran (2006), that concluded faculty beliefs about student academic misconduct were lower than student beliefs were.

Overall, the AP classes serve a student population that mostly possesses a higher level of academic ability. Generally, Beaumont students are historically very competitive academically; on the ACT college entrance exam, Beaumont seniors routinely score higher than the county, state, and national average for high schools (Appendix C). In retrospect, when considering the demographics of Horace Mann and Beaumont High Schools, compared with the more rural Pine Valley and South River High Schools (Appendix C), and the difference between the same schools in how the teachers perceived the frequency of incidents of plagiarism in the schools and 
the difference of opinion as to why their students plagiarize, it is possible a student's prerequisite intellectual ability may affect whether or not they plagiarize.

Senior English teachers are the biggest source of information related to research and writing and plagiarism in their student's lives, the only ones that will prepare them to complete the college requirements of writing and research when their time comes. High school English teachers absolutely perceive good research skills as integral to their students’ success in fulfilling the expectations they will face in college, and they communicate this to their students. Although teachers agree that research and writing skills are important for succeeding in college classes, research from Wilhoit (1994) found that fewer students are prepared to do a research paper in college and they do not understand the relationship "between plagiarism and the rules about quoting, paraphrasing, and documenting material” (p. 163). Wilhoit deduced that students may be committing plagiarism because they have not been instructed well in the past and simply do not know how to do credible research.

With the lack of administrative involvement in instances of plagiarism in this county, classroom teachers have the most influence over what happens after a student plagiarizes. When deducing what the appropriate discipline would be for the various degrees of intent for acts of plagiarism found in Table 1, most teachers perceive it is necessary to adjust the discipline for accidental versus deliberate plagiarism. This is possibly why a study by Ashworth \& Bannister (1997) found it would not be best to apply the same discipline solution to every instance of plagiarism.

Based on the data collected for this research, including the data in the display table created for the relevant results (Appendix M), the following is concluded about high school English teachers’ perspectives on plagiarism. 


\section{Major Research Conclusions on Teachers’ Perspectives on Plagiarism}

1. Students in high schools located in communities with a higher socioeconomic level have English teachers who perceive they plagiarize less, and for more honorable reasons than do teachers of students in schools located in more rural, less well-off communities.

2. Evidence in this research indicates most English teachers perceive a relationship exists between the degree of parental involvement in a student's life and why, and if they plagiarize.

3. English teachers distinguish between intentional and unintentional forms of plagiarism and take this into consideration when grading student work.

4. English teachers view plagiarism as part of a larger discussion of morals and ethics in their classroom, and try to attach personal value to the act of doing the right thing.

5. English teachers have a constructive and helpful outlook, and view using the writing, then re-writing process as a necessary tool to improve their lessons and effectively reduce plagiarism through improved instruction.

\section{RQ2: Practices on Plagiarism}

Prevention. Teachers sometimes use obvious strategies in an effort to prevent instances of plagiarism in their classroom. Data analyzed in the classroom handouts and interview transcripts in this study, as well as the data contained in the data display table (Appendix N) supports the major conclusions about teachers’ practices on plagiarism stated at the end of this section. When relevant for making comparisons, demographic information about the high schools and the communities (Appendix C) where they are located is included in the data display table (Appendix N).

The results suggested the time high school English teachers spend in the classroom teaching their students how to write a research paper is extensive compared to other learning 
objectives and lasts an average of several weeks or the majority of one grading period. Although there are relatively few $12^{\text {th }}$ grade English content standards and objectives related to research and writing for West Virginia students, an inherent reason for the extended class time used to master just six course objectives out of 34 (Appendix L) is the more sophisticated and complex nature of the writing used to report research. Also, adding to the length of the project are the several days the English teachers typically take their students outside the classroom to perform research in the library or a computer lab. Senior English students use technological as well as manual research methods to find sources, and ultimately key the research paper using a word processing program.

The primary reason the amount of classroom time dedicated to the instruction of research and writing is large, is according to the data in this study the participants used the writing process to teach research and writing to their students. The writing process is a logical and comprehensive process that requires students to submit works in progress, then receive feedback from the teacher, and finally revise the rough draft for a final grade. Research by Renard (1999/2000) suggests using the writing process decreases the instances of plagiarism. The Renard study further maintains the effectiveness of collecting works in progress to ensure that a student's writing style between the works in progress and the final paper can be matched. The same study concluded that if students are required to create works in progress they will be more likely not to plagiarize and go ahead and do the work themselves.

According to the MIT Writing and Communication Center Website, the writing process is a "recursive process," meaning a student may have to go back to the pre-writing step involving generating and developing ideas during the process of revision (The Writing Process, 2008). English teachers overwhelmingly use the writing process to teach research and writing to their students. They perceive one of the benefits of using the writing process is the yielding of an 
opportunity for them to give necessary and critical feedback to their students, allowing them to correct possible instances of plagiarism during the process, thereby effectively reducing the instances of plagiarism overall in their classrooms.

In addition, Renard (1999/2000), maintains the instances of plagiarism in research reports can be reduced if the teacher avoids assigning very general research topics that are not much more than fact-finding missions. The results indicated most senior English teachers in this study realize this and modify their assignments or methods to reduce plagiarism. Assigning research papers with too general topics involves no opportunity for the student to put forth the thought processes necessary to develop a theory or personal opinion of the research they are reading, so as a result they never develop an individual relationship with the data. April Thompson describes how she perceives choosing a research topic

See the problem a lot of kids are allowed to [use general topics] in some other classes they have because they're just given an assignment like find out about this topic which is usually too general, and write it up and turn it in to me ... [so basically] as long as they turn something in.

Detection. Teachers' efforts in detecting plagiarism are integral to identifying the possible need for re-teaching of the following research and writing behaviors: paraphrasing, citing sources, and directly quoting. In a study by Thomas (2004), experts claimed a teacher has to first be familiar enough with their students’ work in order to detect plagiarism and realize the words are not the students' before the teacher can implement technology to verify what they already think. According to the evidence in the data display table (Appendix N), most all English teachers require their students to produce writing samples, therefore giving them a comparative baseline of their students’ abilities. 
The plagiarism detection methods, both manual and electronic, used by senior English teachers in this county are almost identical. As I expected, most of the participants first suspect plagiarism when reading their student's paper. The teachers are familiar with their students’ writing styles, and are able to quickly realize when their student's words are not his own. Teachers verify plagiarism by keying suspicious words or phrases into an Internet search engine, initially exclusively Google (Appendix N), and if necessary some may use other search engines to successfully retrieve hyperlinks to web pages that contain the verbatim text.

According to the data collected in this study, computer technology isn't the only technology used when some students prepare a research paper. About one-third of the participants used the more objective methods described in Table 3 to detect plagiarism by requiring their students to submit photocopies of all the sources they had used in their papers. Teachers were then able to compare suspicious passages with the photocopied sources. Using technology to duplicate images, such as the process to photocopy, is an intelligent use of a normally readily available technology that saves the teacher's time spent performing an online search, while at the same time reinforcing to the student the importance of attributing credit where credit is due. This study found that English teachers in this county were competent in finding and utilizing accessible resources, and they combined their own instincts with affordable technology to first detect, and then verify instances of plagiarism (Appendix N).

Most English teachers did use the Google search engine, available free to them by way of their school's computer network to verify the detection of plagiarism in their students' papers (Appendix N). The high schools that participated in this study did not routinely make online plagiarism detection services available to their teachers as the costs can be prohibitive. Online plagiarism detection services are evolving as plagiarism evolves. The scope of plagiarism has transcended the classroom and reared its unattractive head in media journalism, manuscripts, 
magazine cover shots, and speeches causing law suits and damaged reputations. As a result, the provider of Turnitin.com, a development company called iParadigms LLC, according to the home page of their web site has developed a new tool, called iThenticate, to expand its services to other entities also concerned with plagiarism, such as book publishers, corporations, and law firms (Turnitin.com Home Page, 2008).

In Table 3, plagiarism detection methods are categorized as being more or less subjective or objective. The results indicated the participants collectively used some more, and some less subjective methods to detect and verify plagiarism in their students’ work. The participants went further than just using the most subjective method outlined in Table 3-comparing suspicious text with student's perceived abilities and writing samples in order to confirm plagiarism in their students' papers, and they all mentioned, or gave indication that they integrated technology in their detection methods-described in Table 3 as a less subjective means of detecting plagiarism in students' work.

Some teachers also use less subjective means by requiring students to submit photocopies of their sources to aid in plagiarism detection. If their students included the photocopied pages from every source they cited, this could indeed hasten the detection and verification process for the teachers. However, if a teacher requires students to turn in photocopies of sources to aid in detection of plagiarism, the challenge would be not only to realize when the student had included all of the sources, but also to realize when they had not.

Categories describing different levels of technology integration in plagiarism detection methods are described in Table 2. The results of this study suggested the category that best describes the methods used by the participants in this study is 'Technology has been Integrated'. Applied to Table 2, this indicates the teachers are integrating technology when detecting plagiarism either by being familiar with web pages known to be resources for the assigned 
research topics, or by using a search engine to find the source of suspicious text included in their students’ writing, so plagiarism can be verified. The data display table (Appendix N) displays data that indicates the English teachers in this study almost exclusively used the Google website’s search engine to verify plagiarism by locating the exact source of the copied and pasted, or poorly paraphrased text.

This research also studied the various methods used by teachers in the classroom to deter all forms of cheating in their classrooms. I had hoped with this inquiry to gather a plethora of new, unique and insightful methods cultivated over time that would prove to be more interesting strategies than those I already used. However, most of the teachers reported using more conventional methods. I suppose the participants would have revealed more diverse methods had they had more time to think about just what, and all they do.

Evidence analyzed from the interview data suggested there was a relationship between the size of a classroom and the number of students in the class, and the type of methods a teacher used to deter cheating on tests. Several of the teachers felt their classrooms were overcrowded and were limited to relying on the re-organization of the contents of the test to deter cheating and used different answer keys which resulted in additional outstanding time and effort. They could not more simply move or seat the students apart due to the limited space available in their classroom.

Overall, the analysis revealed that teachers see plagiarism and its effects on learning as a growing problem in the classroom and also accepted they [teachers] need to keep abreast of the technological means available to improve the instruction of research and writing, as well as detect plagiarism. Jackie Marshall acknowledged using less-technological means for instruction about and detection of plagiarism, and admitted, “This is probably an area where if we had an in- 
service that was actually viable, I would love to have more training on this. I will use anything anybody shows me and the easier it is the better.”

Most English teachers have either a written or oral classroom policy on plagiarism usually involving a grade cut, or complete failure of the project. In addition to lowering a student's grade, it is possible the disciplinary actions could also include detention mandated by the school's administration (Appendix N).

The existence and communication of a standard school-wide policy that includes parental notification to discipline students who plagiarize can make the option of copying and pasting an undesirable one therefore effectively reducing instances of plagiarism. The results of this study suggested that although most teachers do not involve parents, except in repeat incidents or extreme cases, teachers in schools that have a school-wide discipline policy perceive there to be fewer incidents of plagiarism. The only school in this study where both senior English teachers felt that plagiarism was not a problem was also the only school that had a communicated school discipline policy on plagiarism and encouraged their teachers to use it. The results of this study suggest that any discipline that attracts the parent's attention may be viewed by the students as highly undesirable, serving to discourage the students from plagiarizing thereby further reducing instances of plagiarism in the classroom.

Based on the data collected for this research, including the data in the display table created for the relevant results (Appendix N), the following is concluded about high school English teachers' practices regarding the detection and prevention of plagiarism in the classroom. 


\section{Major Research Conclusions on Teachers’ Practices on Plagiarism}

1. English teachers have and enforce an oral or written classroom policy on plagiarism that they communicate to their students before they begin the research project.

2. Having a communicated and enforced school-wide discipline policy for acts of plagiarism may reduce the number of incidents of it in the school.

3. Senior English teachers spend a disproportionate amount of time during the course most, and sometimes all - of one grading period collectively due to the amount of reading and research involved, the necessity of technology outside the classroom for production and research of the project, as well as instruction in the research writing behaviors and the use of the writing process.

4. To detect plagiarism, high school English teachers combine their own instinct with affordable technology to detect and verify instances of plagiarism.

\section{Recommendations to Secondary English Teachers}

Prevention. The results of this research indicated factors that should be considered by teachers when completing written research projects in their senior English classrooms. One factor pertaining to the timing of the research project during the course involved completing the usually point-intensive project too close to the end of the class. This can cause those students who fail the project to risk graduating from high school due to students having no time to earn better grades to increase their overall grade average to a passing standard.

Another caveat to timing a lengthy, and sometimes difficult research project too close to the end of a high school student's senior year is the lack of needed attention because they are building up to and concentrating on graduation and may lack the focus needed to successfully complete the research paper. This interview data in study revealed that teachers realize the 
shorter the amount of time left until the end of the school year, the more likely it is that seniors may not “. . . work at their full capacity, [and they may have] already shut down a bit.”

As another factor, teaching students how to paraphrase what they read from other sources will help them to be able to add effectively to their own research without being afraid to use their own words. A participant in the pilot study (Newlon, 2003) who was a young science teacher shared with me a very good method to teach students how to paraphrase. She required her students to first get in pairs, and then tell each other about a television show they had watched recently. She explained to her students the thought process they used to summarize what they had seen on television and then told to their partner was the same process they will use to paraphrase the resources they will read when completing their research project.

Teachers should also spell out the requirements for the research paper in a handout, including requirements for quality and variety of resources used, as well as length and format. Students benefit by having a model of a research paper and example citations from which to follow when keying their own paper, as some students may lack the ability to format the necessary parts of a research paper in a word processing package.

When planning to control instances of plagiarism in the classroom, secondary English teachers should have a communicated classroom policy overall for academic dishonesty, including plagiarism. Furthermore they should encourage their administration to take a strong stand on plagiarism by developing a school-wide enforced policy that includes some type of detention or suspension which routinely requires the parents be made aware, and would supplement any grade cut given by the teacher when enforcing their classroom policy.

Another factor that may reduce plagiarism in their classroom is when teachers effectively bring up the discussion of this phenomenon in more than one area in their curriculum. Of course plagiarism will be discussed anytime students are using outside resources as references when 
completing a writing assignment, but every time ethics including the subject of right vs. wrong comes up in the classroom, that presents an opportunity to clarify how plagiarism is also a choice of right vs. wrong.

Detection. When utilizing technology to detect plagiarism in student work most secondary teachers use the affordable search engine by Google to verify suspicious text. Unfortunately, not all instances of plagiarism can be detected by any one search engine. Meta search engine websites, such as Metacrawler.com, Brainboost.com, and ChunkIt!.com offer teachers ways to access more than one search engine at the same time. In fact, using a search engine should only be the first step in utilizing technology to absolutely detect plagiarism, especially in higher education where the stakes and consequences can be much higher.

As negative press is broadcast about widespread student cheating, colleges and universities are increasingly paying what can be expensive subscriptions for their faculties’ use of online plagiarism detection services, such as Turnitin.com. When schools use these services, it reduces instances of plagiarism on their campuses thereby helping to avoid the possible academic embarrassment that can result if a school’s administration leaves plagiarism unattended.

Computer programs in addition to web-based resources are available to detect plagiarism in a variety of situations. Based on Wilson Taylor's cloze procedure (1953), the Glatt Plagiarism Screening Program at a cost of \$300 per CD, replaces every fifth word in the student's paper with a standard-sized blank. This program is used when the original material cannot be found (Gaither, 2008), and the student's assessment is based on how well and how quickly they fill in the blanks. CopyCatchGold is another dedicated computer program that detects plagiarism “among students, rather than from 'outside sources'.” The program is sophisticated and will 
continue to detect plagiarism even "when the student changes the order of sentences, replaces words with synonyms, or uses only part of the paper” (Gaither, 2008).

Before using a general purpose computer program or online plagiarism detection service that indicates the copied text, teachers should be aware that the program or service they use will highlight all instances of text taken from another source, including those passages that have been cited correctly in the student's paper. It is then the teacher's job to discern which passages have not been given credit.

\section{Recommendations for Schools}

Schools have a responsibility to their teachers and students to encourage teachers to use and then enforce a policy on plagiarism that requires discipline outside of what the classroom teacher has rendered. An institutional approach to valuing academic integrity and reducing plagiarism is very helpful in convincing students that it is that important. Encouraging teachers to enforce a school policy in their classroom can go a long way in convincing teachers that if they do have reason to accuse a student of plagiarism, they will not be met with a lack of administrative support, or face the dreaded bureaucratic struggles that kept them from referring students to the office in the first place.

To effectively reduce instances of plagiarism, schools can provide their English departments with subscriptions to online plagiarism detection services, such as Turnitin.com. Although the pricing structure of these services can be prohibitive for some public school systems, research on plagiarism by Martin (2005), revealed in a study, completed over five college semesters that once students in an English class realized their professor was uploading their papers to an online plagiarism detection service, instances of plagiarism significantly reduced. 


\section{Limitations of the Study}

In this study participants told me what they say, what they do, and how they feel about plagiarism in their classrooms. Classroom documents submitted by the teachers were collected to provide triangulation and further support the findings of this study. Direct observation was not a data collection method used; therefore it was not possible to confirm what the participants actually do in their classrooms when teaching research and writing or when addressing issues related to plagiarism.

A limitation of this study emerged when during data collection there were instances when it appeared to me the participants had prepared themselves specifically for the purposes of my discussion with them. When studying the documents Carrie Riggs submitted, I observed her handouts on research, writing and plagiarism consisted of many printed web pages that according to the date printed in the footer on each web page (Appendix D), had been printed just two days before they were submitted as data for this research. However, it is reasonable to say it is possible the web pages had been updated on the web site and the teacher was simply replacing older pages in their students' handouts with the newest ones. However, the fact that the packet of handouts was dated just two days earlier before data collection opens the possibility that some of, or the majority of the documents, were only very recently selected for use in the classroom.

Another reason I found this to be a limitation of this study was when Roxanne Carr specifically mentioned during our interview that since she had an appointment for a couple of months to speak with me about plagiarism, she had researched the topic. During our interview she shared with me some of the information she had recently read about plagiarism, as well as her astonishment that the things she had read were actually true. This participant, in addition to having researched plagiarism prior to our conversation, also submitted to me online documents 
she uses as classroom handouts. The footer date on some of these documents was less than three weeks before our interview.

Consequently, it is possible that the two teachers just previously mentioned, as well as other participants involved in this study may have prepared for their interviews and the collection of their classroom documents by updating or gathering extra last-minute materials, as well as becoming familiar with recent research on plagiarism. This is not viewed as a weakness in the teachers' abilities to manage plagiarism in their classroom, but rather a limitation in the research methods used in this study. Interestingly, both of these participants had over 20 years experience teaching English.

\section{Further Research}

Future studies that research the historic evolution of this phenomenon and the accompanying human or social dynamic could lend valuable insight to those studying academic dishonesty and plagiarism. Research by McCabe \& Trevino (1996) revealed a lack of longitudinal studies in the available research of academic dishonesty that would reveal how cheating has evolved over time.

The analysis suggested the teachers used many varied instructional strategies and materials and could greatly benefit by professional development, as well as the sharing of ideas, research on plagiarism, and other resources. Teachers could improve their ability to decrease instances of plagiarism by exploring the capabilities of currently available technology to both prevent and detect plagiarism, as well as building on their colleagues' knowledge of how to better manage plagiarism in their classroom. This perhaps could be done in the venue of a locally-offered continuing education class through the county's board of education, or a professional development workshop offered at an association’s conference. 
Further research on teachers’ perspectives on plagiarism could examine whether teachers decisively ignore instances of plagiarism. Teachers may ignore instances of plagiarism due to the administrative bureaucracy involved, or the amount of personal and professional liability that can be associated with accusing a student of a potentially serious infraction. Further research on teachers’ practices on plagiarism could examine

Donald McCabe, a veteran researcher of academic dishonesty, maintains there is a difference in the number of incidents of plagiarism in public versus private high schools, although he maintains there is no "solid data” to support any variation due to school size, ruralness, or makeup of the student body (D. L. McCabe, personal communication, September 27, 2005). Although there may be no data suggesting a difference in the frequency of incidents of plagiarism based on these school characteristics, future research on school characteristics and their effects on incidents of plagiarism may however reveal differences in frequency of plagiarism in schools from different socioeconomic levels. Teacher expectations for research and writing may be higher in schools where there are a larger percentage of academically achieving students. Future research on teacher expectations related to research and writing may reveal differences in what teachers expect in schools with lower or higher socioeconomic levels. Future research may reveal the effect of teacher expectations on how often high school students plagiarize.

Future, more widespread research is needed on the specific methods teachers use to integrate technology into the instruction of research and writing, as well as the detection and prevention of plagiarism. Data from this research would help to estimate the overall use of school technology resources in the English classroom. The opportunities for students to commit plagiarism and for teachers to detect plagiarism continue to evolve as technology evolves. The best recommendation for teachers to prevent plagiarism is to ensure instruction on research and 
writing is meaningful and comprehended by their students, and to have a communicated policy to deal with instances of plagiarism that involves discipline outside expected grade cuts in the classroom. 


\section{References}

Anson, C. (2003). Student plagiarism: Are teachers part of the solution or part of the problem? Teaching Excellence, 15(1), 2003-2004.

Ashworth, P. \& Bannister, P. (1997). Guilty in whose eyes? University students' perceptions of cheating and plagiarism in academic... Studies in Higher Education, 22(2), 187.

Auer, N. \& Krupar, E. (2001). Mouse-click plagiarism: The role of technology in plagiarism and the librarian's role in combating it. Library Trends, 49(3).

Avoiding Plagiarism. (2006). Retrieved March 29, 2006, from Purdue University Online Writing Lab Website: http://owl.english.purdue.edu/handouts/research/r_plagiar.html

Baggaley, J. \& Spencer, B. (2005). The mind of a plagiarist. Learning, Media and Technology, March, 2005, 30(1), 55. Retrieved November 25, 2005, from ProQuest Education Journals.

Biernacki, C. (2004). An investigation of faculty teaching behaviors that may influence students' decisions to engage in acts of academic dishonesty in higher education. Unpublished master’s thesis, University of Central Florida, Orlando, FL.

Binghamton University Student Academic Honesty Code (2008). Retrieved November 8, 2008, from http://bulletin.binghamton.edu/program.asp?program_id=703\#1

Campbell, C. R., Swift, C. O., \& Denton, L. T. (2000). Cheating goes hi-tech: Online term paper mills. Journal of Management Education, 24(6), 726-740.

Cheating crisis in America’s schools. (2006, April 29). ABC News Article. Retrieved March 12, 2006 from http://abcnews.go.com/Primetime/print?id=132376.

Colorado teacher on leave after alleged anti-Bush remarks. (2006, March 2). Associated Press, Fox News Article. Retrieved on March 5, 2006 from 
http://www.foxnews.com/story/0,2933,186672,00.html

Community Profile. (2000). Census information presented online. Retrieved April 6, 2006, available from http://www.epodunk.com/

Cronbach, L. J. (1975, February). Beyond the two disciplines of scientific psychology. American Psychologist, 30(2), 116-127.

Culwin, F. \& Lancaster, T. (2000). A review of electronic sources for plagiarism detection in student submissions. Eighth Annual Conference on the Teaching of Computing. Edinburgh: Centre for Information and Computer Science. Retrieved March 13, 2006 from http://www.ics.ltsn.ac.uk/pub/conf2000/Papers/culwin.htm.

Davis, S., Grover, C., Becker, A., \& McGregor, L. (1992). Academic Dishonesty: Prevalence, determinants, techniques, and punishments. Teaching of Psychology, 19(1), 16-19.

Drum, A. (1986). Responding to plagiarism. College Composition Communication, 37, 241242.

Eleff, Z. (2007). It can happen here too: turnitin.com. Retrieved March 15, 2009 from http://media.www.yucommentator.com/media/storage/paper652/news/2007/10/22/Featur es/It.Can.Happen.Here.Too.Turnitin.com-3032987.shtml

Fox, K. H. (1998). Due process and student academic misconduct. American Business Law Journal, 25, 671-700.

Freedman, M. (1998.) Don’t blame the internet for plagiarism. Education Week. 18(14), p. 36.

Gaither, R. (2008). Resources for instructors: plagiarism detection services. Retrieved February 27, 2009, from http://www.lib.umich.edu/acadintegrity/instructors/violations/detection.htm

Hard, J., \& Moran, A. (2006). Faculty and college student beliefs about the frequency of student academic misconduct. Journal of Higher Education. 77(6), p. 1058. 
Hardin, C. \& Bader, C. (1999). Your cheatin' heart: Dishonest or misinformed? Selected Conference Papers, Vol. 5. National Association for Developmental Education: Detroit. Hartwick College Academic Honesty Policy (2005). Retrieved November 1, 2005, from http://www. hartwick.edu/x3136.xml

Hoepfl, M. (1997). Choosing qualitative research: A primer for technology education researchers. Journal of Technology Education, 9, 1.

Hoover, Eric (2002). Honor for honor’s sake? The Chronicle of Higher Education, 48(34), 3942.

Hostos Community College Academic Integrity Policy (2008). Retrieved November 10, 2008, from http://www.hostos.cuny.edu/sdem/student_life_aip.html

Isserman, M. (2003). Plagiarism: A lie of the mind. The Chronicle of Higher Education, 49(34), B.12.

Judge dismisses copyright infringement complaint against iparadigms, provider of turnitin.com. (2008, March 18). iParadigms LLC, provider of Turnitin.com and iThenticate News Releases. Retrieved December, 7, 2008, from http://turnitin.com/static/media.html\#case

Marsh, R. L. (1993). Eliciting cryptomnesia: Unconscious plagiarism in a puzzle task. Journal of Experimental Psychology: Learning, Memory, and Cognition, 19, 3.

Martin, D. F. (2005). Plagiarism and technology: A tool for coping with plagiarism [Abstract]. Journal of Education for Business, 80(3), 149 - 152.

McCabe, D. L. \& Pavela, G. (2000). Some good news about academic integrity. Change, 33(5), 32-39.

McCabe, D. L. \& Trevino, L. K. (1996). What we know about cheating in college: Longitudinal trends and recent developments, Change, 28(1), 28 - 33. 
McMurtry, K. (2001). E-cheating: Combating a $21^{\text {st }}$ century challenge. T H E Journal. 29(4), 36.

Merriam, S. (1990). Case study research in education: A qualitative approach. San Francisco: Jossey-Bass.

Newlon, G. (2003). Plagiarism in the classroom: What part does the teacher play? Unpublished manuscript. Morgantown, WV: West Virginia University.

Newstead, S. E., Franklyn-Stokes, A., \& Armstead, P. (1996). Individual differences in student cheating. Journal of Educational Psychology, 88, 229-241.

Patton, M. (2002) ( $3^{\text {rd }}$ ed). Qualitative research \& evaluation methods. Thousand Oaks, CA.: Sage Publications.

Pincus, H. \& Schmelkin, L. (2003). Faculty perceptions of academic dishonesty: A multidimensional scaling analysis. The Journal of Higher Education, 74(2), 196-209.

Policing academic plagiarism. (2005, November 25). MSNBC News Article by Michael E. Ross. Retrieved March 12, 2006, from http://www.msnbc.msn.com/id/9959128/

Reading and language arts content standards and objectives for west virginia schools. (2003). Retrieved January 17, 2006, from West Virginia Department of Education’s Website: http://wvde.state.wv.us/policies/p2520.1_ne.doc

Renard, L. (1999/2000). Cut and paste 101: Plagiarism and the net. Educational Leadership, 57(4), pp. $38-42$.

Ryman, G. (2003). Teacher awareness of computer-based plagiarism detection tools. Unpublished master's thesis, Shenandoah University, Shenandoah, VA. Saddlemire, M. (2005). Faculty perceptions of undergraduate academic dishonesty. [Abstract] Pro Quest Digital Dissertations (UMI No. 3160371). 
Seals, L. (2005, August 28). Ethics case: We erred, and now we are taking action. Richmond Times-Dispatch. Retrieved January 14, 2006 from http://www.timesdispatch.com $\underline{\text { /servlet/Satellite?pagename=RTD/MGArticle/RTD_BasicArticle\&c=MGArticle\&cid=10 }}$ $\underline{31784694532}$

Shaw, K. (1978). Understanding the curriculum: The approach through case studies. Journal of Curriculum Studies, 10(1), 1-17.

Stephens, J. (2004). Justice or just us? What to do about cheating. Carnegie Foundation for the Advancement of Teaching: Carnegie Perspectives. Retrieved November 3, 2005, from http://www.carnegiefoundation.org/perspectives/sub.asp?key=245\&subkey=577\&printab $\underline{\text { le}=\text { true }}$

Sutherland-Smith, W. (2005). Pandora’s box: Academic perceptions of student plagiarism in writing. Journal of English for Academic Purposes, 4(1), 83-95.

Tanner, C. (2004). Moral decline or pragmatic decision making?: Cheating and plagiarism in perspective. Journal of Nursing Education, 43(7), 291-292.

The Writing Process. (2008). Retrieved November 3, 2008, from Massachusetts Institute of Technology Online Writing and Communication Center Website: http://web.mit.edu/writing/Writing_Process/writingprocess.html

Thomas, D. A. (2004). How educators can more effectively understand and combat the plagiarism epidemic. Brigham Young University Education \& Law Journal, 2, 421-430.

Thomas, D. R. (2003). A general inductive approach for qualitative data analysis. School of Population Health, University of Auckland, August, 2003.

Turnitin.com Home Page. (2008). Retrieved December 7, 2008 from http://www.turnitin.com/static/index.html 
U. S. Census Bureau. (2000). State and County Quick Facts. Retrieved April 12, 2006 from http://quickfacts.census.gov/qfd/states/54000.html

Wilhoit, S. (1994). Helping students avoid plagiarism. College Teaching, 42(4), 161-165.

Yin, R. (2003) (3 $3^{\text {rd }}$ ed). Case study research: Design and methods. Thousand Oaks, CA.: Sage Publications. 
Appendices

Appendix A Cover Letter \& Participant Application Form Appendix B Interview Protocol and Script Appendix C ..Demographic Data Samples

Appendix D Research Handout submitted by C. Riggs Appendix E Research Assignment Handout submitted by J. Richards Appendix F. Research Assignment Handout submitted by J. Marshall Appendix G Research Assignment Handout submitted by T. Queen Appendix $\mathrm{H}$ Plagiarism Policy submitted by R. Carr Appendix I Grading Rubric submitted by R. Carr Appendix $\mathrm{J}$ Plagiarism Policy submitted by B. Hinkle Appendix K Sample Originality Report printed from Turnitin.com Appendix L West Virginia Department of Education CSOs for $12^{\text {th }}$ Grade English Appendix M ......... Data Display to Support Conclusions on Teachers’ Perspectives on Plagiarism Appendix N...............Data Display to Support Conclusions on Teachers’ Practices on Plagiarism 


\title{
Appendix A
}

\section{WestVirginiaUniversity}

\author{
College of Human Resources and Education \\ Dear Potential Research Participant:
}

I am a teacher at [Laura B. Tyler] High School and a doctoral student at West Virginia University conducting a research study to determine how plagiarism is addressed by the senior English teachers in [one county's] high schools. Dr. Neal Shambaugh is my dissertation advisor and this research project will fulfill the requirements necessary for the completion of my doctoral degree, as well as provide you with helpful and pertinent information about how your colleagues deal with plagiarism.

Your participation would be greatly appreciated. It would involve about 45 minutes to an hour of your time to participate in an informal, audio taped interview in your classroom at a time convenient for you. I will be collecting any samples of classroom hand outs you use that deal with plagiarism.

Your participation is voluntary and there will be no penalty if you choose not to participate. You do not have to answer every interview question and you may withdraw from the study at any time. Your responses will be kept anonymous and confidential during and after the study. Fictitious names for the teachers and the schools will be used for the sake of anonymity. I have received support from your county's administration and your school's principal for completing this research. West Virginia University's IRB acknowledgment of this study is on file.

Through your participation in this research project, not only will you be assisting a colleague with a challenging academic requirement, you will be providing valuable feedback that will also be used to create staff development training sessions in the future to help teachers deal with this growing academic phenomenon. When reporting the results of this study, I expect them to take the form of a modified "round table discussion" revealing what real teachers do about a real problem.

Please read and complete the enclosed, short form and return in the self-addressed stamped envelope by February 15, 2008. I will be in contact with the participants to schedule the interview at a time convenient for them.

I would appreciate your participation in this exciting and worthwhile research project and look forward to hearing back from you. After the interviews are completed, participants' names will be put in a drawing. The first four teacher's names drawn out of a total of nine names (if all teachers participate) will each win a $\$ \mathbf{5 0}$ cash prize award. Please feel free to call me at [Laura B. Tyler] HS at 304-[555-5555], or home at 304-[999-9999], or email me at GJN2007@aol.com if you have any questions. Your help in researching this problem is very much needed and extremely appreciated.

Sincerely,

Geraldine Newlon, Teacher, [Laura B. Tyler] High School

Doctoral Candidate, West Virginia University

neal.shambaugh@mail.wvu.edu

Phone: 304-293-2060

Department of Technology, Learning, \& Culture

Fax: 304-293-2279

PO Box 6122, 504 Allen Hall

Morgantown, WV 26506-6122 


\section{Appendix A}

\section{PARTICIPANT APPLICATION FORM}

Name:

School:

$\square \quad$ Yes, I agree to participate in this needed study. Please contact me to set up a convenient time.

$\square \quad$ I may agree to participate in this study after talking with you about some questions I have. Please contact me.

$\square \quad$ No, I do not agree to participate in this study.

Preferred Method to Contact Me:

$\square \quad$ Home
$\square \quad$ School
$\square \quad$ Cell
$\square$
$\square \quad$ E-mail

Preferred Time to Contact Me:

(day)

(evening) 


\section{Appendix B}

\section{Script for Study \& Interview Protocol}

\section{Script for Study}

Good Afternoon. First let me thank you for agreeing to participate in my study. The purpose of my research is to find out how high school English teachers are managing plagiarism in their classrooms. The information gathered will be used to fulfill the requirements necessary for the completion of my doctoral program. The only requirement for you to participate in this study is that you are a $12^{\text {th }}$ grade English teacher in the county school system under study.

I am not evaluating you in any way, I just want to gather data on how different teachers address plagiarism in their classrooms. I assure you that your responses will remain anonymous and confidentiality will be maintained before, during, and after this study.

Your participation is voluntary and you do not have to respond to every item or question. Do I have your permission to tape the interview so I won't miss any of it or mix up something you say? If at any time you would like me to turn off the recorder, I will.

Thank you for agreeing to participate in this study. 


\section{Appendix B}

\section{Interview Protocol}

1. How many years teaching experience do you have?

--what grade levels/classes have you taught during that time?

--what was your last degree?

2. During your years of teaching have you had experiences with plagiarism? (If so) please describe your experiences.

--how did you find it?

-- what did you do?

-- what policies were in effect? --do you have a handout on the policy?

--was administration involved?

3. Describe how you make decisions about consequences for plagiarism in your classes? --are there ever any exceptions to this?

4. Briefly describe an example of a research assignment you give in your senior English class and the expectations you have of your students.

--ask for a handout?

5. Describe what you currently do to teach your students how to properly prepare a research report, including properly citing references, paraphrasing or quoting text or anything that would help prevent your students from unknowingly committing acts of plagiarism?

--examples of any handouts, examples, exercises, or other information you give your students on this topic

6. In your opinion, how common are acts of plagiarism in your school?

--what makes you feel this way?

7. Why do you think students plagiarize?

8. What do you say to your students about plagiarism?

--how often do you talk about it?

--any related handouts?

9. Over the course of your career describe any changes you have made in how you do things in an effort to decrease the instances of academic dishonesty overall in your classroom.

10. Is there anything you care to add about the topics we have discussed, or is there anything I haven’t asked that you think I should know about your perspectives or practices concerning plagiarism? 


\section{Appendix C}

\section{Beaumont High School Attendance Area Demographic Statistics}

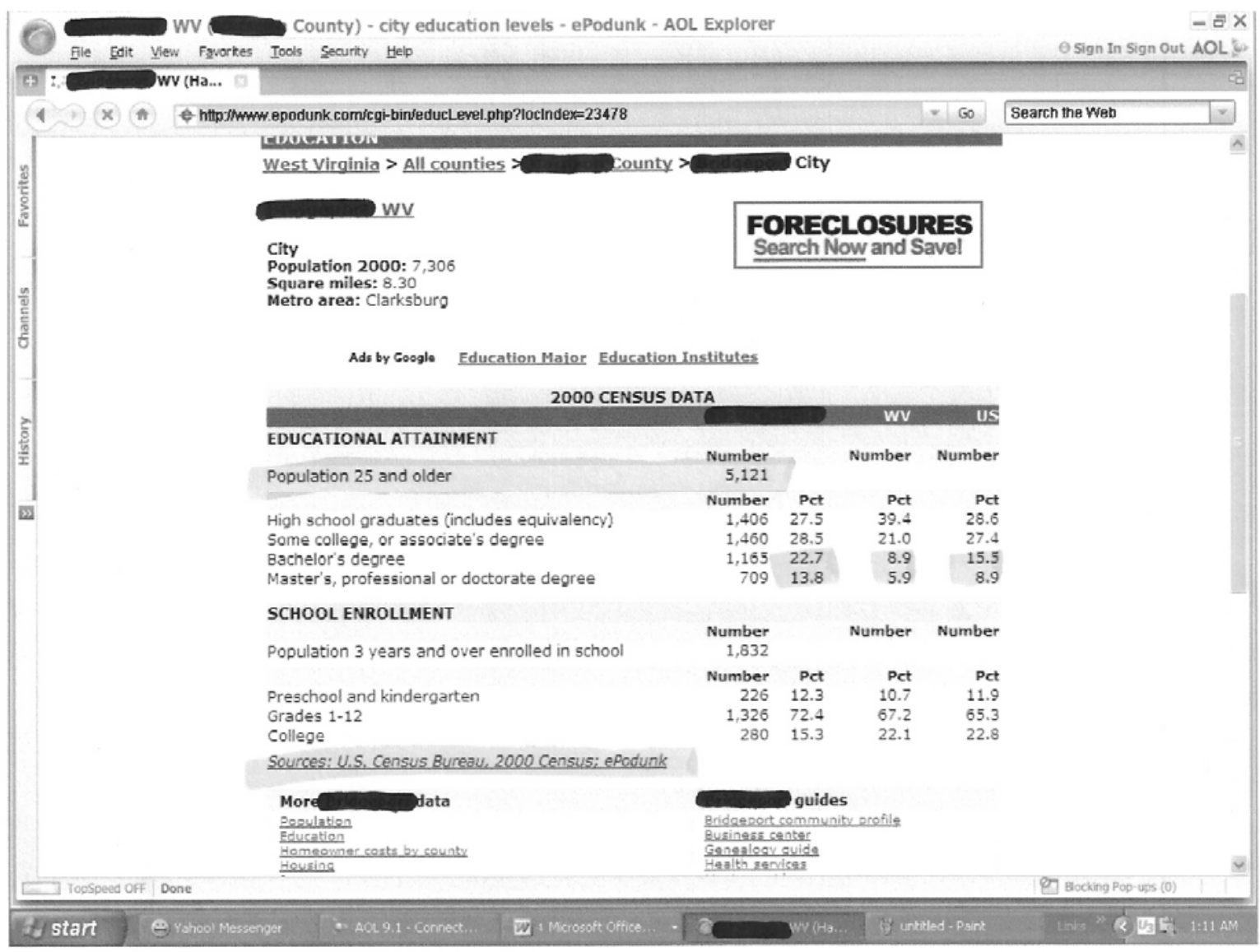




\section{Appendix C}

\section{Beaumont High School Attendance Area Demographic Statistics}

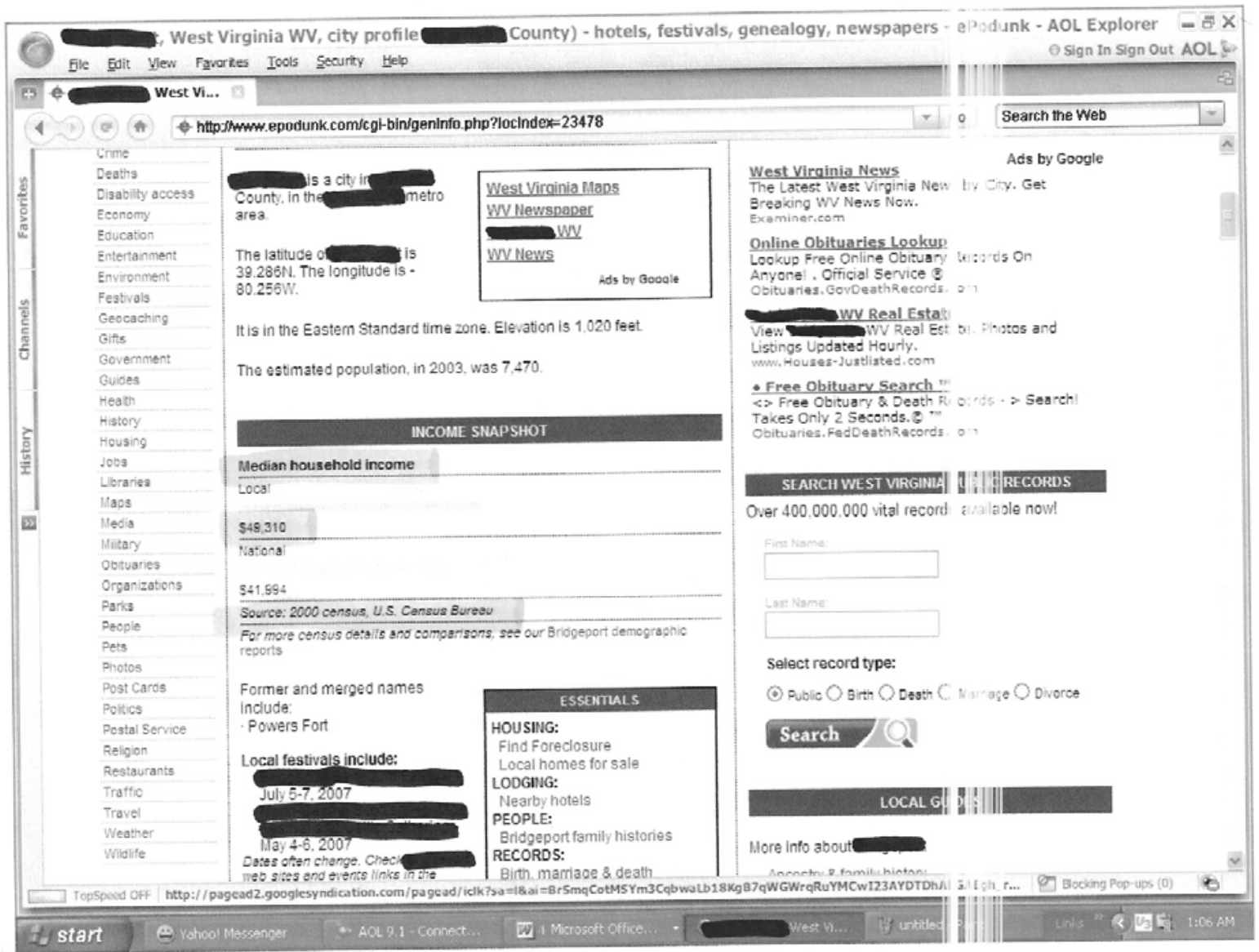




\section{Appendix C}

Pine Valley High School Attendance Area Demographic Statistics

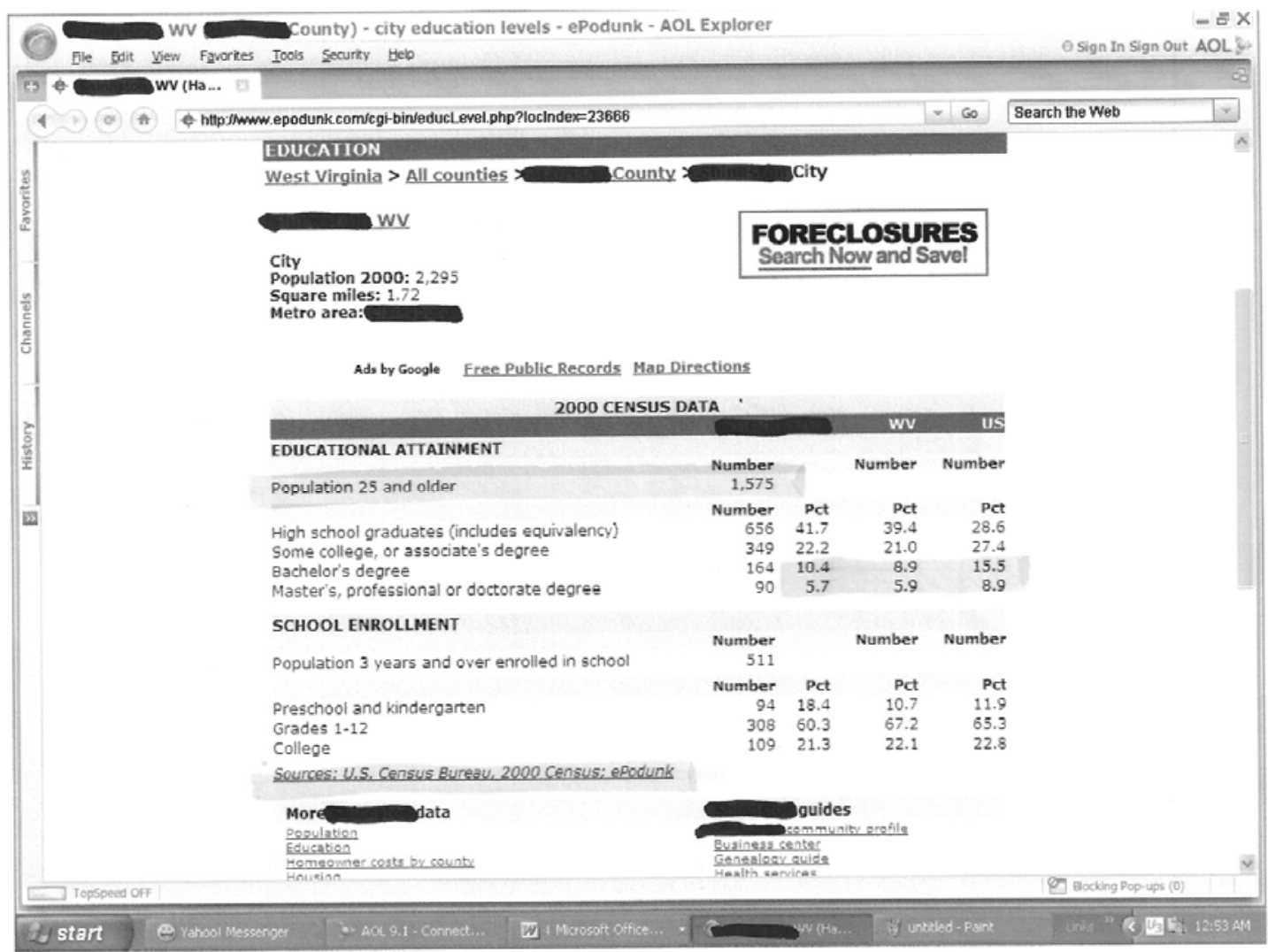




\section{Appendix C}

\section{Pine Valley High School Attendance Area Demographic Statistics}

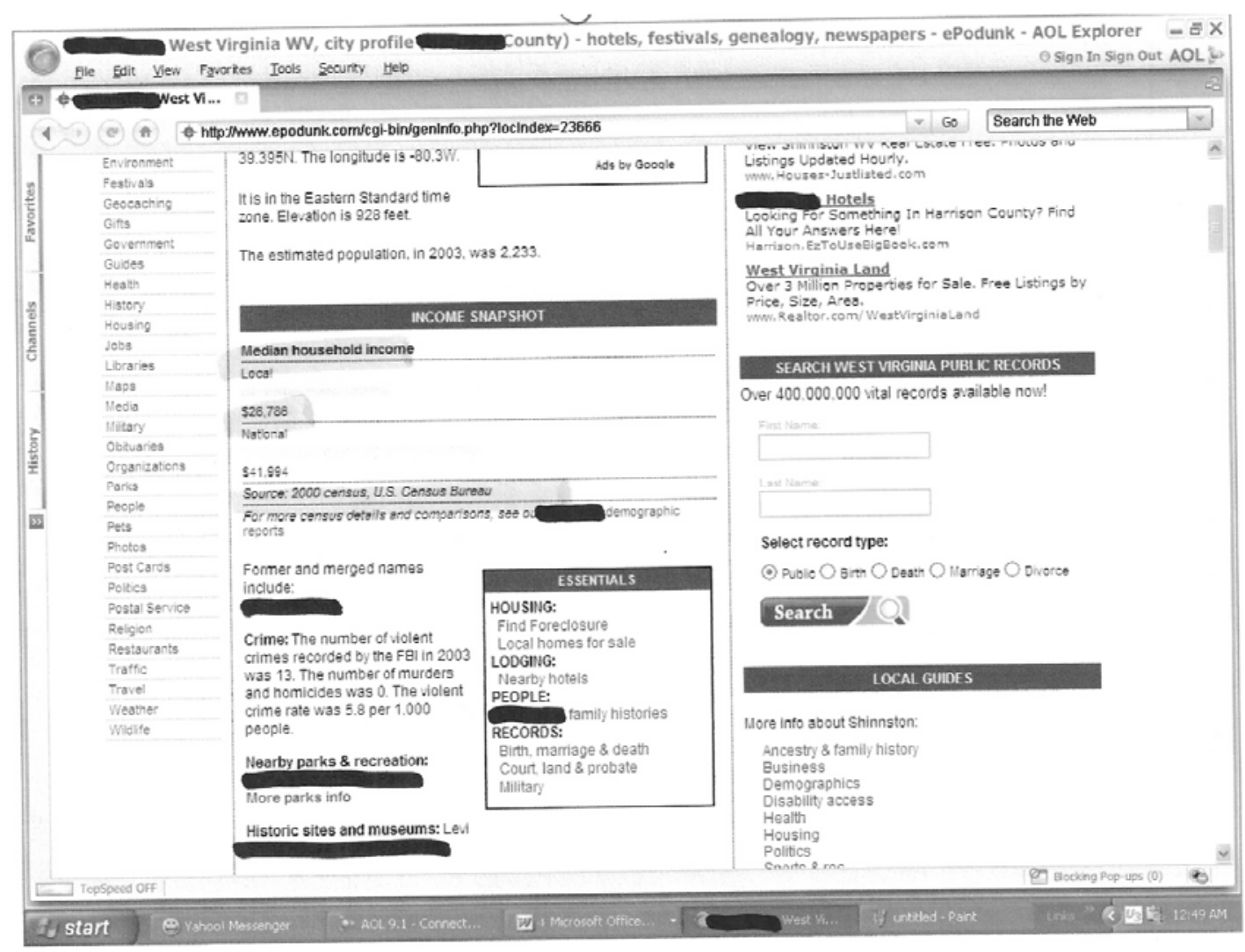




\section{Appendix C}

\section{South River High School Attendance Area Demographic Statistics}

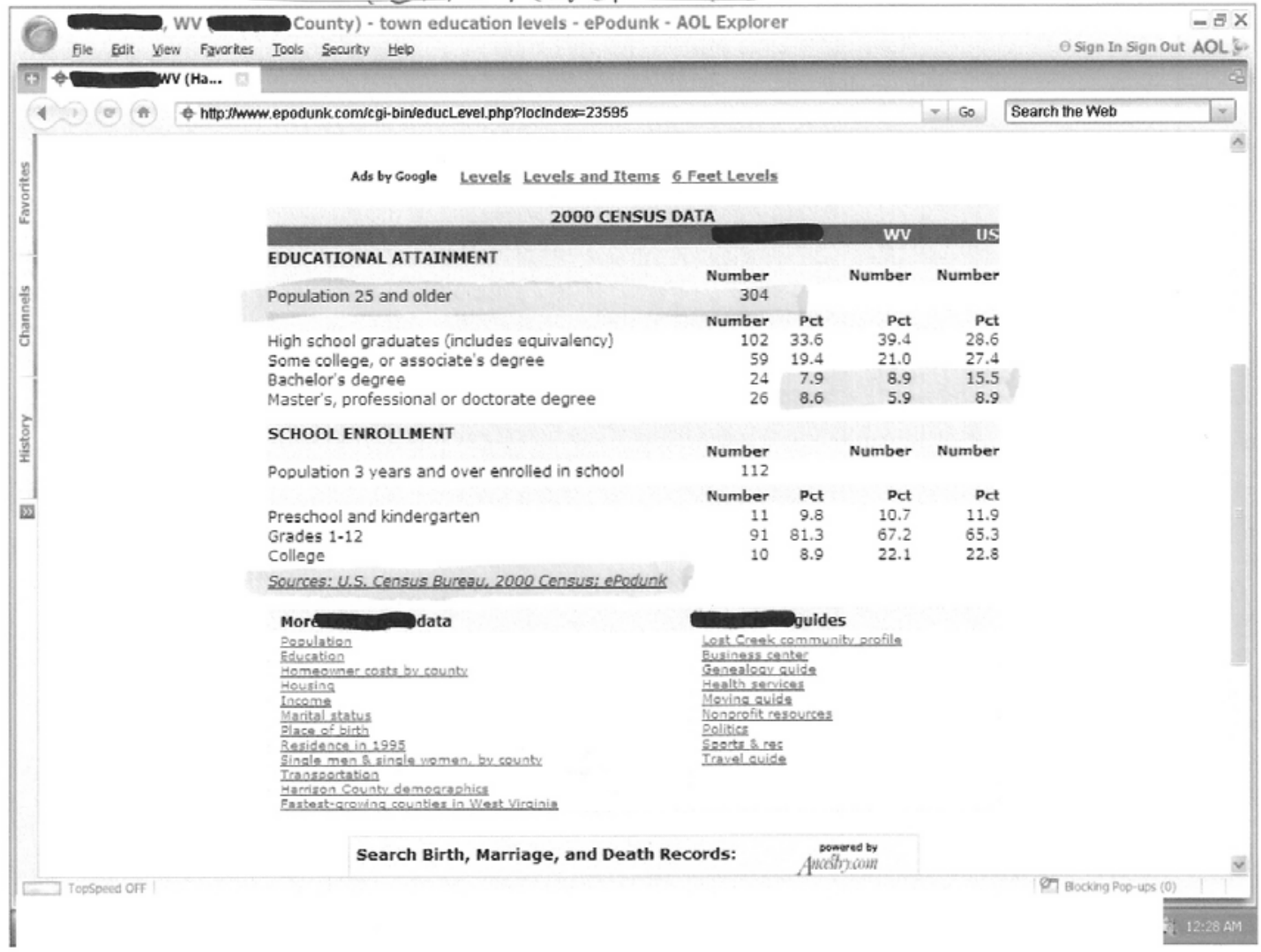




\section{Appendix C}

\section{South River High School Attendance Area Demographic Statistics}

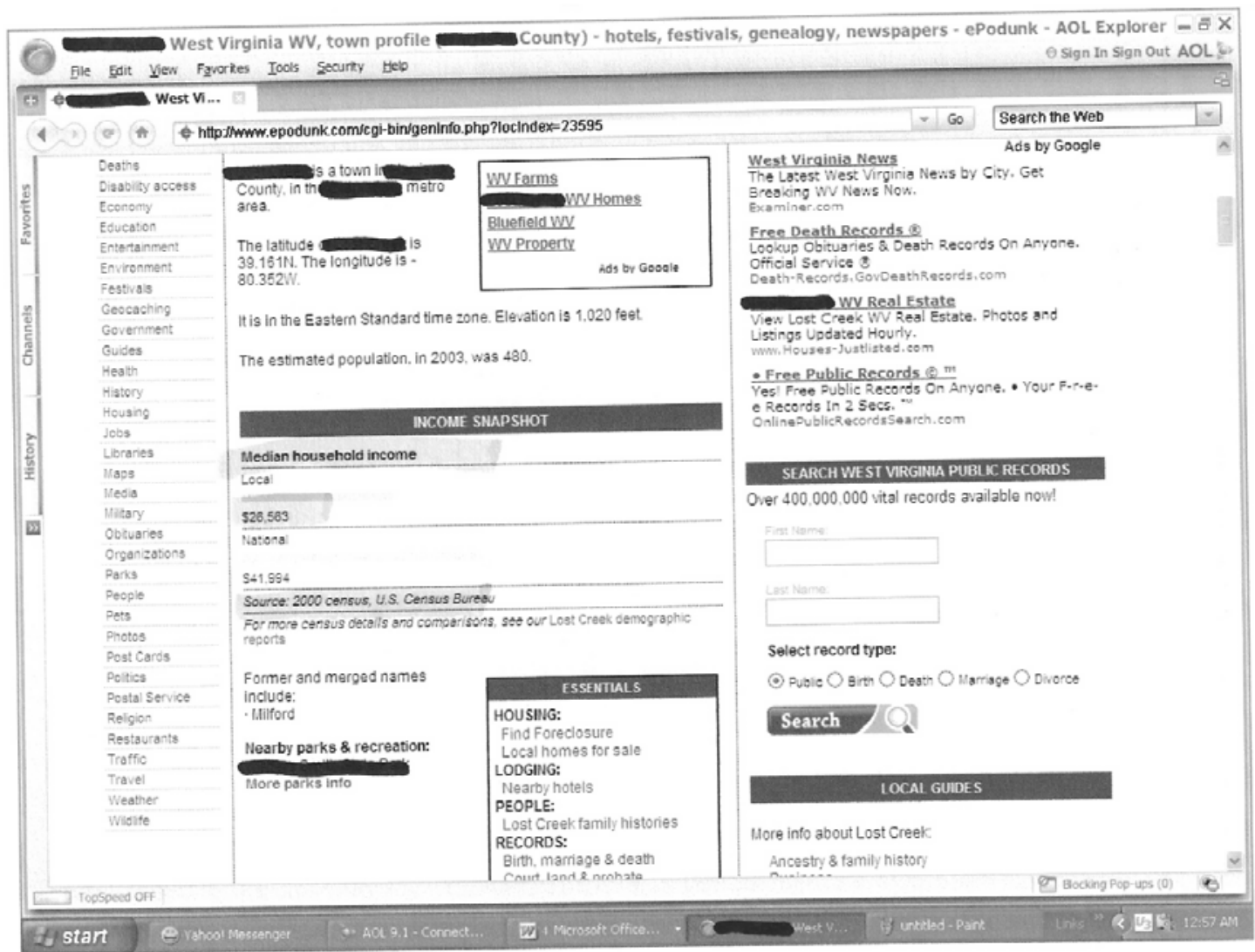




\section{Appendix C}

\section{Horace Mann and Laura B. Tyler High School Attendance Area Demographic Statistics}

Table DP-1. Profile of General Demographic Characteristics: 2000 Geographic area: city, West Virginia

[For information on confidentiality protection, nonsampling error, and definitions, see text]

\begin{tabular}{|c|c|c|c|c|c|}
\hline Subject & Number & Percent & Subject & Number & Percent \\
\hline Total population.......................... & 16,743 & 100.0 & $\begin{array}{l}\text { HISPANIC OR LATINO AND RACE } \\
\quad \text { Total population. } \ldots \ldots \ldots \ldots \ldots \ldots \ldots \ldots \ldots\end{array}$ & 16,743 & 100.0 \\
\hline SEX AND AGE & & & Hispanic or Latino (of any race) $\ldots \ldots \ldots \ldots \ldots \ldots$ & 177 & 1.1 \\
\hline Male............ & 7,752 & 46.3 & Mexican $\ldots \ldots \ldots \ldots \ldots \ldots \ldots \ldots$ & 32 & 0.2 \\
\hline 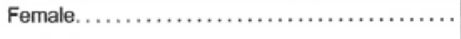 & 8,991 & 53.7 & Puerto Rican................................... & 23 & 0.1 \\
\hline Under 5 years ... & 934 & 5.6 & $\begin{array}{l}\text { Cuban .................... } \\
\text { Other Hispanic or Latino. }\end{array}$ & $\begin{array}{r}6 \\
116\end{array}$ & 0.7 \\
\hline $\begin{array}{l}5 \text { to } 9 \text { years ... } \\
10 \text { to } 14 \text { years. }\end{array}$ & 1,003 & & Not Hispanic or Latino ............... & 16,566 & 98.9 \\
\hline $\begin{array}{l}10 \text { to } 14 \text { years. } \\
15 \text { to } 19 \text { years. }\end{array}$ & $\begin{array}{r}966 \\
1,063\end{array}$ & $\begin{array}{l}5.8 \\
6.3\end{array}$ & White alone.................. & 15,584 & 93.1 \\
\hline 20 to 24 years .............. & 948 & 5.7 & RELATIONSHIP & & \\
\hline 25 to 34 years... & 2,185 & 13.1 & Total population... & 16,743 & 100.0 \\
\hline 35 to 44 years ...... & 2,386 & 14.3 & In households.......... & 16,381 & 97.8 \\
\hline 45 to 54 years.$\ldots \ldots \ldots \ldots \ldots \ldots \ldots \ldots \ldots$ & 2,277 & 13.6 & Householder.. & 7,447 & 44.5 \\
\hline 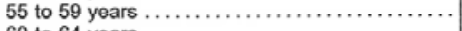 & 839 & 5.0 & 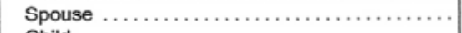 & 3,095 & 18.5 \\
\hline 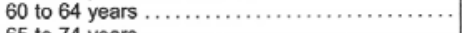 & 681 & 4.1 & Child............ & 4,396 & 26.3 \\
\hline 65 to 74 years $\ldots \ldots \ldots \ldots \ldots \ldots \ldots \ldots \ldots \ldots \ldots \ldots \ldots \ldots \ldots \ldots \ldots$ & 1,479 & 8.8 & Own child under 18 years..$\ldots \ldots \ldots \ldots \ldots$ & 3,191 & 19.1 \\
\hline 75 to 84 years ........ & 1,439 & 8.6 & Other relatives $\ldots \ldots \ldots \ldots \ldots \ldots \ldots \ldots \ldots \ldots \ldots$ & 717 & 4.3 \\
\hline 85 years and over... & 543 & 3.2 & Under 18 years $\ldots \ldots \ldots \ldots \ldots \ldots \ldots \ldots \ldots \ldots$ & 242 & 1.4 \\
\hline Median age (years). . & 40.5 & $(\mathrm{X})$ & Nonrelatives $\ldots \ldots \ldots \ldots \ldots \ldots \ldots \ldots \ldots$ & 726 & 4.3 \\
\hline 18 years and over. & 13,211 & 78.9 & In group quarters ............................ & $\begin{array}{l}386 \\
362\end{array}$ & $\begin{array}{l}2.3 \\
2.2\end{array}$ \\
\hline Male ....... & 5,935 & 35.4 & 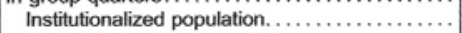 & 300 & 1.8 \\
\hline Female $\ldots \ldots \ldots \ldots \ldots \ldots \ldots \ldots \ldots \ldots \ldots \ldots \ldots \ldots \ldots \ldots \ldots$ & 7,276 & 43.5 & Noninstitutionalized population ................... & 62 & 0.4 \\
\hline 21 years and over $\ldots \ldots \ldots \ldots \ldots \ldots \ldots \ldots \ldots \ldots$ & 12,590 & 75.2 & & & \\
\hline 62 years and over.. & 3,851 & 23.0 & HOUSEHOLD BY TYPE & & \\
\hline 65 years and over...................... & 3,461 & 20.7 & Total households.............. & 7,447 & 100.0 \\
\hline 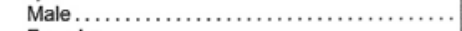 & 1,196 & 7.1 & Family households (families)............. & 4,382 & 58.8 \\
\hline 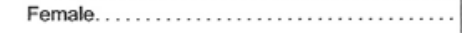 & 2,265 & 13.5 & With own children under 18 years ............ & 1,864 & 25.0 \\
\hline & & & Married-couple family ................. & 3,095 & 41.6 \\
\hline RACE & & & With own children under 18 years ............ & 1,176 & 15.8 \\
\hline One race... & 16,519 & 98.7 & Female householder, no husband present...... & 1,000 & 13.4 \\
\hline White..... & 15,715 & 93.9 & With own children under 18 years... & 523 & 7.0 \\
\hline Black or African American ................ & 641 & 3.8 & Nonfamily households. & 3,065 & 41.2 \\
\hline American Indian and Alaska Native ............ & 21 & 0.1 & Householder living alone... & 2,730 & 36.7 \\
\hline$\cdots \cdots \cdots \cdots \cdots$ & 60 & 0.4 & Householder 65 years and over. & 1,292 & 17.3 \\
\hline $\begin{array}{l}\text { Asian Indian .. } \\
\text { Chinese. }\end{array}$ & $\begin{array}{r}15 \\
8\end{array}$ & 0.1 & ndividuals under 18 years ...... & & \\
\hline 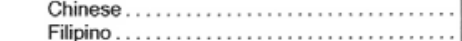 & $\begin{array}{r}8 \\
11\end{array}$ & -1 & Households with individuals 65 years and over... & 2,527 & $\begin{array}{l}27.6 \\
33.9\end{array}$ \\
\hline $\begin{array}{l}\text { Filipino } \ldots \ldots \ldots \ldots \ldots \ldots \ldots \ldots \ldots \ldots \ldots \ldots \ldots \ldots \ldots \ldots \ldots \ldots \ldots \ldots \\
\text { Japanese } \ldots \ldots \ldots \ldots \ldots \ldots \ldots \ldots \ldots \ldots \ldots\end{array}$ & $\begin{array}{r}11 \\
3\end{array}$ & 0.1 & & & 33.9 \\
\hline & $\begin{array}{r}3 \\
12\end{array}$ & & Average ho & 2.20 & $(\mathrm{X})$ \\
\hline $\begin{array}{l}\text { Korean....... } \\
\text { Vietnamese.. }\end{array}$ & $\begin{array}{r}12 \\
2\end{array}$ & $\begin{array}{r}0.1 \\
-\end{array}$ & Average famil & 2.87 & $(x)$ \\
\hline Other Asian ${ }^{1}$. & 9 & 0.1 & & & \\
\hline Native Hawailian and Other Pacific Islander.... & 8 & - & HOUSING OCCUPANCY & & \\
\hline Native Hawaiian..$\ldots \ldots \ldots \ldots \ldots \ldots \ldots \ldots$ & - & - & $\begin{array}{l}\text { Total housing units... } \\
\text { Occupied housing units }\end{array}$ & $\begin{array}{l}8,662 \\
7,447\end{array}$ & $\begin{array}{r}100.0 \\
86.0\end{array}$ \\
\hline Guamanian or Chamorro ..................... & $\overline{7}$ & - & Vacant housing units.......... & 1,215 & 14.0 \\
\hline $\begin{array}{l}\text { Samoan............. } \\
\text { Other Pacific Islande }\end{array}$ & $\begin{array}{l}7 \\
1\end{array}$ & - & For seasonal, recreational, or & & \\
\hline 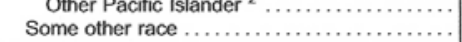 & $\begin{array}{r}1 \\
74\end{array}$ & 0.4 & occasional use..................... & 47 & 0.5 \\
\hline Two or more races $\ldots \ldots \ldots \ldots \ldots \ldots \ldots \ldots \ldots \ldots$ & 224 & 1.3 & Homeowner vacancy rate (percent). & 4.0 & $(\mathrm{X})$ \\
\hline $\begin{array}{l}\text { Race alone or in combination with one } \\
\text { or more other races: }{ }^{3}\end{array}$ & & & (percent) $\ldots \ldots \ldots \ldots \ldots \ldots$ & 14.2 & $(\mathrm{X})$ \\
\hline White .................. & 15,930 & 95.1 & HOUSING TENURE & & \\
\hline Black or African American . & 735 & 4.4 & $\begin{array}{l}\text { Occupied housin } \\
\text { Owner-occupied hous }\end{array}$ & $\begin{array}{l}7,447 \\
4,704\end{array}$ & \\
\hline American Indian and Alaska Native...... & 94 & 0.6 & Renter-occupied housing units ..................... & $\begin{array}{l}4,104 \\
2,743\end{array}$ & $\begin{array}{l}63.2 \\
36.8\end{array}$ \\
\hline 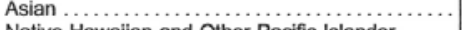 & 87 & 0.5 & 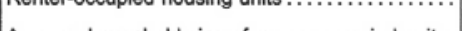 & & \\
\hline $\begin{array}{l}\text { Native Hawailian and Other Pacific Islander....... } \\
\text { Some other race. }\end{array}$ & $\begin{array}{r}14 \\
120\end{array}$ & $\begin{array}{l}0.1 \\
0.7\end{array}$ & $\begin{array}{l}\text { Average household size of owner-occupied units. } \\
\text { Average household size of renter-occupied units. }\end{array}$ & 2.29 & $(X)$ \\
\hline other race $\ldots \ldots \ldots \ldots \ldots \ldots \ldots \ldots \ldots \ldots \ldots \ldots \ldots \ldots \ldots$ & 120 & 0.7 & Average household size of renter-occupied units . & 2.04 & $(\mathrm{X})$ \\
\hline
\end{tabular}

- Represents zero or rounds to zero. $(X)$ Not applicable.

1 Other Asian alone, or two or more Asian categories.

2 Other Pacific Islander alone, or two or more Native Hawaiian and Other Pacific Islander categories.

${ }^{3}$ In combination with one or more of the other races listed. The six numbers may add to more than the total population and the six percentages may add to more than 100 percent because individuals may report more than one race.

Source: U.S. Census Bureau, Census 2000. 


\section{Appendix C}

\section{Horace Mann and Laura B. Tyler High School Attendance Area Demographic Statistics}

Table DP-2. Profile of Selected Social Characteristics: 2000

Geographic area: city, West Virginia

[Data based on a sample. For information on confidentiality protection, sampling error, nonsampling error, and definitions, see text]

\begin{tabular}{|c|c|c|c|c|c|}
\hline Subject & Number & Percent & Subject & Number & Percent \\
\hline $\begin{array}{l}\text { SCHOOL ENROLLMENT } \\
\text { Population } 3 \text { years and over }\end{array}$ & & & $\begin{array}{l}\text { NATIVITY AND PLACE OF BIRTH } \\
\text { Total population. .............. }\end{array}$ & 16,542 & 100.0 \\
\hline enrolled in school.......... & 3,413 & 100.0 & Native................................. & 16,325 & 98.7 \\
\hline Nursery school, preschool... & 161 & 4.7 & Born in United States...... & 16,247 & 98.2 \\
\hline Kindergarten................... & 223 & 6.5 & State of residence.... & 13,546 & 81.9 \\
\hline Elementary school (grades $1-8) \ldots \ldots \ldots \ldots \ldots \ldots$ & 1,578 & 46.2 & Different state $\ldots \ldots \ldots \ldots \ldots \ldots \ldots \ldots \ldots \ldots$ & 2,701 & 16.3 \\
\hline High school (grades 9-12).................... & 774 & 22.7 & Born outside United States..$\ldots \ldots \ldots \ldots \ldots$ & 78 & 0.5 \\
\hline College or graduate school. & 677 & 19.8 & Foreign born............................... & 217 & 1.3 \\
\hline EDUCATIONAL ATTAINMENT & & & Entered 1990 to March $2000 \ldots \ldots \ldots \ldots \ldots$ & $\begin{array}{r}42 \\
155\end{array}$ & 0.3 \\
\hline Population 25 years and over.... & 11,707 & 100.0 & Naturalized citizen................ & $\begin{array}{r}155 \\
62\end{array}$ & 0.9 \\
\hline Less than 9 th grade..$\ldots \ldots \ldots \ldots \ldots \ldots \ldots \ldots \ldots$ & 713 & $\begin{array}{r}100.0 \\
6.1\end{array}$ & Not a citizen ......................... & 62 & 0.4 \\
\hline 9 th to 12 th grade, no diploma... & 1,590 & 13.6 & REGION OF BIRTH OF FOREIGN BORN & & \\
\hline High school graduate (includes equivalency). & 4,800 & 41.0 & Total (excluding born at sea).$\ldots \ldots \ldots \ldots \ldots$ & 217 & 100.0 \\
\hline Some college, no degree...$\ldots \ldots \ldots \ldots \ldots \ldots$ & 2,230 & 19.0 & 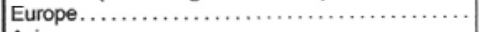 & 130 & 59.9 \\
\hline Associate degree $\ldots \ldots \ldots \ldots \ldots \ldots \ldots \ldots$ & 506 & 4.3 & Asia $\ldots \ldots \ldots \ldots \ldots \ldots \ldots \ldots$ & 57 & 26.3 \\
\hline Bachelor's degree ..................... & 1,205 & 10.3 & Africa ............ & - & - \\
\hline Graduate or professional degree $\ldots \ldots \ldots \ldots \ldots \ldots$ & 663 & 5.7 & 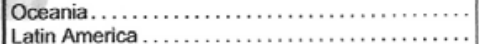 & 26 & 12. \\
\hline Percent high school graduate or higher ......... & 80.3 & $(\mathrm{X})$ & Northern America. .......................... & 4 & 1.8 \\
\hline Percent bachelor's & 16.0 & $(\mathrm{X})$ & LANGUAGE SPOKEN AT HOME & & \\
\hline MARITAL STATUS & & & Population 5 years an & 15,644 & 100.0 \\
\hline Population 15 years an & 13,743 & 100.0 & English only ........... & 15,185 & 97.1 \\
\hline Never married ..... & 3,407 & 24.8 & Language other than English. & 459 & 2.9 \\
\hline Now married, except separated & 6,751 & 49.1 & Speak English less than "very well". & 157 & 1.0 \\
\hline Separated .................. & 343 & 2.5 & Spanish ................................ & 125 & 0.8 \\
\hline Widowed .......... & 1,665 & 12.1 & Speak English less than "very well". & 40 & 0.3 \\
\hline$\ldots \ldots \ldots \ldots \ldots$ & 1,448 & 10.5 & $\begin{array}{l}\text { Other Indo-European languages ........ } \\
\text { Speak Enqlish less than "very well" }\end{array}$ & 277 & 1.8 \\
\hline Divorced ... & 1,577 & 11.5 & $\begin{array}{l}\text { Speak English less than "very well" ........... } \\
\text { Asian and Pacific Island languages............ }\end{array}$ & 65 & 0.4 \\
\hline Female. . & 891 & 6.5 & $\begin{array}{l}\text { Asian and Pacific Island languages............. } \\
\text { Speak English less than "very well" } \ldots \ldots \ldots \ldots\end{array}$ & $\begin{array}{l}48 \\
43\end{array}$ & 0.3 \\
\hline GRANDPARENTS AS CAREGIVERS & & & & & 0.3 \\
\hline Grandparent living in household with & & & $\begin{array}{l}\text { ANCESTRY (single or multiple) } \\
\text { Total population.................. }\end{array}$ & 16,542 & 100.0 \\
\hline $\begin{array}{l}\text { one or more own grandchildren } \\
18 \text { years } \ldots \ldots \ldots \ldots \ldots \ldots \ldots \ldots \ldots\end{array}$ & & & Total ancestries reported.......... & 16,388 & 99.1 \\
\hline 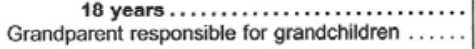 & $\begin{array}{l}299 \\
155\end{array}$ & $\begin{array}{r}100.0 \\
51.8\end{array}$ & 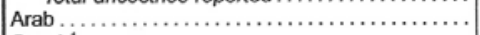 & 69 & 0.4 \\
\hline & & & 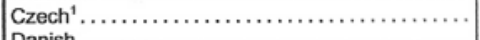 & 51 & 0.3 \\
\hline VETERAN STATUS & & & 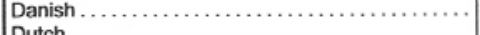 & 2 & \\
\hline Civilian population 18 years and & 13,140 & 100.0 & Dutch.... & 320 & 1.9 \\
\hline Civilian veterans. & 1,959 & 14.9 & 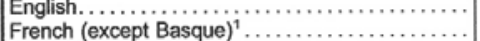 & $\begin{array}{r}1,808 \\
270\end{array}$ & $\begin{array}{r}10.9 \\
1.6\end{array}$ \\
\hline DISABILITY STATUS OF THE CIVILIAN & & & French Canadian ${ }^{1}$............................ & 28 & 0.2 \\
\hline NONINSTITUTIONALIZED POPULATION & & & 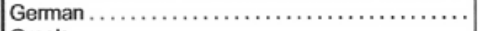 & 2,593 & 15.7 \\
\hline Population 5 to 20 years... & 3,185 & 100.0 & Greek........ & 23 & 0.1 \\
\hline With a disability ............. & 290 & 9.1 & Hungarian . . . . . . . . . . . . . & 61 & 0.4 \\
\hline Population 21 to 64 years.. & 8,886 & 100.0 & $\begin{array}{l}\mid \operatorname{Irish}^{1} \ldots \ldots \ldots \ldots \ldots \ldots \ldots \ldots \\
\operatorname{Italian} \ldots \ldots \ldots \ldots \ldots \ldots \ldots\end{array}$ & $\begin{array}{l}2,368 \\
2,394\end{array}$ & $\begin{array}{l}14.3 \\
14.5\end{array}$ \\
\hline With a disability. & 2,128 & 23.9 & Lithuanian ......................... & & 14.9 \\
\hline Percent employed..$\ldots \ldots \ldots \ldots \ldots \ldots \ldots \ldots \ldots$ & 45.2 & (X) & (n................ & 8 & - \\
\hline No disability .......... & 6,758 & 76.1 & Polish..................................... & 321 & 1.9 \\
\hline Percent employed . & 74.7 & $(\mathrm{X})$ & Portuguese ................................ & & \\
\hline Population 65 years and over ........... & 3,235 & 100.0 & 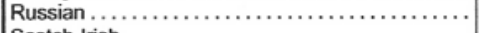 & 36 & 0.2 \\
\hline With a disability . & 1,561 & 48.3 & 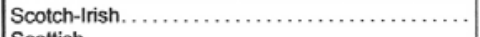 & 452 & 2.7 \\
\hline RESIDENG & & & Scottish .......... & 172 & 1.0 \\
\hline $\begin{array}{l}\text { RESIDENCE IN } 1995 \\
\text { Population } 5 \text { years and over }\end{array}$ & & & Slovak .............. & 120 & 0.7 \\
\hline $\begin{array}{l}\text { Population } 5 \text { years and over } \\
\text { Same house in } 1995 \ldots \ldots \ldots \ldots \ldots\end{array}$ & 15,644 & 100.0 & Subsaharan African........ & 24 & 0.1 \\
\hline 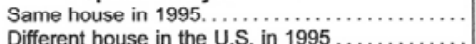 & 9,278 & 59.3 & Swedish..................... & 21 & 0.1 \\
\hline $\begin{array}{l}\text { Different house in the U.S. in } 1995 . \\
\text { Same county ................. }\end{array}$ & 6,299 & 40.3 & 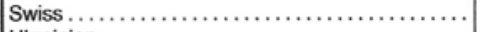 & 64 & 0.4 \\
\hline $\begin{array}{l}\text { Same county } \ldots \ldots \ldots \ldots \ldots \\
\text { Different county ........... }\end{array}$ & 4,348 & 27.8 & 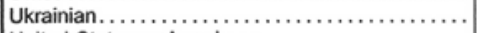 & & \\
\hline Different county ............ & 1,951 & 12.5 & United States or American......................... & 3,079 & 18.6 \\
\hline Same state ........... & 843 & 5.4 & Welsh........... & 157 & 0.9 \\
\hline Different state... & 1,108 & 7.1 & West Indian (excluding Hispanic groups)... & & \\
\hline Elsewhere in $1995 \ldots$ & 67 & 0.4 & Other ancestries $\ldots \ldots \ldots \ldots \ldots \ldots \ldots \ldots \ldots \ldots \ldots \ldots \ldots \ldots$ & 1,945 & 11.8 \\
\hline
\end{tabular}

-Represents zero or rounds to zero. (X) Not applicable.

${ }^{1}$ The data represent a combination of two ancestries shown separately in Summary File 3. Czech includes Czechoslovakian. French includes Alsatian. French Canadian includes Acadian/Cajun. Irish includes Celtic.

Source: U.S. Bureau of the Census, Census 2000 


\section{Appendix C}

\section{Horace Mann and Laura B. Tyler High School Attendance Area Demographic Statistics}

Table DP-3. Profile of Selected Economic Characteristics: 2000

Geographic area: city, West Virginia

[Data based on a sample. For information on confidentiality protection, sampling error, nonsampling error, and definitions, see text]

\begin{tabular}{|c|c|c|c|c|c|}
\hline Subject & Number & Percent & Subject & Number & Percent \\
\hline $\begin{array}{l}\text { EMPLOYMENT STATUS } \\
\text { Population } 16 \text { years and over. }\end{array}$ & 13,558 & 100.0 & $\begin{array}{l}\text { INCOME IN } 1999 \\
\text { Households. }\end{array}$ & 7,406 & 100.0 \\
\hline In labor force ...................... & 7,286 & 53.7 & Less than $\$ 10,000$. . & 1,223 & 16.5 \\
\hline Civilian labor force. & 7,258 & 53.5 & $\$ 10,000$ to $\$ 14,999$. & 987 & 13.3 \\
\hline Employed ........ & 6,617 & 48.8 & $\$ 15,000$ to $\$ 24,999 \ldots$. & 1,265 & 17.1 \\
\hline Unemployed .................... & 641 & 4.7 & $\$ 25,000$ to $\$ 34,999 .$. & 1,069 & 14.4 \\
\hline Percent of civilian labor force... & 8.8 & $(\mathrm{X})$ & $\$ 35,000$ to $\$ 49,999$. . & 1,216 & 16.4 \\
\hline Armed Forces............................. & 28 & 0.2 & $\$ 50,000$ to $\$ 74,999 .$. & 947 & 12.8 \\
\hline Not in labor force............................... & 6,272 & 46.3 & $\$ 75,000$ to $\$ 99,999 \ldots$ & 405 & 5.5 \\
\hline Females 16 years and over .............. & 7,484 & 100.0 & $\$ 100,000$ to $\$ 149,999$. & $\begin{array}{r}187 \\
35\end{array}$ & $\begin{array}{l}2.5 \\
0.5\end{array}$ \\
\hline In labor force .............................. & 3,530 & 47.2 & $\begin{array}{l}\$ 150,000 \text { to } \$ 199,999 . \\
\$ 200,000 \text { or more } \ldots . .\end{array}$ & 72 & $\begin{array}{l}0.5 \\
1.0\end{array}$ \\
\hline $\begin{array}{l}\text { Civilian labor force } \ldots \ldots \ldots \ldots \ldots \ldots \ldots \\
\text { Employed } \ldots \ldots \ldots \ldots \ldots \ldots \ldots \ldots \\
\end{array}$ & $\begin{array}{l}3,530 \\
3,212\end{array}$ & $\begin{array}{l}47.2 \\
42.9\end{array}$ & Median household income (dollars).... & 27,722 & $(\mathrm{X})$ \\
\hline Own children under 6 years............. & 1,004 & 100.0 & With earnings............. & 4,974 & \\
\hline All parents in family in labor force... & 675 & 67.2 & Mean earnings (dollars) ${ }^{1}$. & 37,614 & $(\mathrm{X})$ \\
\hline COMMUTING TO WORK & & & With Social Security income... & 2,740 & 37.0 \\
\hline Workers 16 years and over ........... & 6,524 & 100.0 & Mean Social Security income (dollars) $)^{1}$. & 10,953 & $(X)$ \\
\hline Car, truck, or van - - drove alone........... & 5,271 & 80.8 & $\begin{array}{l}\text { With Supplemental Security Income..... } \\
\text { Mean Supplemental Security Income }\end{array}$ & 545 & 7.4 \\
\hline - carpooled.. & 573 & 8.8 & (dollars) $)^{1} \ldots \ldots \ldots \ldots . . . . . . . . . .$. & 5,145 & $(\mathrm{X})$ \\
\hline Public transportation (including taxicab). & 129 & 2.0 & With public assistance income. & 257 & 3.5 \\
\hline Walked............................. & 312 & 4.8 & Mean public assistance income (dollars) ${ }^{1}$ & 2,864 & $(\mathrm{X})$ \\
\hline Other means.... & 58 & 0.9 & With retirement income .............. & 1,606 & 21.7 \\
\hline Worked at home ... & 181 & 2.8 & Mean retirement income (dollars) ${ }^{1}$ & 21,518 & $(\mathrm{X})$ \\
\hline Mean travel time to work (minutes) ${ }^{1}$ & 17.4 & (X) & Families .... & 4,316 & 100.0 \\
\hline Employed civilian population & & & Less than $\$ 10,000$. & 392 & 9.1 \\
\hline $16 \mathrm{y}$ & 6,617 & 100.0 & $\$ 10,000$ to $\$ 14,999$. & 397 & 9.2 \\
\hline OCCUPATION & & & $\$ 15,000$ to $\$ 24,999$. & 728 & 16.9 \\
\hline Management, professional, and related & & & $\$ 25,000$ to $\$ 34,999 .$. & 637 & 14.8 \\
\hline occupatio & 2,028 & 30.6 & $\$ 35,000$ to $\$ 49,999 \ldots$ & 808 & 18.7 \\
\hline Service & 1,229 & 18.6 & $\$ 50,000$ to $\$ 74,999 \ldots$ & 802 & 18.6 \\
\hline Sales and offic & 1,961 & 29.6 & $\$ 75,000$ to $\$ 99,999$. & 345 & 8.0 \\
\hline Farming, fishing, & - & -1 & $\$ 100,000$ to $\$ 149,999 \ldots$ & 134 & 3.1 \\
\hline Construction, extraction, and maintenance & & & $\$ 150,000$ to $\$ 199,999$. & 19 & 0.4 \\
\hline occup & 662 & 10.0 & $\$ 200,000$ or more ...... & 54 & 1.3 \\
\hline $\begin{array}{l}\text { Production, transportation, and material moving } \\
\text { occupations }\end{array}$ & & & Median family income (dollars). & 35,075 & $(\mathrm{X})$ \\
\hline occupations ............................. & 737 & 11.1 & Per capita income (dollars) ${ }^{1} \ldots$ & 17,587 & $(X)$ \\
\hline INDUSTR & & & Median earnings (dollars): & & \\
\hline 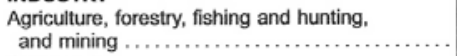 & 74 & 1.1 & $\begin{array}{l}\text { Male full-time, year-round workers........ } \\
\text { Female full-time, year-round workers ... }\end{array}$ & $\begin{array}{l}30,194 \\
22,388\end{array}$ & $\begin{array}{l}(X) \\
(X)\end{array}$ \\
\hline Constr & $\begin{array}{l}431 \\
399\end{array}$ & 6.5 & & & \\
\hline Manufacturing.... & $\begin{array}{l}399 \\
181\end{array}$ & $\begin{array}{l}6.0 \\
2.7\end{array}$ & & below & below \\
\hline $\begin{array}{l}\text { Whole: } \\
\text { Retail }\end{array}$ & $\begin{array}{l}181 \\
924\end{array}$ & $\begin{array}{r}2.7 \\
14.0\end{array}$ & & poverty & poverty \\
\hline $\begin{array}{l}\text { Retail trade } \ldots \ldots \ldots \ldots \ldots \ldots \ldots \ldots \ldots \ldots \ldots \\
\text { Transportation and warehousing, and utilities ..... }\end{array}$ & $\begin{array}{l}924 \\
419\end{array}$ & 6.3 & Subject & level & level \\
\hline Information. & 168 & 2.5 & & & \\
\hline $\begin{array}{c}\text { Finance, insurance, real estate, and rental and } \\
\text { leasing } . . . \ldots \ldots \ldots\end{array}$ & 400 & 6.0 & $\begin{array}{l}\text { POVERTY STATUS IN } 1999 \\
\text { Families .............. }\end{array}$ & & \\
\hline Professional, scientific, management, adminis- & & & $\begin{array}{l}\text { Families .................. } \\
\text { With related children under } 18 \mathrm{y}\end{array}$ & $\begin{array}{l}637 \\
498\end{array}$ & 25.4 \\
\hline trative, & 612 & 9.2 & With related children under 5 years. & 212 & 29.4 \\
\hline Educational, health and social services ......... & 1,489 & 22.5 & & & \\
\hline 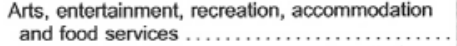 & 649 & 9.8 & $\begin{array}{l}\text { Families with female househ } \\
\text { husband present............ }\end{array}$ & 325 & 34.8 \\
\hline Other services (except public administration) ... & 288 & 4.4 & With related children under 18 & 253 & 46.3 \\
\hline Public administration......................... & 583 & 8.8 & With related children under 5 years. & 107 & 62.9 \\
\hline CLA: & & & Ind & 3,198 & 19.8 \\
\hline salary workers.... & 4,777 & 72.2 & 18 years and over.... & 2,249 & 17.5 \\
\hline Govemment workers... & 1,410 & 21.3 & 65 years and over. & 385 & 11.9 \\
\hline Self-employed workers in own not incorporated & & & Related children under 18 year & 933 & 28.5 \\
\hline business .............. & 404 & 6.1 & Related children 5 to 17 years .......... & 648 & 27.1 \\
\hline Unpaid family workers $\ldots \ldots \ldots \ldots \ldots \ldots \ldots$ & 26 & 0.4 & Unrelated individuals 15 years and over.......... & 1,154 & 30.3 \\
\hline
\end{tabular}

-Represents zero or rounds to zero. (X) Not applicable.

If the denominator of a mean value or per capita value is less than 30 , then that value is calculated using a rounded aggregate in the numerator. See text.

Source: U.S. Bureau of the Census, Census 2000. 


\section{Appendix C}

\section{Horace Mann and Laura B. Tyler High School Attendance Area Demographic Statistics}

Table DP-4. Profile of Selected Housing Characteristics: 2000 Geographic area: West Virginia

[Data based on a sample. For information on confidentiality protection, sampling error, nonsampling error, and definitions, see text]

\begin{tabular}{|c|c|c|c|c|c|}
\hline Subject & Number & Percent & Subject & Number & Percent \\
\hline $\begin{array}{l}\text { Total housing units........ } \\
\text { UNITS IN STRUCTURE }\end{array}$ & 8,611 & 100.0 & & & \\
\hline $\begin{array}{l}\text { UNITS IN STRUCTÜRE } \\
\text { 1-unit, detached.................. }\end{array}$ & 6.401 & 74.3 & 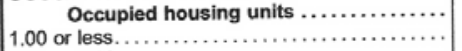 & $\begin{array}{l}7,395 \\
7,346\end{array}$ & 100.0 \\
\hline $\begin{array}{l}\text { 1-unit, detached............... } \\
\text { 1-unit, attached ........... }\end{array}$ & $\begin{array}{r}0,401 \\
162\end{array}$ & 1.9 & $\begin{array}{l}1.00 \text { or less............... } \\
1.01 \text { to } 1.50 \ldots \ldots \ldots \ldots\end{array}$ & $\begin{array}{r}7,346 \\
41\end{array}$ & $\begin{array}{r}99.3 \\
0.6\end{array}$ \\
\hline 2 units ................... & 637 & 7.4 & $\begin{array}{l}1.01 \text { to } 1.50 \ldots \ldots \ldots \ldots \ldots \ldots \\
1.51 \text { or more } \ldots \ldots \ldots \ldots \ldots \ldots\end{array}$ & $\begin{array}{r}41 \\
8\end{array}$ & $\begin{array}{l}0.6 \\
0.1\end{array}$ \\
\hline 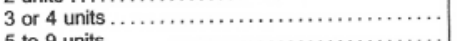 & 440 & 5.1 & & & 0.1 \\
\hline 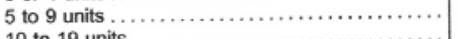 & 331 & 3.8 & Specified owner-occupled units. & 4,379 & 100.0 \\
\hline 10 to 19 units.............. & 243 & 2.8 & VALUE & & \\
\hline 20 or more units ............ & 309 & 3.6 & Less than $\$ 50,000$. & 1,742 & 39.8 \\
\hline Mobile home............... & 88 & 1.0 & $\$ 50,000$ to $\$ 99,999 . . .$. & 1,986 & 45.4 \\
\hline Boat, RV, van, etc.......... & 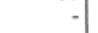 & - & $\$ 100,000$ to $\$ 149,999 \ldots \ldots \ldots \ldots \ldots \ldots \ldots \ldots \ldots \ldots$ & 436 & 10.0 \\
\hline YEAR STRUCTURE BUILT & & & $\begin{array}{l}\$ 150,000 \text { to } \$ 199,999 \ldots \ldots \ldots \ldots \ldots \ldots \ldots \ldots \ldots \ldots \ldots \ldots \ldots \ldots \ldots \ldots \ldots \ldots \ldots \ldots \ldots \\
\$ 200,000 \text { to } \$ 299,999 \ldots \ldots \ldots \ldots \ldots \ldots\end{array}$ & $\begin{array}{r}101 \\
88\end{array}$ & $\begin{array}{l}2.3 \\
2.0\end{array}$ \\
\hline 1999 to March $2000 . . . \ldots .$. & 8 & 0.1 & $\begin{array}{l}\$ 200,000 \text { to } \$ 299,999 \ldots \ldots \ldots \ldots \ldots \ldots \ldots \ldots \\
\$ 300,000 \text { to } \$ 499,999 \ldots \ldots \ldots \ldots \ldots \ldots \ldots\end{array}$ & $\begin{array}{l}88 \\
17\end{array}$ & $\begin{array}{l}2.0 \\
0.4\end{array}$ \\
\hline 1995 to $1998 \ldots \ldots \ldots \ldots$ & 149 & 1.7 & $\begin{array}{l}\$ 300,000 \text { to } \$ 499,999 \ldots \ldots \ldots \ldots \ldots \ldots \\
\$ 500,000 \text { to } \$ 999,999 \ldots \ldots \ldots \ldots \ldots \ldots\end{array}$ & & 0.4 \\
\hline 1990 to $1994 \ldots \ldots \ldots$ & 75 & 0.9 & $\$ 1,000,000$ or more. . ................. & 9 & 0.2 \\
\hline 1980 to $1989 \ldots \ldots \ldots$ & 198 & 2.3 & Median (dollars).......... & 58,800 & $(X)$ \\
\hline $\begin{array}{l}1970 \text { to } 1979 \ldots \ldots \ldots \ldots \ldots \ldots \ldots \ldots \ldots \\
1960 \text { to } 1969 \ldots \ldots \ldots \ldots \ldots \ldots \ldots \ldots \ldots\end{array}$ & 588 & 6.8 & & & \\
\hline $\begin{array}{l}1960 \text { to } 1969 \ldots \ldots \ldots \ldots \ldots \ldots \ldots \ldots \ldots \ldots \ldots \ldots \ldots \ldots \ldots \ldots \ldots \ldots \ldots \ldots \\
1940 \text { to } 1959 \ldots \ldots \ldots \ldots \ldots \ldots \ldots \ldots \ldots\end{array}$ & $\begin{array}{r}795 \\
3070\end{array}$ & 9.2 & MORTGAGE STATUS AND SELECTED & & \\
\hline & $\begin{array}{l}3,070 \\
3,728\end{array}$ & 35.7 & MONTHLY OWNER COSTS & & \\
\hline & 3,728 & 43.3 & 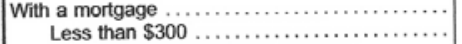 & $\begin{array}{r}2,700 \\
53\end{array}$ & $\begin{array}{r}48.0 \\
1.2\end{array}$ \\
\hline ROOMS & & & $\$ 300$ to $\$ 499 \ldots . .$. & 462 & 10.6 \\
\hline 1 room...... & 52 & 0.6 & $\$ 500$ to $\$ 699$. & 640 & 14.6 \\
\hline 2 rooms.......... & 187 & 2.2 & $\$ 700$ to $\$ 999$ & 592 & 13.5 \\
\hline 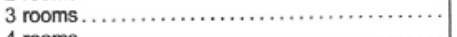 & 728 & 8.5 & $\$ 1,000$ to $\$ 1,499$. & 274 & 6.3 \\
\hline 4 rooms...$\ldots \ldots \ldots \ldots \ldots$ & 1,350 & 15.7 & $\$ 1,500$ to $\$ 1,999$.. & 58 & 1.3 \\
\hline 5 rooms $\ldots \ldots \ldots \ldots \ldots \ldots \ldots \ldots \ldots \ldots$ & 2,112 & 24.5 & $\$ 2,000$ or more ... & 21 & 0.5 \\
\hline 6 rooms .................... & 1,842 & 21.4 & Median (dollars)......... & 669 & (X) \\
\hline 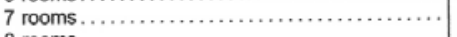 & 1,068 & 12.4 & Not mortgaged ............. & 2,279 & 52.0 \\
\hline 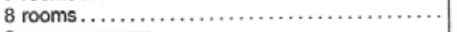 & 608 & 7.1 & Median (dollars). & 222 & $(\mathrm{X})$ \\
\hline 9 or more rooms $\ldots \ldots \ldots \ldots \ldots \ldots \ldots \ldots \ldots \ldots \ldots \ldots \ldots$ & 664 & 7.7 & SFIECTED MONTHIY OWNER COSTS & & \\
\hline Median (rooms) $\ldots \ldots \ldots \ldots \ldots \ldots \ldots \ldots \ldots \ldots \ldots \ldots \ldots$ & 5.4 & $(X)$ & $\begin{array}{l}\text { SELECTED MONTHLY OWNER COSTS } \\
\text { AS A PERCENTAGE OF HOUSEHOLD }\end{array}$ & & \\
\hline $\begin{array}{l}\text { Occupied housing units ....... } \\
\text { YEAR }\end{array}$ & 7,395 & 100.0 & $\begin{array}{l}\text { INCOME IN } 1999 \\
\text { Less than } 15.0 \text { percent. } \ldots \ldots \ldots \ldots \ldots . . . . .\end{array}$ & & \\
\hline YEAR HOUSEHOLDER MOVED INTO UNIT & & & Less than 15.0 percent. . & 2,002 & 45.7 \\
\hline 1999 to March $2000 \ldots \ldots \ldots \ldots \ldots \ldots \ldots \ldots \ldots \ldots \ldots \ldots \ldots$ & $\begin{array}{l}1,217 \\
1,881\end{array}$ & 16.5 & 15.0 to 19.9 percent..... . & 711 & 16.2 \\
\hline 1990 to 1994 . & $\begin{array}{l}987 \\
987\end{array}$ & 13.3 & 25.0 to 29.9 percent . & 307 & 7.0 \\
\hline $\begin{array}{l}1980 \text { to } 1989 \\
1970 \text { to } 1979\end{array}$ & & $\begin{array}{l}13.3 \\
11.4\end{array}$ & 30.0 to 34.9 percent... & 273 & 6.2 \\
\hline $\begin{array}{l}1970 \text { to } 1979 . \ldots \ldots \ldots \ldots \\
1969 \text { or earlier ........... }\end{array}$ & $\begin{array}{r}842 \\
1,481\end{array}$ & $\begin{array}{l}11.4 \\
20.0\end{array}$ & 35.0 percent or more $\ldots \ldots \ldots \ldots \ldots \ldots$. & 620 & 14.2 \\
\hline 1969 or earlier ......... & & 20.0 & Not computed ................... & 54 & 1.2 \\
\hline VEHICLES AVAILABLE & & & Specified renter-occupied units. & 2,728 & 100.0 \\
\hline None $\ldots \ldots \ldots \ldots \ldots$ & 1,211 & 16.4 & GROSS RENT & & \\
\hline $1, \ldots \ldots \ldots \ldots \ldots \ldots \ldots$ & 3,357 & 45.4 & Less than $\$ 200$ & 186 & 6.8 \\
\hline $2 \ldots \ldots \ldots \ldots \ldots \ldots \ldots \ldots$ & 2,226 & 30.1 & $\$ 200$ to $\$ 299$. & 346 & 12.7 \\
\hline 3 or more ............... & 601 & 8.1 & $\$ 300$ to $\$ 499 \ldots \ldots \ldots \ldots \ldots$ & 1,344 & 49.3 \\
\hline IEATING FUEL & & & $\$ 500$ to $\$ 749 \ldots \ldots \ldots \ldots \ldots \ldots \ldots \ldots \ldots \ldots \ldots \ldots \ldots \ldots \ldots \ldots \ldots$ & 535 & 19.6 \\
\hline $\begin{array}{l}\text { HOUSE HEATING FUEL } \\
\text { Utility gas } \ldots \ldots \ldots \ldots \ldots \ldots\end{array}$ & 6,685 & & $\begin{array}{l}\$ 750 \text { to } \$ 999 \ldots \ldots \ldots \ldots \ldots \ldots \\
\$ 1,000 \text { to } \$ 1,499 \ldots \ldots \ldots \ldots \ldots . . .\end{array}$ & $\begin{array}{l}94 \\
16\end{array}$ & $\begin{array}{l}3.4 \\
0.6\end{array}$ \\
\hline Bottled, tank, or LP gas. & 51 & $\begin{array}{r}90.4 \\
0.7\end{array}$ & $\begin{array}{l}\$ 1,000 \text { to } \$ 1,499 \ldots \ldots \ldots \\
\$ 1,500 \text { or more } \ldots \ldots \ldots . .\end{array}$ & & \\
\hline ............ & 520 & 7.0 & 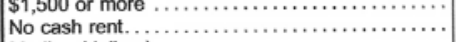 & 207 & 7.6 \\
\hline Fuel oil, kerosene, etc ... & & 0.1 & Median (dollars)......... & 398 & $(\mathrm{X})$ \\
\hline Coal or coke............ & 7 & 0.1 & & & \\
\hline Wood ................... & 34 & 0.5 & GROSS RENT AS A PERCENTAGE OF & & \\
\hline Solar energy $\ldots \ldots \ldots \ldots \ldots \ldots \ldots \ldots \ldots \ldots \ldots \ldots \ldots \ldots \ldots \ldots \ldots$ & 8 & & $\begin{array}{l}\text { HOUSEHOLD INCOME IN } 1999 \\
\text { Less than } 15.0 \text { percent. }\end{array}$ & 555 & 20.3 \\
\hline Other fuel ........ & 84 & 1.1 & $\begin{array}{l}\text { Less than } 15.0 \text { percent. .................. } \\
15.0 \text { to } 19.9 \text { percent } . . . . . . . . . .\end{array}$ & 340 & $\begin{array}{ll}20.3 \\
12.5\end{array}$ \\
\hline No fuel used.... & 5 & 0.1 & $\left|\begin{array}{l}15.0 \text { to } 19.9 \text { percent } \ldots \ldots \ldots \ldots \ldots \ldots \ldots \ldots \ldots \\
20.0 \text { to } 24.9 \text { percent } \ldots \ldots \ldots \ldots \ldots \ldots \ldots \ldots \ldots \ldots\end{array}\right|$ & 304 & 11.1 \\
\hline SELECTED CHARACTERISTICS & & & 25.0 to 29.9 percent $\ldots \ldots \ldots \ldots \ldots \ldots \ldots \ldots \ldots \ldots$ & 155 & 5.7 \\
\hline Lacking complete plumbing facilities... & 36 & 0.5 & 30.0 to 34.9 percent ...... & 227 & 8.3 \\
\hline Lacking complete kitchen facilities.... & 35 & 0.5 & 35.0 percent or more... & 896 & 32.8 \\
\hline No telephone service $\ldots \ldots \ldots \ldots \ldots \ldots \ldots \ldots \ldots$ & 338 & 4.6 & Not computed... & 251 & 9.2 \\
\hline
\end{tabular}

-Represents zero or rounds to zero. (X) Not applicable

Source: U.S. Bureau of the Census, Census 2000. 
Appendix C

2006 Pathways Information for $11^{\text {th }}$ and $12^{\text {th }}$ Grade Students**

\begin{tabular}{|c|c|c|c|}
\hline School Number & School Name & $\begin{array}{l}\text { Pathway } \\
\mathrm{E}=\text { Entry } \\
\mathrm{P}=\text { Professional } \\
\mathrm{S}=\text { Skilled }\end{array}$ & $\begin{array}{l}\% \text { of Total } 11^{\text {th }} \text { and } 12^{\text {th }} \\
\text { Grade Students Enrolled }\end{array}$ \\
\hline \multirow{3}{*}{111} & Beaumont HS & $E$ & 4 \\
\hline & Beaumont HS & $\mathrm{P}$ & 80 \\
\hline & Beaumont HS & $\mathrm{S}$ & 16 \\
\hline \multirow[t]{3}{*}{222} & Laura B. Tyler HS & $\mathrm{E}$ & 13 \\
\hline & Laura B. Tyler HS & $\mathrm{P}$ & 62 \\
\hline & Laura B. Tyler HS & $\mathrm{S}$ & 24 \\
\hline \multirow[t]{3}{*}{333} & Pine Valley HS & $\mathrm{E}$ & 15 \\
\hline & Pine Valley HS & $\mathrm{P}$ & 57 \\
\hline & Pine Valley HS & S & 27 \\
\hline \multirow[t]{3}{*}{444} & South River HS & $\mathrm{E}$ & 15 \\
\hline & South River HS & $\mathrm{P}$ & 42 \\
\hline & South River HS & $\mathrm{S}$ & 35 \\
\hline \multirow[t]{3}{*}{555} & Horace Mann HS & $\mathrm{E}$ & 21 \\
\hline & Horace Mann HS & $\mathrm{P}$ & 48 \\
\hline & Horace Mann HS & $\mathrm{S}$ & 27 \\
\hline
\end{tabular}

** I received this data as part of a packet of information on the county's program of study that was given to all high school teachers in February, 2006. 
Appendix C

Fax Cover Sheet for Personal Communication of Lunch Data

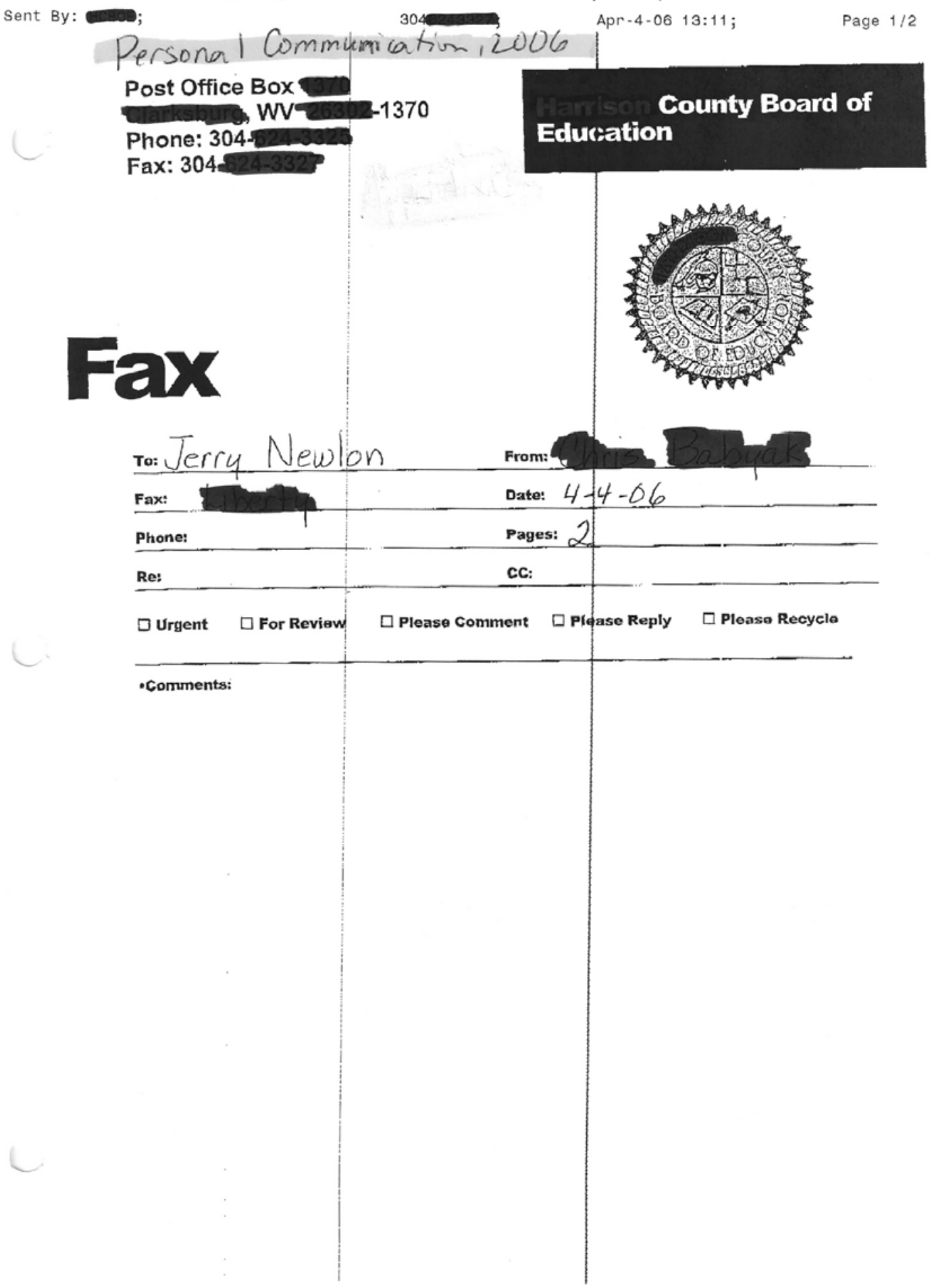


Appendix C

Percentage of Total Student Population that Receives Free or Reduced Lunch 2005-2006 Academic Year**

\begin{tabular}{|c|c|}
\hline School Name & $\begin{array}{c}\text { Percentage of Total Students Receiving Free } \\
\text { or Reduced Lunch }\end{array}$ \\
\hline Beaumont High School & 14.61 \\
\hline Laura B. Tyler High School & 51.75 \\
\hline Pine Valley High School & 43.85 \\
\hline Horace Mann High School & 42.06 \\
\hline South River High School & 42.44 \\
\hline
\end{tabular}

** This data was submitted by the county's board of education via facsimile transmission. 
Appendix C

Racial Diversity Data for All Five High Schools 2005-2006 Academic Year**

\begin{tabular}{|l|c|c|c|}
\hline \multicolumn{1}{|c|}{ School Name } & Total Students & Total White & Percent White \\
\hline Beaumont HS & 842 & 819 & 97 \\
\hline Laura B. Tyler HS & 622 & 596 & 96 \\
\hline Pine Valley HS & 626 & 619 & 99 \\
\hline South River HS & 410 & 396 & 93 \\
\hline Horace Mann HS & 715 & 667 & 93 \\
\hline
\end{tabular}

** This data was received in a personal phone conversation with the WVEIS Coordinator at the county's board of education office on April 11, 2006. 
Appendix C

ACT Test Score Results for All Five High Schools

2004-2005 Test Dates**

\begin{tabular}{|l|c|c|}
\hline \multicolumn{1}{|c|}{ School Name } & $\begin{array}{c}\text { Number of Students Taking } \\
\text { Test }\end{array}$ & Composite Score \\
\hline Beaumont HS & 164 & 22.1 \\
\hline Laura B. Tyler HS & 80 & 20.5 \\
\hline Pine Valley HS & 77 & 20.9 \\
\hline Horace Mann HS & 128 & 20.5 \\
\hline South River HS & 48 & \\
\hline
\end{tabular}

** This data was excerpted from an employee publication dated October, 2005 that was produced and distributed by the county's board of education. 


\section{Appendix D}

\section{Research Handout submitted by C. Riggs}$$
\text { He mivludes this info to give Page } 1 \text { of } 3
$$ \\ Preventing Plagiarism: Resources for Educators

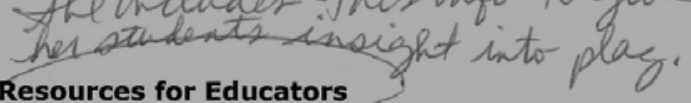

ie most important steps in preventing plagiarism are those taken to address its

causes. The strategies in this section are intended as guidelines to help you:

- become aware of the reasons plagiarism occurs

- identify the different forms of plagiarism

- integrate plagiarism prevention techniques into your courses

Why Students Plagiarize $\$$

There are many reasons students plagiarize. Sometimes deadlines come around more quickly than expected, sometimes assignments feel overwhelming, and sometimes the boundaries of plagiarism and research just get confused. But what situations are most likely to result in plagiarism? More importantly, how can they be avoided? Learning to identify the factors that make plagiarism an attractive alternative is the best way to stop it before it starts.
- Believe it or not...

Studies show that students will cheat more if they feel their peers are cheating-- not only do they feel more justified in doing so, but they also feel compelled to cheat just to "keep up".

Just like hacking into websites, plagiarizing papers can be something of a thrill in itself. For many students it becomes a question of ingenuity: "can I sneak a plagiarized pape nast my professor?" But there is usually more behind intentional plagiarism than just ne thrill of deception.

\section{- Searching vs. Researching}

Today's students learn quickly that finding and manipulating data on the internet is a valuable skill. With the wealth of information available online, the production of original analysis and interpretation may seem like "busy work" compared to finding the best or most obscure sources.

Teach your students that the real skills they need to learn are interpretation and analysis -- how to process the information they find. Tell them that anyone with some basic knowledge can find information on the internet -- it's what they do with that information that is important.

. "But their words are better"

Some students might think, "Why sweat over producing an analysis that has already been done better, by someone who knows more?" Students may also be intimidated by the quality of work found online, thinking their own work cannot compare.

Tell your students that what interests you most is seeing how they understand the assigned topic, and how they develop their own style and voice. This might go a long way toward making them feel more comfortable with writing. Explain to them that you know writing is a learning process, and that you do not expect them to be as brilliant as experts who have devoted years to the subject. You may also want to let them know that their experiences and the context of your class give them a unique perspective that may give them a far more interesting angle on the issues than those of the "experts."

- Making the Grade - this was qound heavily is Beaumont HS. Higher Students are under enormous pressure from family, peers, and instructors to compete for scholarships, admissions, and, of course, places in the job market. They often see education as a rung in the ladder to success, and not an active process valuable in itself. Because of this, students tend to focus on the end results of their research, rather than the skills they learn in doing it.
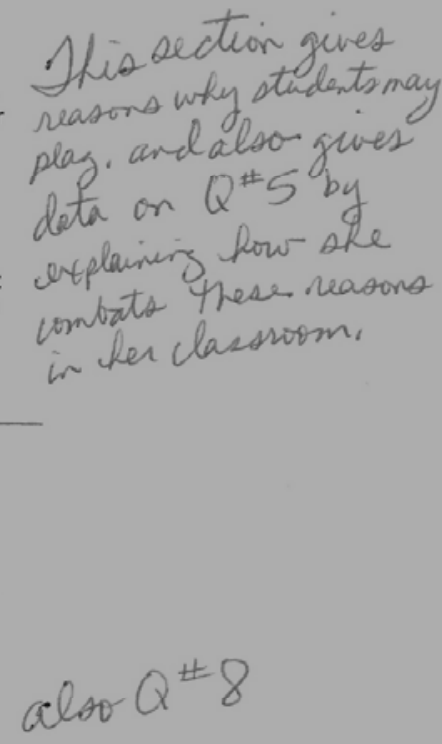

http://www.turnitin.com/rescarch_site/e_pp_ed_text.html 


\section{Appendix D}

\section{Research Handout submitted by C. Riggs}

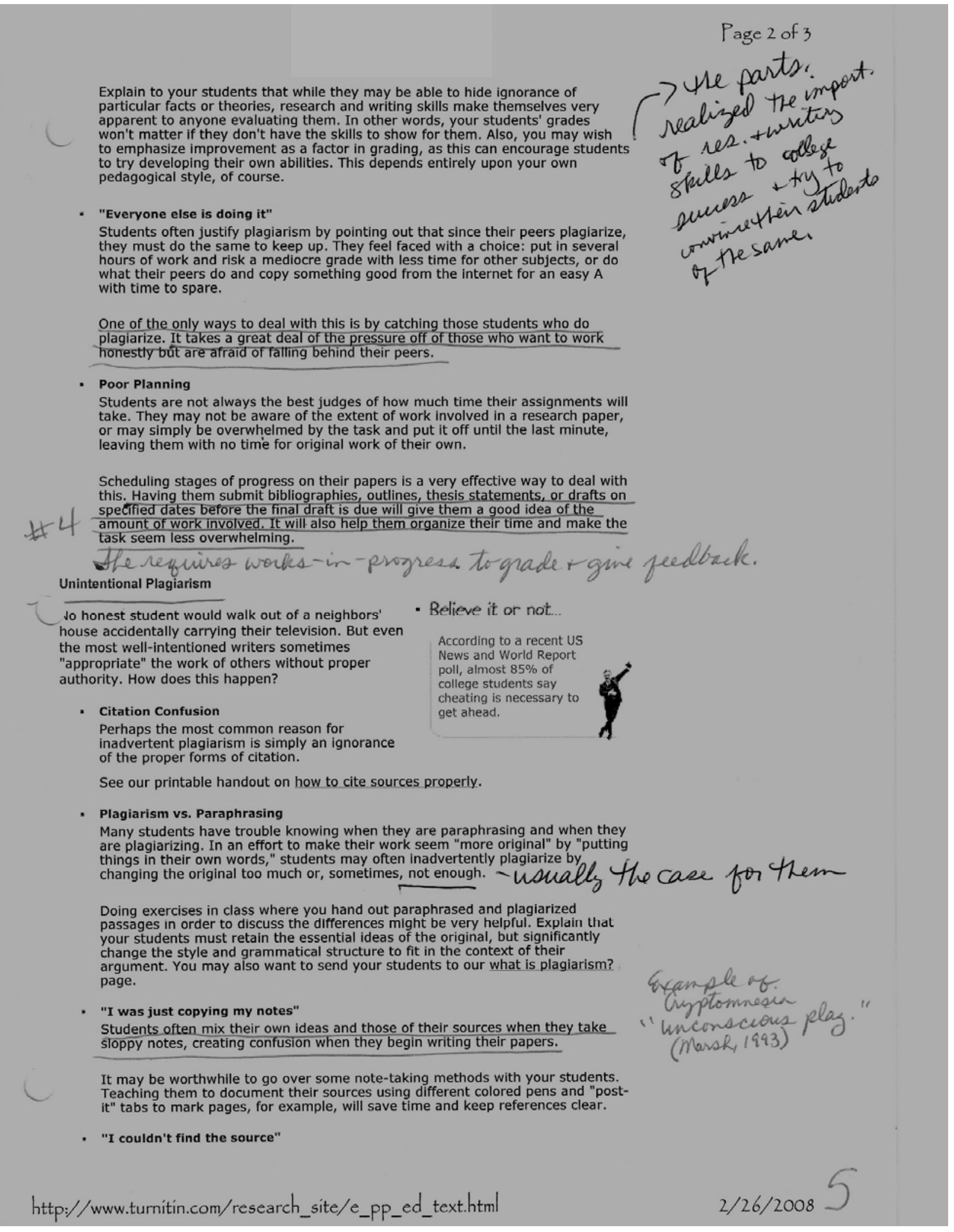




\section{Appendix D}

\section{Research Handout submitted by C. Riggs}

Students are often sloppy about writing down the bibliographic information of their sources, leaving them unable to properly attribute information when it comes to writing the paper.

Explain how important it is to keep careful track of references during the notetaking stage. Students may be eager to focus entirely on the content of their research, and need to be told that how they handle their reference material is a significant part of the assignment. Having them turn in bibliographies before they turn in the paper itself will also encourage them to pay more attention to their squrces. Ahe doeathis as evidencel in ker intervien

- "I thought we didn't have to quote facts"

Because the internet makes information so readily available, students may find it difficult to tell the difference between "common knowledge" they are free to use, and original ideas which are the intellectual property of others.

The easiest thing to do is teach your students the maxim "When in doubt, cite sources."

- Confusion about expectations

Students may not be aware of what proper research requires. They may think they are being asked simply to report critical commentary, or to "borrow" from a number of sources to show that they have "done their homework." In either case, it becomes a problem if what they turn in tends to be predominantly the work of others.

One of the most common sources of confusion is the ambiguity of terms such as "analyze" and "discuss." You should explain to your students that these words have specific meanings in academic discourse, and that they imply a degree of original thought that goes beyond mere "reporting." Emphasizing your interest in their own ideas will also help them understand what you expect from them.

\section{¿ultural Perspectives on Plagiarism}

Not all cultures take the same view of plagiarism. The Western notion that "ideas" can be the property of individuals may actually seem absurd to those with different views on what constitutes shared information or public discourse. Students from cultures which have a more collective sense of identity, for example, may have a difficult time understanding the distinctions some cultures draw between individual and public property. You might spend some very productive class time discussing your students perspectives on this issue. 


\section{Appendix E}

\section{Research Assignment Handout submitted by J. Richards}

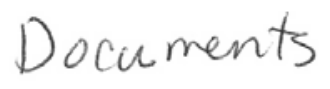

Research Paper

\section{English 10}

Length: $\quad 500-700$ words

Topic: Career research

Sources: 5

Requirements:

1. 5 Source cards

2. 50 Note cards

3. Outline

4. Thesis Statement

5. Rough Draft

6. Final Paper
a. Title page
b. Introduction (including thesis)
c. Body (3-5 pages)
d. Conclusion
e. Works cited

Name:

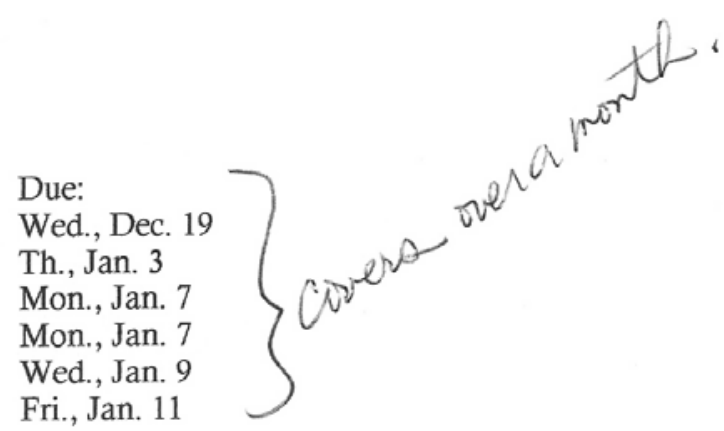

Sources: (possibilities)

1. General reference

2. Books

3. Vertical file

4. Internet

5. Magazine articles

6. Interviews

7. Occupational Outlook Handbook

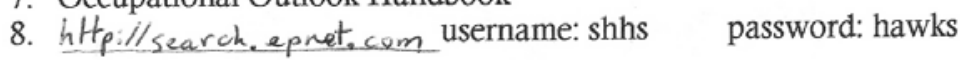

*Do not use Wikipedia as a cited source. However, you may use it to get ideas for possible subtopics.

${ }^{*}$ Use pages 218-245 in your Elements of Language text to assist you with the process of researching and writing a research paper.

Computer Lab Days - Dec. 13-14; 18-20; Jan. 8-9 (No printing permitted except for rough draft and final report.)

Library Days - 


\section{Appendix E}

\section{Research Assignment Handout submitted by J. Richards}

\section{English 12 - Online periodicals unit}

Week1 -- Periodical review - Access computer lab. Read an article from a magazine that can be found online such as and complete the following activity: Determine and state what is the main point of the article, put one paragraph into your own words - paraphrasing. Extra articles read and completed will equal extra credit. Hand in work at end of the period. Be sure to include source information (Author, Title, Name of Magazine or Newspaper, Date, and Page Number)

Week 2 -- Periodical review - Access computer lab. Read an article from a magazine that can be found online such as and complete the following activity: Read an article that is an opinion such as an editorial where persuasion is being used. Discuss how you feel about the issue being presented. Also discuss the effectiveness of the author in causing you to see his/her side of the issue. Be sure to include source information (Author, Title, Name of Magazine or Newspaper, Date, and Page Number)

Week 3 -- Periodical review - Access computer lab. Read an article from a magazine that can be found online such as and complete the following activity: Read an article that tells about a 2008 Presidential candidate. What is this candidates position on issues? If you were granted an opportunity to interview this person, what 10 questions would you ask him/her? Would you vote for this person? Why or Why not? Be sure to include source information (Author, Title, Name of Magazine or Newspaper, Date, and Page Number)

Week 4 -- Periodical review - Access computer lab. Read an article from a magazine that can be found online such as and complete the following activity: Read any article and make a 10-15 question quiz over the material. This can be True/False or Multiple Choice. Be sure to include source information (Author, Title, Name of Magazine or Newspaper, Date, and Page Number)

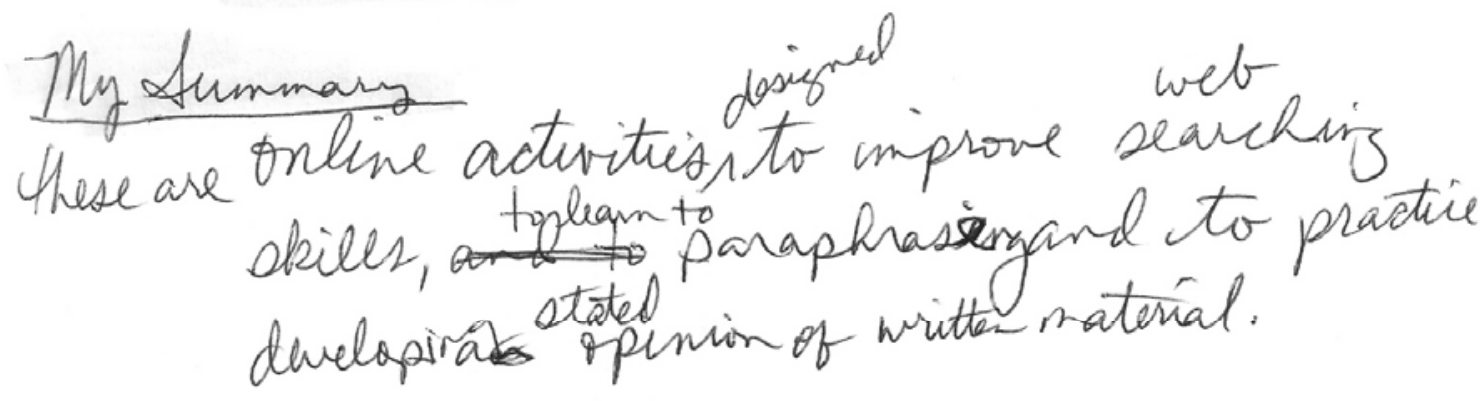


Plagiarism in High Schools 168

Appendix F

Research Assignment Handout submitted by J. Marshall

Research Papers - The next 2 weeks - We will be going to the Library. This week it will be Tuesday, Wednesday, Thursday and Friday.

Must Have on Research Papers

Title Page

3 - 5 Pages

Bibliography Page

4 Sources (minimum)

(only $\stackrel{1}{=}$ Encyclopedia)

$\varnothing$ NO Wikipedia $\varnothing$

You may have unlimited websites unlimited magazines newspapers " "books

lou can take notes from an interview or T.V.

(OVER) 
Plagiarism in High Schools

169

Appendix F

Research Assignment Handout submitted by J. Marshall

(1) topic - General topic

(2) thesis

3 notecards - must be turned in with paper

(4) Source cards -publication information

(5) Check \# of notecards weekly -for grade.

Things you should have on notecards + source cards.

New York Times Mag. Source CArD

Date

Publication.

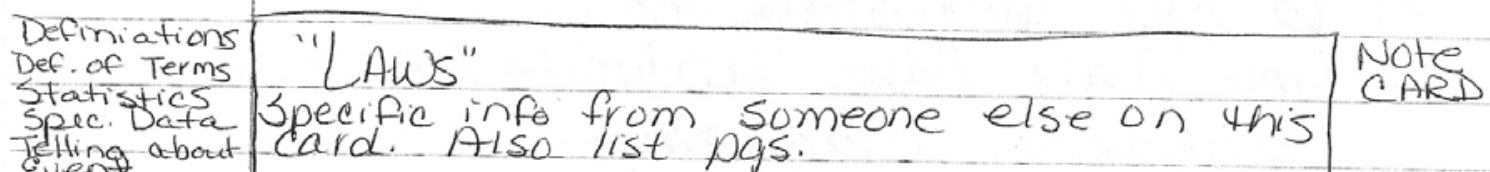
Evening about card. Also list pas.

WORD FER
WORD

If you put it in your own words that is paraphrasing - this does not go on notecards

wive outline

vi s) - Rough draft

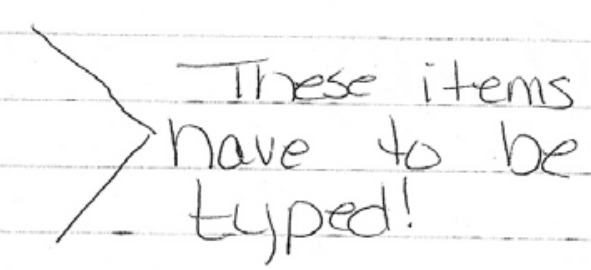




\section{Appendix G}

\section{Research Assignment Handout submitted by T. Queen}

\section{English 12 - \\ Research Paper Information}

This involves developing research skills and your ability to synthesize information into a well-written paper. Closely follow the guidelines for the research paper. It should be written in MLA format. I will go over this format, but it would also be useful to borrow or purchase the most recent edition of the MLA handbook. Some students jeopardize their status for passing the class/graduating by not completing a research paper. Please do not let this happen to you. Everyone can do this with some effort. If you need extra help, please feel free to ask. Arrangements can be made for homeroom time or after school. Some class time may be given to work on the paper, so you will need to bring your sources as instructed.

\section{DEADLINES}

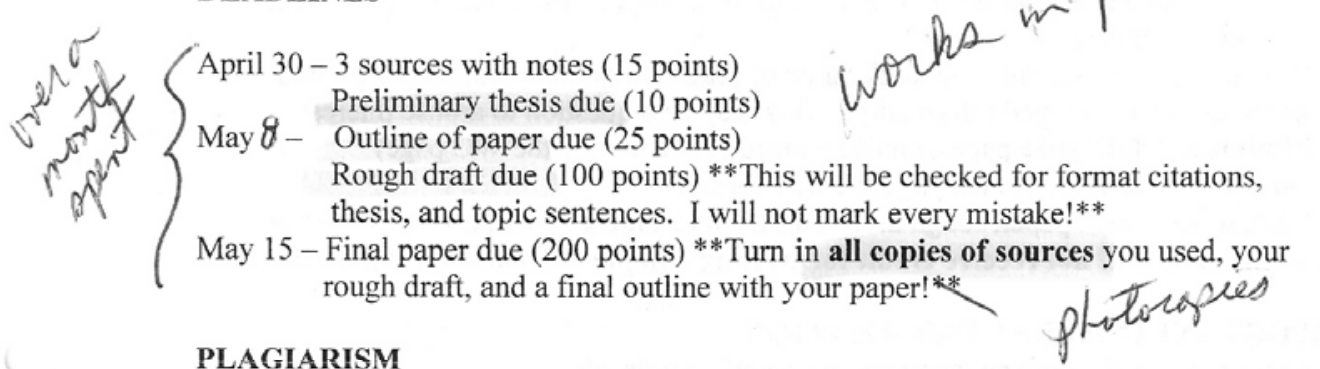

All information received from a source that is not considered common knowledge must be documented. Paraphrased material (a section of summarized information), as well as direct quotations, must be documented. Paraphrasing does not mean just changing a few words. Any plagiarism in your paper will result in failure of the assignment. If you have questions about plagiarism, please see me.

\section{SOURCES}

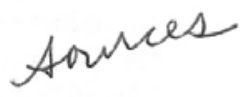

1. Use at leas five separate sources. Only one of those sources may be an encyclopedia.

2. For every source listed on the Works Cited page, you must have an internal citation.

3. Please use a variety of sources. Do not rely too heavily on the internet without searching other resources.

\section{DOCUMENTATION}

For internal citations (every time you use information from a source), use the author's last name and page number. Use no punctuation between the author's name and page [ex. (Hart 24).] If there is no author, use only the first word of the title (excluding a, an, the) and the page number. You should have a combination of paraphrased and directly quoted information.* Remember, your entire paper should not be cited information. Your own thoughts/insights must be included (without using "I feel," I believe," "I found," etc.) 


\section{Appendix G}

\section{Research Assignment Handout submitted by T. Queen}

\section{ROUGH DRAFT}

*Must contain citations!

*Turn in Works Cited page

*Must be typed!

*Should be at least 2 pages - does not have to have to include a conclusion

\section{FINAL PAPER}

1. Typed in 12 point Times New Roman font on $81 / 2 \times 11$ inch white paper, using 1 inch margins.

2. Follow MLA format!!!!!!!!!!

*This includes your last name and page number in the upper right hand corner $1 / 2$ " from the top of each page.

*Your first page should include the following information typed in the upper left hand corner, beginning 1" from the top of the paper: name, instructor's name, class, and date).

3. You need an original title (not underlined or placed in quotation marks), centered under the above-mentioned information. This may be a question to arouse interest.

4. Minimum 4 full typed pages, double-spaced (not counting the WC page)

5. Double-spaced Works Cited page in MLA format

6. Enclose your final paper, rough draft, outline, and copies of sources in a folder or envelope. You will not receive credit for writing a paper without turning in sources!

\section{IMPORTANT GENERAL INFORMATION}

*No informal wording (slang, contractions, trendy words, etc)

* Must be written in $3^{\text {rd }}$ person point of view

*Must have a strong thesis that is clearly persuasive

* All topic sentences should support and clearly relate to your thesis

*Everything in your paragraph should relate back to the topic sentence of that paragraph

*Introduction, conclusion, and topic sentences should not contain cited information

*No personal pronouns

*Avoid "very," "things," "a lot," and other words that may be replaced with more decisive diction

*Go over and over and over your paper for mistakes (both with content and grammar). Read your paper aloud to check for mistakes. Have someone else read your paper to see if it makes sense. Check for your weaknesses (or have someone else check) in your writing. Proofread!!!!!!!

*Make sure you have a mixture of directly quoted and paraphrased information within your paper.

*Make sure your paragraphs exhibit diversity in citations. 
Appendix $\mathrm{H}$

Plagiarism Policy submitted by R. Carr

\section{PLAGIARISM WARNING!}

Please note that I gave you a handout referencing plagiarism and how to avoid it. An additional one is likewise offered. You should re-read the Rough Draft handout (second and third pages) given you many days ago before you submit your complete term paper to me.

I will be checking each student paper for plagiarism. If you have copied even a paragraph that has factual information you did not cite/attribute, then I will deduct points for plagiaristic behavior. Note that on the rubric I distributed, the final category is MLA Research style, which encompasses citations, parenthetical notes, and your original work.

Also, don't forget that your work should be something you have not written before. The reasons already stated for doing this paper were: 1) exposure to MLA style and research methodology that prepare students for college and 2) expansion of new knowledge through research.

Please be reminded that you were given several opportunities during class and in the IMC and the computer lab to work on your paper. As previously stated, late papers will result in a points deduction and grade cut.

We all want to end the year on a positive note. Do your very best work! 
Appendix I

Grading Rubric submitted by R. Carr

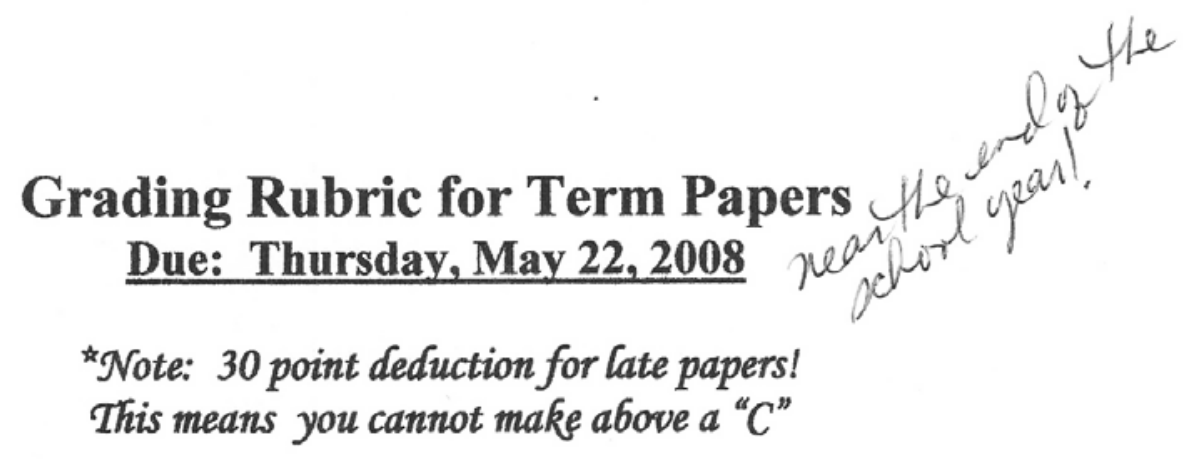

$\begin{array}{lr}\text { Double Spaced Pages } & 25 \text { points } \\ \text { Note Cards } & 25 \text { points } \\ \text { Works Cited Page } & 15 \text { points } \\ \text { Binder (plastic) } & 10 \text { points } \\ \text { Three Different } \\ \text { Resources } \\ \text { Rough Draft } \\ \text { Final Draft } & 25 \text { points } \\ \text { (MLA Style) } & 25 \text { points } \\ & 25 \text { points } \\ & \end{array}$




\section{Appendix J}

\section{Plagiarism Policy submitted by B. Hinkle}

\section{IMPORTANT GENERAL INFO.}

*NO informal wording (slang, contractions, trendy words, etc.)

* must be written in $3^{\text {rd }}$ person point of view.

* must have strong thesis that is clearly persuasive

*all topic sentences should clearly relate to your thesis.

* everything in the paragraph should relate back to the topic sentence of that paragraph.

*introduction, conclusion, and topic sentences should not include cited information.

"no personal pronouns.

"Avoid "very" "things," "a lot," and other words that may be replaced with more decisive diction.

"go over and over your paper for mistakes. Have others check it for mistakes you may have missed (both content and grammar). Read your paper aloud. Have someone else read it to you, so that you can listen for mistakes. Make sure that is all makes sense. PROOFREAD!!!

\section{FINAL PAPER}

*Typed on $81 / 2 \times 11$ inch white paper, using 1 inch margins (check under page set up under File menu) 10-12 point font and in Times New Roman ONLY!!!

*Follow MLA format. This includes title page, and the last name and page number in the upper right hand corner of each page and the appropriate information at the beginning of your paper in the upper left hand corner (Name, Date, Teacher's name, Class, and Date) *You need an original title (do not underline or put it in quotation marks!!)

*Minimum of 4 pages typed, double spaced. (This does not include the work cited page)

* Double space work cited page in MLA format.

*Enclose your final paper, rough draft, outline and outline rough draft, and copies of sources in folder. You will not receive credit for turning in a paper without the sources.

\section{PLAGIARISM}

*All information received from a source that is not considered common knowledge must be documented. Paraphrased material (a section of summarized information that is not your own), as well as direct quotations, must be documented. Paraphrasing does not mean just change a few words. Any plagiarism in your paper will result in failure of the assignment. If you have any questions concerning plagiarism, ask me.

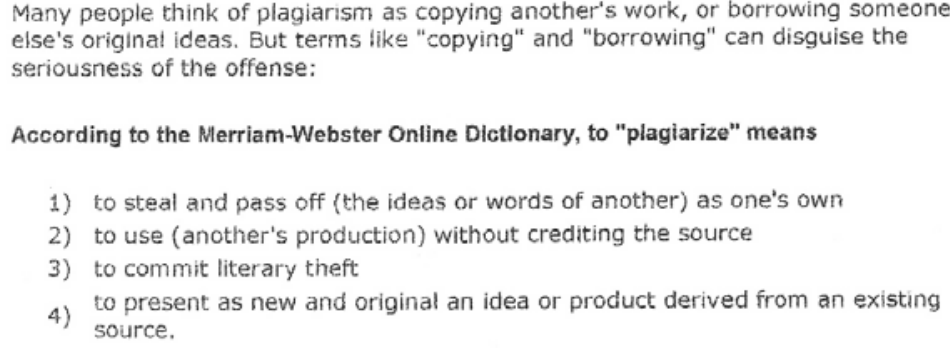




\section{Appendix K}

Sample Originality Report printed from Turnitin.com

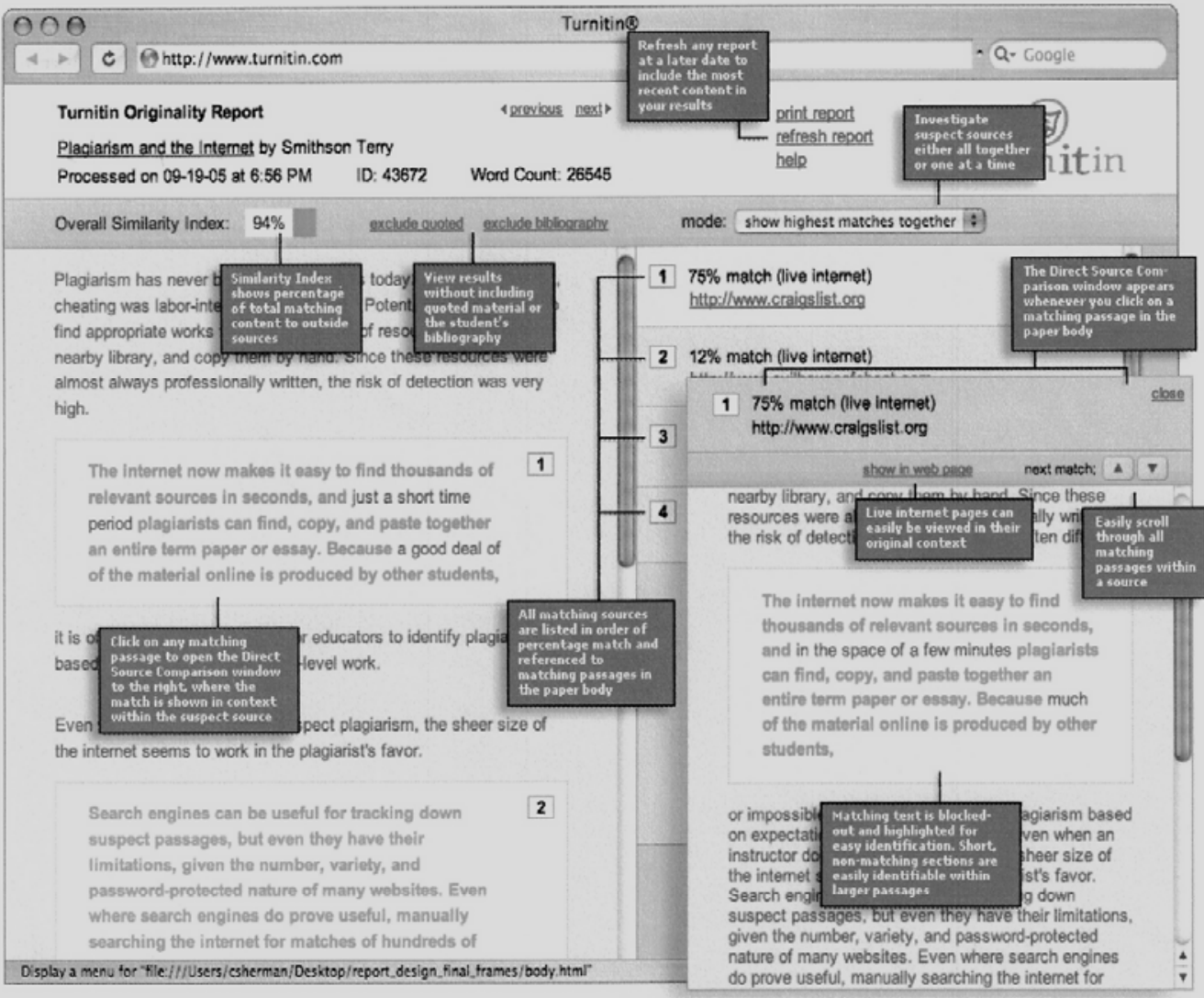


Appendix L

West Virginia Department of Education CSOs for $12^{\text {th }}$ Grade English

\section{Twelfth Grade Reading and English Language Arts Content Standards and Objectives}

Reading and English Language Arts twelfth grade students will focus and polish personal skills and goals. Experiences such as a senior project or a sophisticated persuasive research paper will culminate the graduation experience. Readiness for the work place or post secondary education is the final educational reality check during the twelfth grade year. The expansion and appreciation of language and literature in spoken and written form is a primary focus. West Virginia teachers are responsible for analyzing the benefits of technology for learning and for integrating technology appropriately in the students' learning environment. See the related grade-level Technology Standards and Objectives.

Standard 1: Reading (RLA.S.1)

Students will use skills to read for literacy experiences, read to inform and read to perform a task by:

- identifying and using the dimensions of reading (phonemic awareness, phonics, background knowledge/vocabulary, high frequency words/fluency, comprehension, writing and motivation to read); and

- $\quad$ employing a wide variety of literature in developing independent readers.

Reading Objectives

Students will:

RLA.12.1.1 research, analyze and evaluate the historical, cultural and biographical influences to determine the impact on literary works.

RLA.12.1.2 analyze and evaluate author's choice of genre

RLA.12.1.3 increase the amount of independent reading with emphasis on American, British and World literature.

RLA.12.1.4 apply appropriate reading strategies necessary for various reading purposes (e.g., literary experience; information; task performance).

RLA.12.1.5 analyze and evaluate characteristics of author's style, purpose and technique from a variety of selections by the same author (e.g., critical review; literary/character analysis).

RLA.12.1.6 construct supportable conclusions, make inferences and generalizations, and interpret character traits from explicit and implicit ideas.

RLA.12.1.7 analyze and evaluate persuasive language and techniques (e.g., advertisements; junk mail; web sites; news stories).

RLA.12.1.8 expand vocabulary through reading various literary works and applying word etymologies to determine meaning.

RLA.12.1.9 interpret and evaluate the author's choice of various literary devices and techniques, in particular, figurative language (e.g., personification; archetypes; allegorical patterns).

RLA.12.1.10 analyze and evaluate types of text according to content, structure and tone

RLA.12.1.11 read and evaluate literary criticism applicable to the genre being studied.

\section{Performance Descriptors (RLA.PD.12.1)}

- Distinguished

The student demonstrates exceptional and exemplary performance with distinctive and sophisticated application of knowledge and skills that exceeds the standard in reading. Students read, synthesize and evaluate advanced level texts to form supportable predictions, opinions, inferences and conclusions from implicit ideas. Students interpret and evaluate literary devices and techniques and analyze characters. Students independently research and analyze the impact of historical, cultural and biographical factors on literary works and analyze literary criticism applicable to the genre being 


\title{
Appendix L
}

\author{
West Virginia Department of Education CSOs for $12^{\text {th }}$ Grade English
}

studied. Students examine the universality of literature to determine the interrelationship among literary works.

- Above Mastery

The student demonstrates competent and proficient performance and shows a thorough and effective application of knowledge and skills that exceeds the standard in reading. Students read and synthesize grade level and/or advanced texts to form supportable predictions, opinions, inferences and conclusions from implicit ideas. Students interpret literary devices and techniques and analyze characters. Students independently research and analyze the impact of historical, cultural and biographical factors on literary works and read literary criticism applicable to the genre being studied. Students examine the interrelationship among literary works.

- Mastery

The student demonstrates fundamental course or grade level knowledge and skills by showing consistent and accurate academic performance that meets the standard in reading. Students read and analyze grade level texts to form supportable predictions, opinions, inferences and conclusions from implicit ideas. Students identify and interpret character traits and literary devices. Students research and analyze significant historical, cultural and biographical factors on literary works.

- Partial Mastery

The student demonstrates basic but inconsistent performance of fundamental knowledge and skills characterized by errors and/or omissions in reading. Performance needs further development. Students read grade level texts to form predictions, opinions, inferences and conclusions. Students identify some character traits and literary devices Students identify the impact of historical, cultural and biographical factors on literary works.

- Novice

The student demonstrates substantial need for the development of fundamental knowledge and skills, characterized by fragmented and incomplete performance in reading. Performance needs considerable development.

Standard 2: Writing (RLA.S.2)

Students will employ a wide range of writing strategies to communicate effectively for different purposes by:

- developing the writing process;

- applying grammatical and mechanical properties in writing; and

- gathering and using information for research purposes.

Writing Objectives

Students will:

RLA.12.2.1 employ writing strategies to address specific purposes (e.g., narrative; expository; persuasive; research; creative).

RLA.12.2.2 generate topics and plan approaches to research writing (e.g., graphic organizers; outlines) using pre-writing strategies.

RLA.12.2.3 employ drafting strategies for research writing tasks.

RLA.12.2.4 develop a focused composition that has a clear and logical progression of ideas supported by relevant details.

RLA.12.2.5 use of vocabulary that is vivid, precise and economical.

RLA.12.2.6 use subtle forms of transition in a composition (e.g., sentence links; repetition of key words or sentences).

RLA.12.2.7 apply rhetorical devices (e.g., parallel structure; antithesis; narrative pace)

RLA.12.2.8 write an analysis of a literary selection using terminology and characteristics of the genre and quotations (e.g., apostrophe; symbolism; imagery).

RLA.12.2.9 produce functional writing related to life skills (e.g., letter of job application; scholarship application; essay; personal letter).

RLA.12.2.10 produce a summative project (e.g., research paper, power point presentation; web page) using an accepted format (e.g., MLA; APA). 


\section{Appendix L}

\section{West Virginia Department of Education CSOs for $12^{\text {th }}$ Grade English}

RLA.12.2.11 refine a personal style and voice in writing.

RLA.12.2.12 correct errors in organization, content, usage, mechanics and spelling in all writing using revisions and editing strategies.

RLA.12.2.13 access and evaluate information through a variety of primary and secondary sources (e.g., personal interviews; SIRS; Congressional Quarterly).

RLA.12.2.14 employ a sound note taking system that can be applied to classroom, library and/or interview.

RLA.12.2.15 integrate the concept of intellectual property and plagiarism in all media (e.g., media copyright laws; private/public domain).

RLA.12.2.16 produce a detailed outline for use in a summative project.

RLA.12.2.17 analyze and select choice of pronunciation and spelling (e.g., dictionary; spell check; thesaurus).

RLA.12.2.18 select appropriate editing strategies to correct errors in mechanics.

RLA.12.2.19 recognize and correct errors in subject/verb agreement.

RLA.12.2.20 correct errors in sentence structure and usage (e.g., parallelism; redundancy; misplaced modifiers; subordination)

\section{Performance Descriptors (RLA.PD.12.2)}

- Distinguished

The student demonstrates exceptional and exemplary performance with distinctive and sophisticated application of knowledge and skills that exceeds the standard in writing. Students independently write focused compositions from both student-generated and assigned thesis statements supported by relevant, insightful, detailed and sophisticated diction. Students exhibit personal style and voice in writing. Students extend research skills by producing a summative project using an accepted format.

- Above Mastery

The student demonstrates competent and proficient performance and shows a thorough and effective application of knowledge and skills that exceeds the standard in writing. Students write focused compositions generating a well-worded and correctly placed thesis statement, and incorporating specific, relevant details and vivid, precise diction into their compositions. Students extend research skills by producing a summative project using an accepted format.

- Mastery

The student demonstrates fundamental course or grade level knowledge and skills by showing consistent and accurate academic performance that meets the standard in writing. Students write focused compositions generating a thesis statement, and incorporating relevant details and precise diction. Students extend research skills by producing a researched project following an accepted format.

- Partial Mastery

The student demonstrates basic but inconsistent performance of fundamental knowledge and skills characterized by errors and/or omissions in writing. Performance needs further development. Students write compositions with limited focus, a thesis statement and less consistently use precise diction and relevant details. Students extend research skills by attempting to produce a researched project.

- Novice

The student demonstrates substantial need for the development of fundamental knowledge and skills, characterized by fragmented and incomplete performance in writing. Performance needs considerable development.

Standard 3: Listening, Speaking and Viewing (RLA.S.3)

Students will apply their use of spoken, written and/or visual language to communicate

- with a variety of audiences and

- for different purposes.

Listening, Speaking and Viewing Objectives

Students will: 


\section{Appendix L}

\section{West Virginia Department of Education CSOs for $12^{\text {th }}$ Grade English}

RLA.12.3.1 adapt and apply speaking skills in order to participate in a variety of situations (e.g., panel/group discussion; oral presentation; guest speaker).

RLA.12.3.2 correct all usage errors in oral language (e.g., distinguishing colloquial dialectical - slang, and formal versus informal language).

RLA.12.3.3 practice and master listening, speaking and viewing skills (e.g., videos; power point presentations; web pages; and evaluate a selection on audio tape).

\section{Performance Descriptors (RLA.PD.12.3)}

- Distinguished

The student demonstrates exceptional and exemplary performance with distinctive and sophisticated application of knowledge and skills that exceeds the standard in listening, speaking and viewing. Students automatically recognize and apply conventions of oral language and adapt speaking skills appropriate to a variety of situations. Students independently construct presentations that evidence sophisticated mastery of the listening, speaking and viewing objectives.

- Above Mastery

The student demonstrates competent and proficient performance and shows a thorough and effective application of knowledge and skills that exceeds the standard in listening, speaking and viewing. Students recognize and apply conventions of oral language and adapt speaking skills appropriate to a variety of situations. Students construct presentations that evidence thorough and effective mastery of the listening, speaking and viewing objectives.

- Mastery

The student demonstrates fundamental course or grade level knowledge and skills by showing consistent and accurate academic performance that meets the standard in listening, speaking and viewing. Students apply conventions of oral language appropriate to a variety of situations. Students construct presentations that evidence effective mastery of the listening, speaking and viewing objectives.

\section{- Partial Mastery}

The student demonstrates basic but inconsistent performance of fundamental knowledge and skills characterized by errors and/or omissions in listening, speaking and viewing. Performance needs further development. Students occasionally recognize conventions of oral language that are suitable for a variety of situations. Students construct presentations that evidence partial knowledge of the listening, speaking and viewing objectives.

- Novice

The student demonstrates substantial need for the development of fundamental knowledge and skills, characterized by fragmented and incomplete performance in listening, speaking and viewing. Performance needs considerable development. 


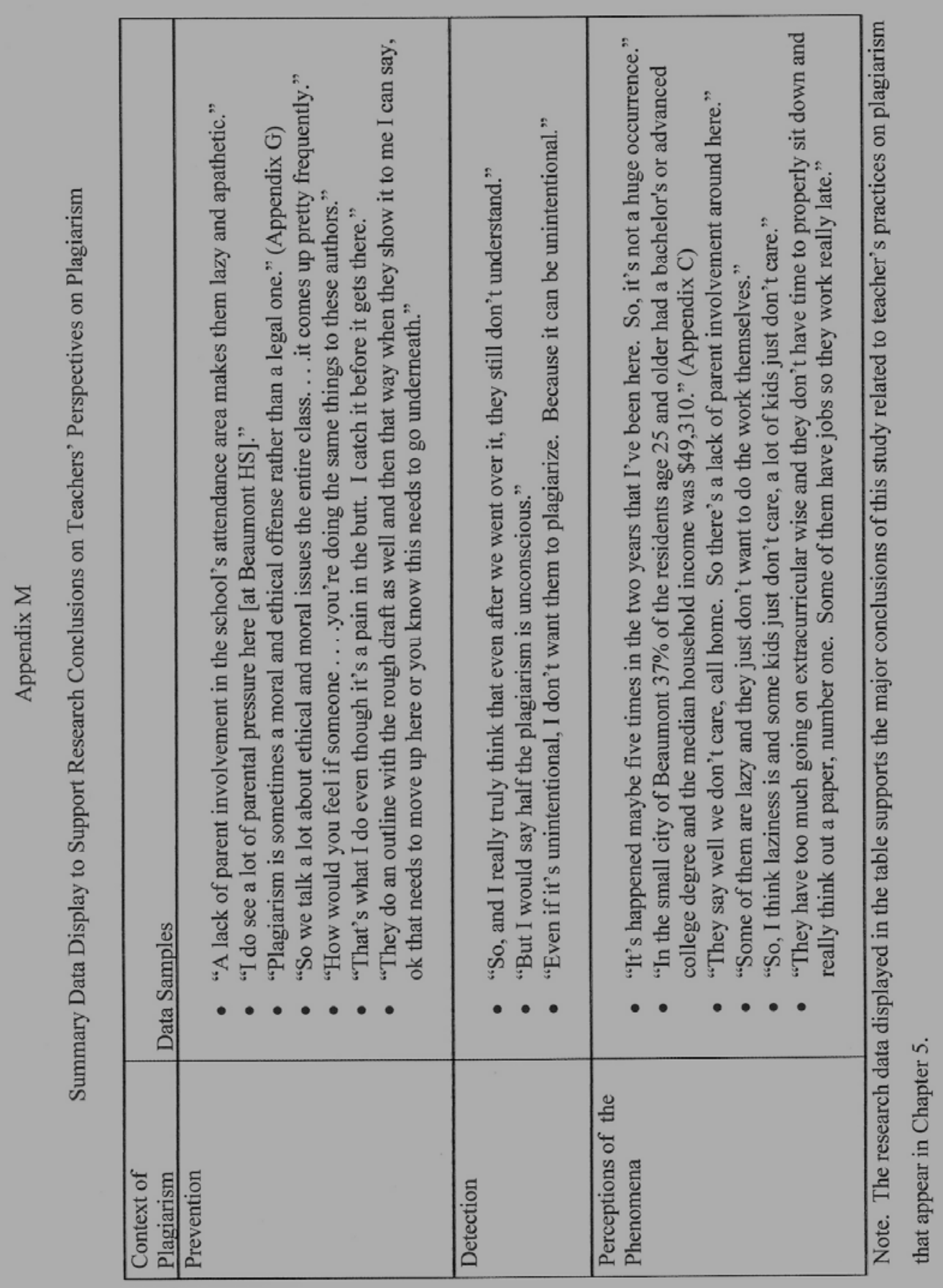




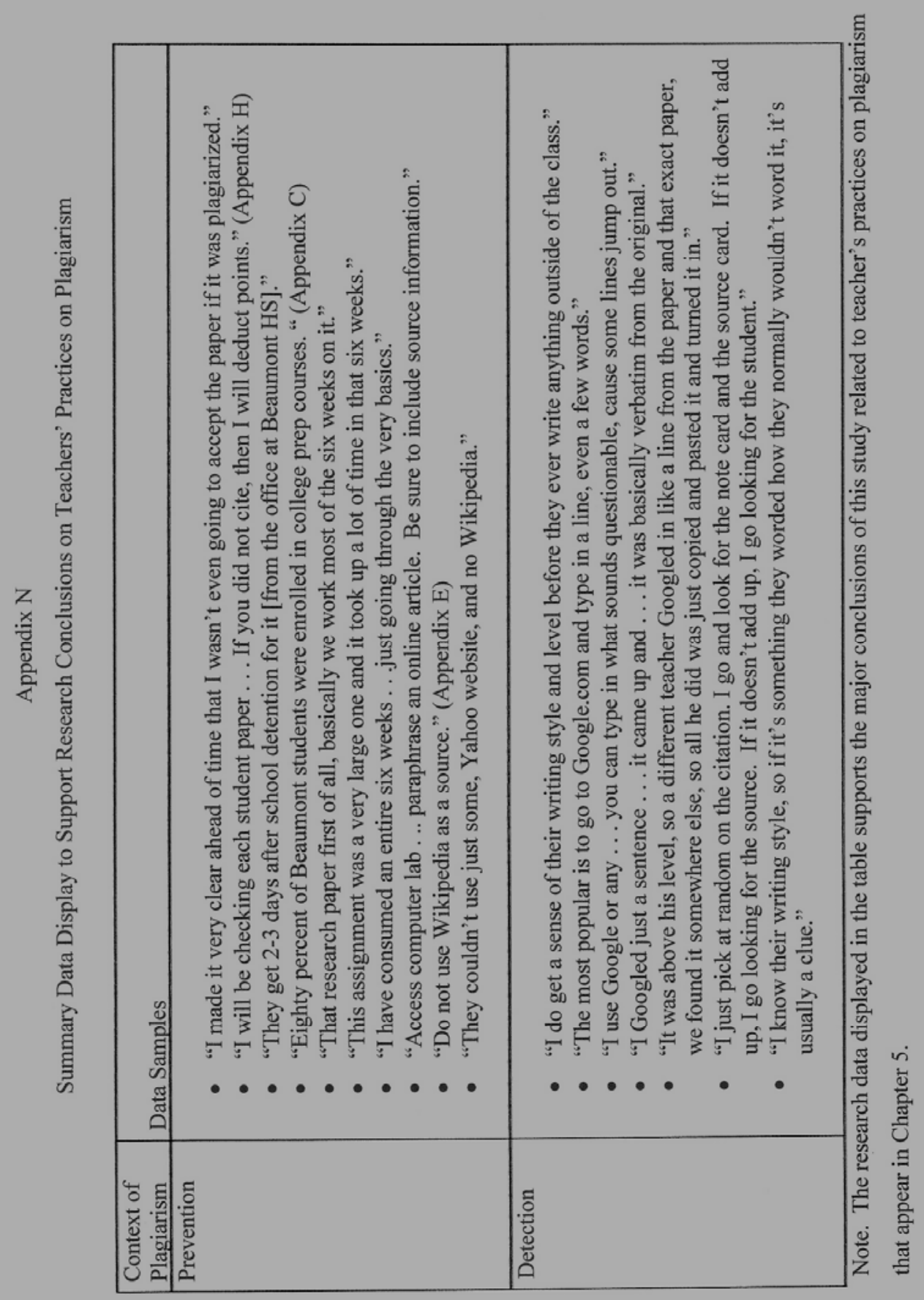

